Model Study of the Cazenovia Creek Ice Control Structure

Gordon E. Gooch and David S. Deck

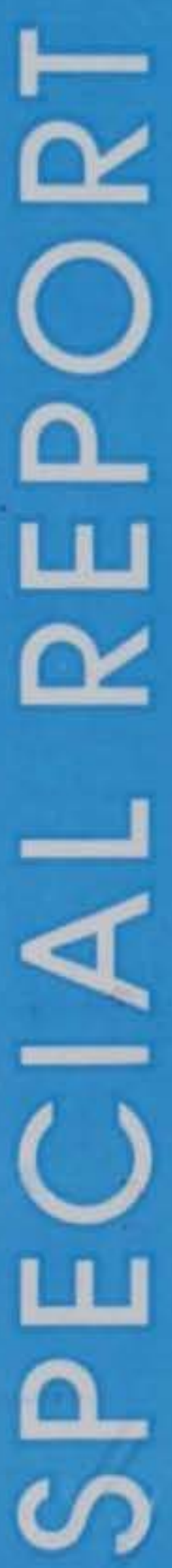


$$
22521733
$$

Special Report 90-29

US-CE-C Property of the

United States Covernment
GB2401

Cles

\section{U.S. Army Corps} of Engineers

Cold Regions Research \& Engineering Laboratory

\section{Model Study of the Cazenovia Creek Ice Control Structure}

Gordon E. Gooch and David S. Deck 


\section{PREFACE}

This report was prepared by Gordon E. Gooch, Civil Engineering Technician, Ice Engineering Research Branch, and David S. Deck, Research Hydraulic Engineer, Ice Engineering Research Branch, Experimental Engineering Division, USA Cold Regions Research and Engineering Laboratory. This study was supported by the U.S. Army Engineer District, Buffalo, under Reimbursable Order No. NCB-1A-83-87RC (Change No. 3), Design Support of Ice Retention Structure for Cazenovia Creek, Detailed Project Report.

The report was technically reviewed by Dr. Jean-Claude Tatinclaux and Dr. James Lever, Ice Engineering Research Branch, USACRREL.

Historical data were provided by the U.S. Army Engineer District, Buffalo, Corps of Engineers Flood Plain Information Report, 1966 (reprinted June 1971).

The authors wish to thank Dr. Tatinclaux for his help in the organization of the material presented and, in particular, for his valuable input to the section on Physical Models. Many thanks are due to Calvin Ackerman whose skillful and persistent craftsmanship in the model construction resulted in an accurate calibration and consistent test results.

The contents of this report are not to be used for advertising or promotional purposes. Citation of brand names does not constitute an official endorsement or approval of the use of such commercial products. 


\section{CONTENTS}

Preface

Introduction

Physical models

Cazenovia Creek ICS model

Scale selection

Model ice.

Model construction

Data acquisition system.

Model calibration

Test conditions and procedures

Test conditions

Test procedure

Test results and discussion

Conclusions

Literature cited

Appendix: Test data for Cazenovia Creek model study

Abstract

\section{ILLUSTRATIONS}

Figure

1. Map of Cazenovia Creek watershed

2. Flow chart of key elements in river flooding

3. Plan view of Cazenovia Creek model

4. Schematic of data acquisition system

5. Model calibration: comparison of water surface profiles between model and full-scale

6. Three-hour unit hydrograph for Cazenovia Creek at Ebenezer

7. The Cazenovia Creek ice control structure

8. Hydrographs in model tests with $1.8-\mathrm{m}$ (6-ft) ICS

9. Stage variations at station $0+96$

\section{TABLES}

Table

1. Scaling laws for the Cazenovia Creek model

2. Cazenovia Creek ice-jam floods since 1971

3. Test conditions for Cazenovia Creek model 


\title{
Model Study of the Cazenovia Creek Ice Control Structure
}

\author{
GORDON E. GOOCH AND DAVID S. DECK
}

\section{INTRODUCTION}

Ice-jam flooding of the business and residential communities of West Seneca and Buffalo, New York, along Cazenovia Creek generally occurs during major spring runoff events due to snowmelt and rainfall. During such events, ice jams form where the Cazenovia Creek joins with the Buffalo River because of poor ice transport, which results from a change in slope in the creek and backwater effects from Lake Erie.

Between 1960 and 1965 the City of Buffalo undertook a number of efforts to reduce or eliminate ice-jam flooding along Cazenovia Creek. These efforts fell into three categories: structural projects, ice removal and suppression, and floodplain regulations.

- The structural projects involved levees and floodwalls. Because of cost, these structures were constructed in high-damage areas only, and did not protect the entire floodplain. Dam and reservoir construction was deemed too costly.

- Ice removal and suppression efforts centered around the confluence of Cazenovia Creek with the Buffalo River, where strong, thick ice prevented passage of upstream ice during spring breakup. In principle, keeping this area clear would eliminate ice jamming and the resulting flooding. To that end, a $308 \times 21.5 \times 2.5-\mathrm{m}(1000$ $\times 70 \times 8$ - $\mathrm{ft}$ ) channel was excavated in the creek in the hope of reducing ice production. In addition, thermal discharge to melt the ice and blasting of deposited ice were also attempted, but with limited success. In 1964, the city began using amphibious icebreaking craft to break the ice and help it flow downstream into the Buffalo River and eventually into Lake Erie. This technique periodically required the help of a Coast Guard icebreaker on the Buffalo River to provide a channel for ice passage.

- Zoning regulations were established to limit construction on the floodplain. Those areas that were developed were subject to minimum firstfloor elevations determined by the 1959 flood levels.

Throughout the early 1960s, ice-jam prevention efforts continued with few restrictions. However, in January 1966 the New York State Legislature imposed strict guidelines on river projects. A permit process was implemented to regulate dam rehabilitation or any modification to river channels. In the years that followed, the level of flood protection was inadequate. Seven ice-jam floods were recorded between 1971 and 1982.

An ice-jam flooding prevention plan was prepared by the U.S. Army Corps of Engineers, Buffalo District, with two options. The first option recommended construction of additional levees and floodwalls and a drainage system.

The second option proposed building an ice control structure (ICS) that would hold ice in the creek so it would at least partially melt in place, reducing the amount of ice carried downstream and delaying the ice run long enough for most, if not all, the ice in lower Cazenovia Creek and the Buffalo River to have flowed out into Lake Erie. The ICS was to be located in an undeveloped area where the left bank of the creek was dominated by high cliffs and there was a flood plain on the right bank (Figure 1).

The city of West Seneca and the New York Department of Environmental Conservation requested that a physical hydraulic model study of the proposed ICS be conducted to evaluate its performance before actual construction.

The model study of the proposed Cazenovia Creek Ice Control Structure was conducted in the refrigerated Research Hydraulic Facility of the Ice Engineering Facility of the Cold Regions Research and Engineering Laboratory in Hanover, New Hampshire. This report describes the design, execution, and results of this model study, which led to the eventual acceptance of the proposed ICS by the COE Buffalo District. 


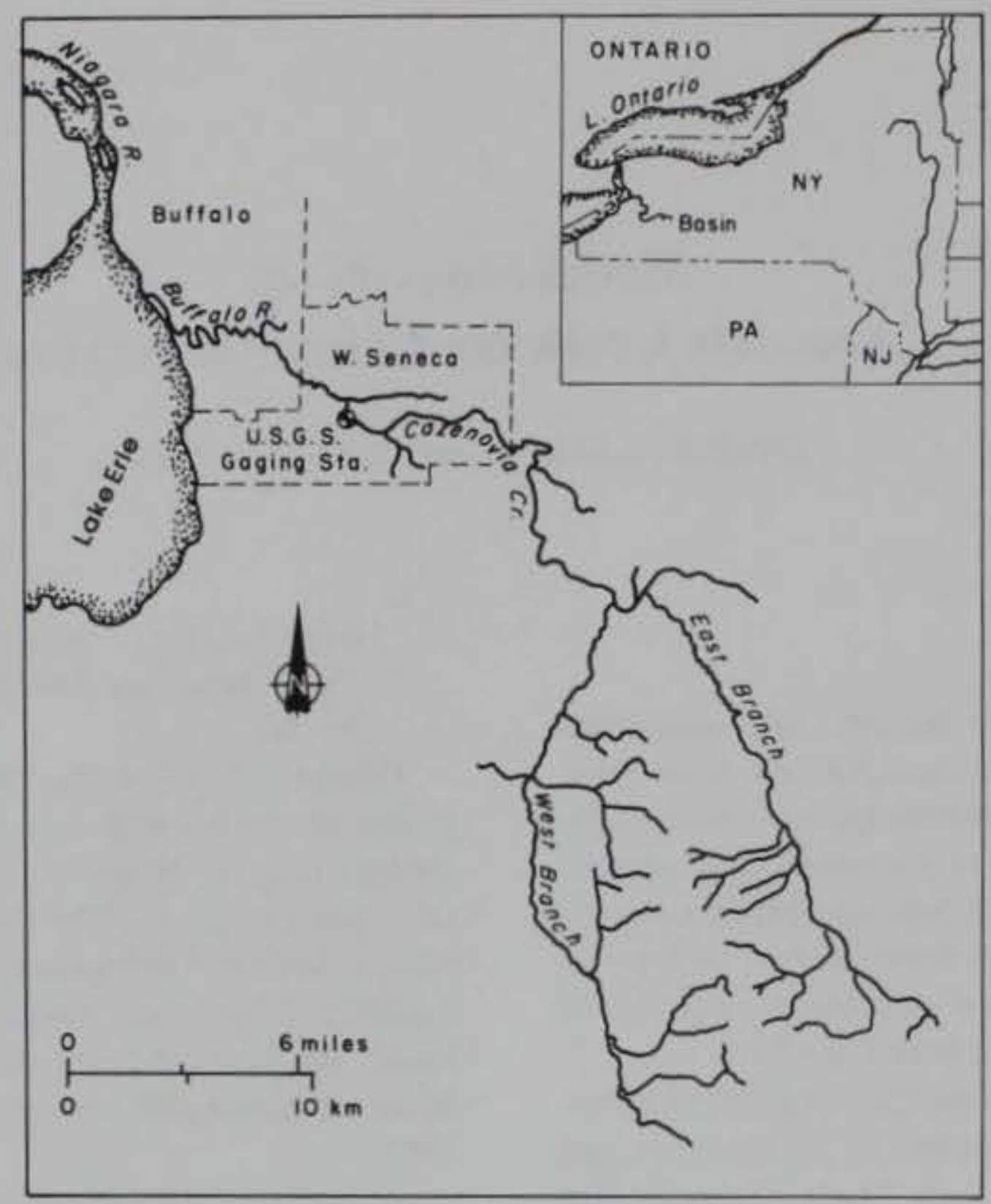

Figure 1. Map of Cazenovia Creek watershed.

\section{PHYSICAL MODELS}

River ice breakup on Cazenovia Creek is similar to that on other Northeast rivers. The key elements needed to cause serious ice-jam flooding are outlined in Figure 2.

Physical models used to study natural phenomena of flowing fluids must in principle satisfy the requirements of geometric similarity, dynamic similarity, and kinematic similarity. Geometric similarity requires that the model reproduces the physical layout of the prototype. Dynamic similarity implies that the ratio of any two forces acting at the prototype scale is reproduced in the model, while kinematic similarity means that flow patterns (i.e., streamline and pathline configurations) in the prototype are reproduced at the model scale. While geometric and dynamic similarities result in kinematic similarity, the converse is not necessarily true, that is, geometric and kinematic similarities do not necessarily result in dynamic similarity.

It can be shown that, for all three similarities to be fully achieved, the only possible geometric scale of a model is 1 -that is, the prototype is the model! Therefore, some of the modeling criteria or constraints must be relaxed. To this end, only those forces that dominate the phenomena under study, such as gravity and inertia, are modeled correctly. Other secondary forces, such as viscous and surface tension forces, are only approximated within reasonable limits (for example, model flow will be turbulent but at a significantly lower Reynolds number than in the prototype).

Because all relevant scaling parameters cannot be simultaneously satisfied, a successful model requires a balance of forces and material properties to reproduce the prototype processes of most concern. The design of such a model requires a coherent selection of both materials and scaling ratios that will result in ice and hydraulic behavior that is generally similar to that observed in the prototype for the required range of conditions. The importance of verification against field data cannot be overemphasized.(Wuebben, in preparation)

The driving force of channel flow, with or without ice, is gravity. Therefore, the ratio of inertia forces to gravity forces should be equal in the model and the prototype. This dictates equal Froude numbers between 


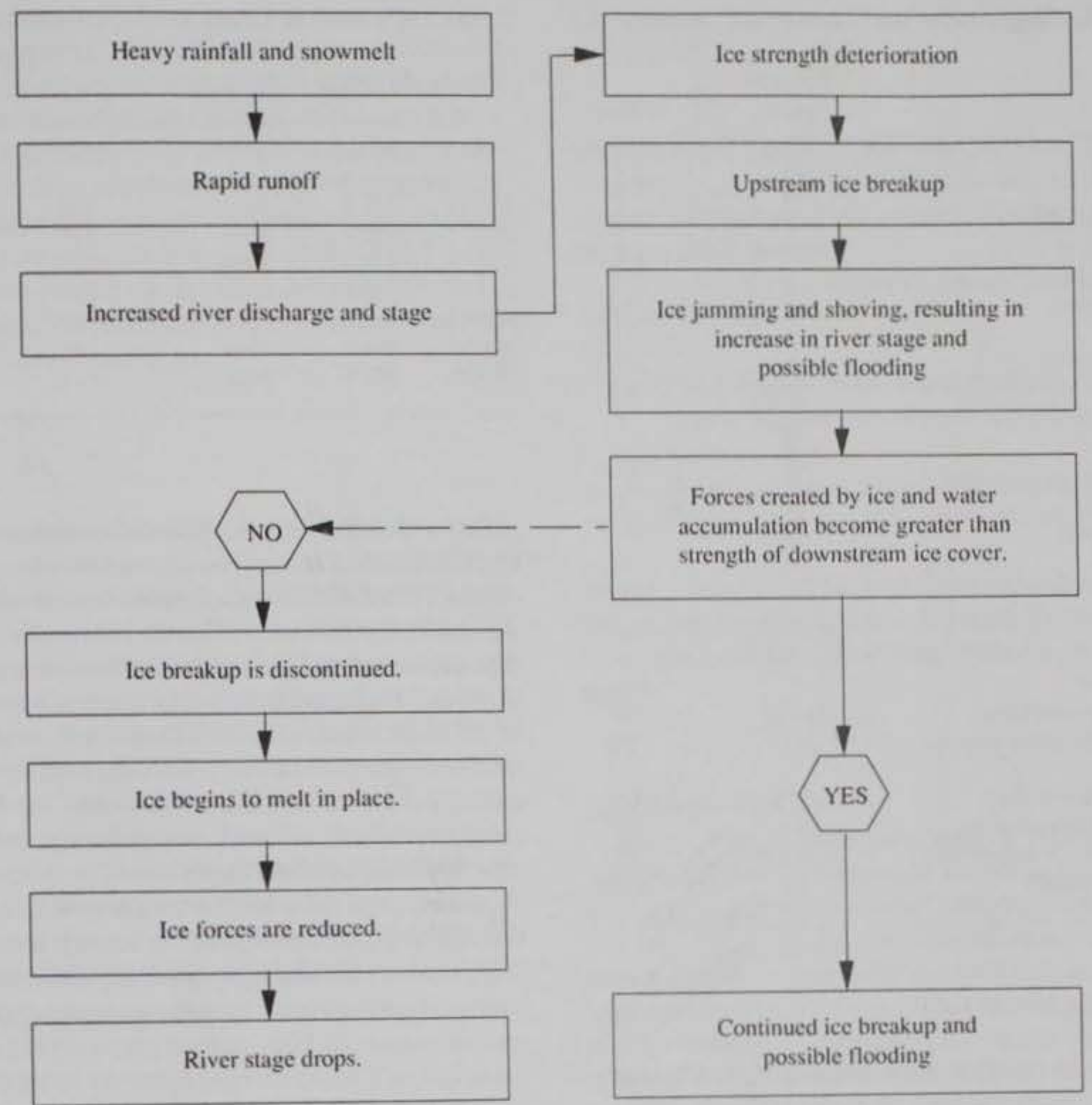

Figure 2. Flow chart of key elements in river flooding.

model and prototype. When an ice cover is present, the ratio of ice forces to gravity forces should also be kept constant, that is the ratio of dimensionless ice strengths at both scales should also be equal to one:

$$
\begin{aligned}
& F_{r}=V_{r} / \sqrt{g_{r} d_{r}}=1 \\
& C_{r}=\frac{\sigma_{r} h_{r}^{2}}{\rho_{r} g_{r} h_{r} L_{r}^{2}}=1
\end{aligned}
$$

$$
\text { where } \begin{aligned}
V_{\mathrm{r}}= & \text { velocity ratio }=V_{\mathrm{p}} / V_{\mathrm{m}} \\
g_{\mathrm{r}} & =\text { gravity ratio }=g_{\mathrm{p}} / g_{\mathrm{m}}=1 \\
L_{\mathrm{r}} & =\text { characteristic horizontal } \\
& \text { length ratio }=L_{\mathrm{p}} / L_{\mathrm{m}} \\
d_{\mathrm{r}}= & \text { flow depth ratio }=d_{\mathrm{p}} / d_{\mathrm{m}}
\end{aligned}
$$

$$
\begin{aligned}
& h_{\mathrm{r}}=\text { ice thickness ratio }=h_{\mathrm{p}} / h_{\mathrm{m}} \\
& \rho_{\mathrm{r}}=\text { density ratio }(\text { water or ice })=\rho_{\mathrm{p}} / \rho_{\mathrm{m}}=1 \\
& \sigma_{\mathrm{r}}=\text { ice strength ratio }=\sigma_{\mathrm{p}} / \sigma_{\mathrm{m}}
\end{aligned}
$$

subscripts: $r=$ full scale/model scale

$$
\begin{aligned}
\mathrm{p} & =\text { prototype (full scale) } \\
\mathrm{m} & =\text { model }
\end{aligned}
$$

To achieve true geometric similarity, an undistorted model is required. However, the extent of the area to be modeled may be so large or the size of the available laboratory so limited that in the resulting model scale the flow depth, in particular, becomes much too small to ensure turbulent flow in the model. A geometrically distorted model must then be used, that is, the scale in the vertical direction, $\beta$, will be smaller than that in the horizontal plane, $\lambda$. Model distortion, $\lambda / \beta$, should be 
Table 1.Scaling laws for the Cazenovia Creek model.

\begin{tabular}{|c|c|c|}
\hline & $\begin{array}{l}\text { Formulal } \\
\text { symbol }\end{array}$ & Scale \\
\hline Horizontal & $\lambda$ & $\lambda$ \\
\hline Vertical & $\beta$ & $\beta$ \\
\hline Length, horizontal & $L$ & $\lambda$ \\
\hline Length,vertical & $\gamma$ & $\beta$ \\
\hline Area, horizontal & $A_{b}$ & $\lambda^{2}$ \\
\hline Area, vertical & $A_{x}^{n}$ & $\lambda \beta$ \\
\hline Volume & $v$ & $\lambda^{2} \beta$ \\
\hline Time & $t$ & $\lambda / \beta^{1 / 2}$ \\
\hline Mass & $M$ & $\lambda^{2} \beta$ \\
\hline Density & $\rho$ & 1 \\
\hline Gravity & $g$ & 1 \\
\hline Velocity & $v$ & $\beta^{1 / 2}$ \\
\hline Acceleration & $a$ & 1 \\
\hline Water discharge & $Q$ & $\lambda \beta^{3 / 2}$ \\
\hline Water depth & $\gamma$ & b \\
\hline River slope & $s$ & $\beta / \lambda$ \\
\hline Head losses & $f-\frac{V L}{4 g Y}$ & $\beta$ \\
\hline Friction factor & $f$ & $\beta / \lambda$ \\
\hline Horizontal friction force & $f \rho v^{2} L^{2}$ & $\lambda \beta^{2}$ \\
\hline $\begin{array}{l}\text { Vertical hydrodynamic forces } \\
\text { (lift) }\end{array}$ & $\rho v^{2} L^{2}$ & $\lambda^{2} \beta$ \\
\hline Gravity forces (vertical) & $\rho g L^{2} Y$ & $\lambda^{2} \beta$ \\
\hline Gravity forces (horizontal) & $\rho g L^{2} y s$ & $\lambda \beta^{2}$ \\
\hline Flexural failure force (vertical) & $F_{\mathrm{b}}=\sigma h^{2}$ & $\lambda^{2} \beta$ \\
\hline Ice flexural strength & $\sigma_{\mathrm{f}}$ & $\lambda^{2} / \beta$ \\
\hline
\end{tabular}

kept as low as possible to minimize adverse effects on the model results and their interpretation.

Once the geometric scale $\lambda$, or in the case of a distorted model scales $\lambda$ and $\beta$, are selected, those for any other physical quantities are prescribed by the applicable modeling laws. In the case of channel flow in the presence of ice, where the modeling laws are given by eq 1 and 2 , the scales are listed in Table 1.

\section{CAZENOVIA CREEK ICS MODEL}

\section{Scale selection}

For the present model of the Cazenovia Creek Ice Control Structure, it was considered sufficient to model the reach upstream from the ICS location over a distance of $1290 \mathrm{~m}(4200 \mathrm{ft})$. It was anticipated that the backwater curve created by a 1.8 - to 2.5 -m (6- to 8 -ft)high weir, the ICS concept, would extend 215 to $250 \mathrm{~m}$ (700 to $800 \mathrm{ft}$ ) upstream; the remainder of the reach would permit calibration of the model under open water conditions and ensure that the flow was well established when it approached the ICS location. The available
Table 2. Cazenovia Creek ice-jam floods since 1971.

\begin{tabular}{|c|c|c|c|c|}
\hline \multirow[b]{2}{*}{ Date } & \multicolumn{2}{|c|}{ Prototype discharge } & \multicolumn{2}{|c|}{$\begin{array}{c}\lambda \beta^{3 / 2} \\
\text { Model discharge }\end{array}$} \\
\hline & $\left(m^{3} / s\right)$ & $\left(f t^{3} / s\right)$ & $\left(m^{3} / m i n\right)$ & (gal/min) \\
\hline $3 / 27 / 71$ & 877.8 & 3100 & 4.16 & 1099 \\
\hline $3 / 02 \pi 72$ & 1642.4 & 5800 & 7.79 & 2057 \\
\hline $1 / 21 / 74$ & 538.0 & 1900 & 2.55 & 674 \\
\hline $2 / 17 / 76$ & 764.6 & 2700 & 3.62 & 957 \\
\hline $3 / 21 / 78$ & 991.1 & 3500 & 4.70 & 1241 \\
\hline $3 / 04 / 70$ & 764.6 & 2700 & 3.62 & 957 \\
\hline $3 / 13 / 82$ & 877.8 & 3100 & 4.16 & 1099 \\
\hline
\end{tabular}

space in the refrigerated hydraulic model area of the CRREL Ice Engineering Facility was $46 \mathrm{~m}$ long by 18.5 $\mathrm{m}$ wide $(150 \times 60 \mathrm{ft})$. The horizontal scale for the model was therefore selected to be $\lambda=40: 1$. At such a scale, the flow depth in the model would have been less than $5 \mathrm{~cm}$ ( $2 \mathrm{in}$.) at the structure and no greater than $0.3 \mathrm{~cm}(0.1 \mathrm{in}$.) in the main reach, since the flow depth in the creek rarely exceeds $61.5 \mathrm{~cm}(2 \mathrm{ft})$. Such shallow depths in the model were unacceptable: flow would not be sufficiently turbulent, accuracy in open-water calibration would be low, and flow depth would be quite small as compared to the minimum ice thickness of $2.5 \mathrm{~cm}(1 \mathrm{in}$.) that can be grown (see Model Ice below). It was therefore necessary to build a geometrically distorted model. Compromise between minimum acceptable flow depth and maximum available pumping capacity in the model area $\left(7.57 \mathrm{~m}^{3}[2000 \mathrm{gal}] / \mathrm{min}\right)$ dictated a vertical scale of $\beta=10: 1$. With $\lambda=40: 1$ and $\beta=10: 1$, an acceptable distortion ratio of 4 was achieved and the maximum prototype flow discharge that could be modeled was about $1700 \mathrm{~m}^{3}\left(6000 \mathrm{ft}^{3}\right) / \mathrm{s}$, roughly twice the discharge at which complete ice breakup in the creek occurs and about equal to the maximum reported discharge during ice-related floods since 1971 (see Table 2).

\section{Model ice}

When model studies involving ice require that mechanical properties of ice be modeled, freshwater ice cannot be used. Instead, ice is grown from a bath of water to which a suitable dopant such as salt, carbamide (urea), or glycol has been added. During ice growth, the dopant is trapped between crystals of pure ice and, with proper techniques for growing and tempering the ice, creates 'brine' pockets that reduce the ice's mechanical properties to the desired levels. Since 1980, the CRREL Ice Engineering Facility has used and tested the ureadoped model ice developed by Timco (1979) as a replacement for saline ice, which caused high levels of corrosion and corresponding maintenance costs. This 
ice is grown from a 1\% solution of urea (or carbamide) in water and has been extensively tested (Hirayama 1983). When the anticipated primary mode of ice failure is in bending, the flexural strength is the mechanical property that must be scaled down. That of the model ice is measured in situ on small cantilever beams of length $L=6$ to 8 times thickness $h$, and with $B=1$ to 2 times $h$. A load is applied at the tip of the cantilever beam until failure. The ice flexural strength $\sigma$ is calculated from the measured failure load $P_{\mathrm{f}}$ by

$$
\sigma=\frac{6 P_{1} L}{B h_{2}}
$$

Experience has shown that the minimum ice thickness and minimum model ice strength that could be achieved with confidence at the CRREL test facilities were $h=2 \mathrm{~cm}$ and $\sigma=20 \mathrm{kPa}$, respectively. The maximum sheet ice thickness to be expected in Cazenovia Creek is $45 \mathrm{~cm}$, and freshwater ice at breakup has a flexural strength of the order of $800 \mathrm{kPa}$. From Table 1 , with $\lambda=40: 1$ and $\beta=10: 1$, the corresponding model values should be $h=4.5 \mathrm{~cm}$ and $\sigma=5 \mathrm{kPa}$. This model ice flexural strength cannot be achieved. It was therefore decided to adjust the ice thickness in the model so that the overall ice resistance to bending, which is proportional to $\sigma \cdot h^{2}$, be correctly modeled with the minimum reliable model ice strength of $20 \mathrm{kPa}$. That is,

$$
\sigma_{r} \cdot h_{r}^{2}=\lambda^{2} \cdot \beta
$$

with

$$
\sigma_{r}=800 / 20=40,
$$

which led to

$$
h_{\mathrm{r}}=20 \text {, }
$$

giving a target model ice thickness of $h=2.25 \mathrm{~cm}$. In other words, an additional distortion was introduced to be able to model what was considered to be one of the most important forces.

The external forces acting on the ice sheet upstream from the ICS are

a. The buoyancy forces due to the frazil ice and ice floes being transported and accumulated below it, and

b. The lifting force exerted on the upstream edge of the ice cover as a flood wave passes by.

The former force will be properly modeled by ensuring that enough ice is carried underneath the model ice sheet, the latter by reproducing characteristic hydrographs.

\section{Model construction}

Construction of the model began in February 1984 with the placement of plywood templates reproducing 40 cross sections of Cazenovia Creek upstream from the ICS site. Plastic piping was installed along the model riverbed to monitor the water level at 8 locations. A sand base followed by a 7.6-cm (3-in.) mortar surface was applied between the templates. The mortar surface was sealed with fiberglass. The model (Fig. 3) was completed in June 1984

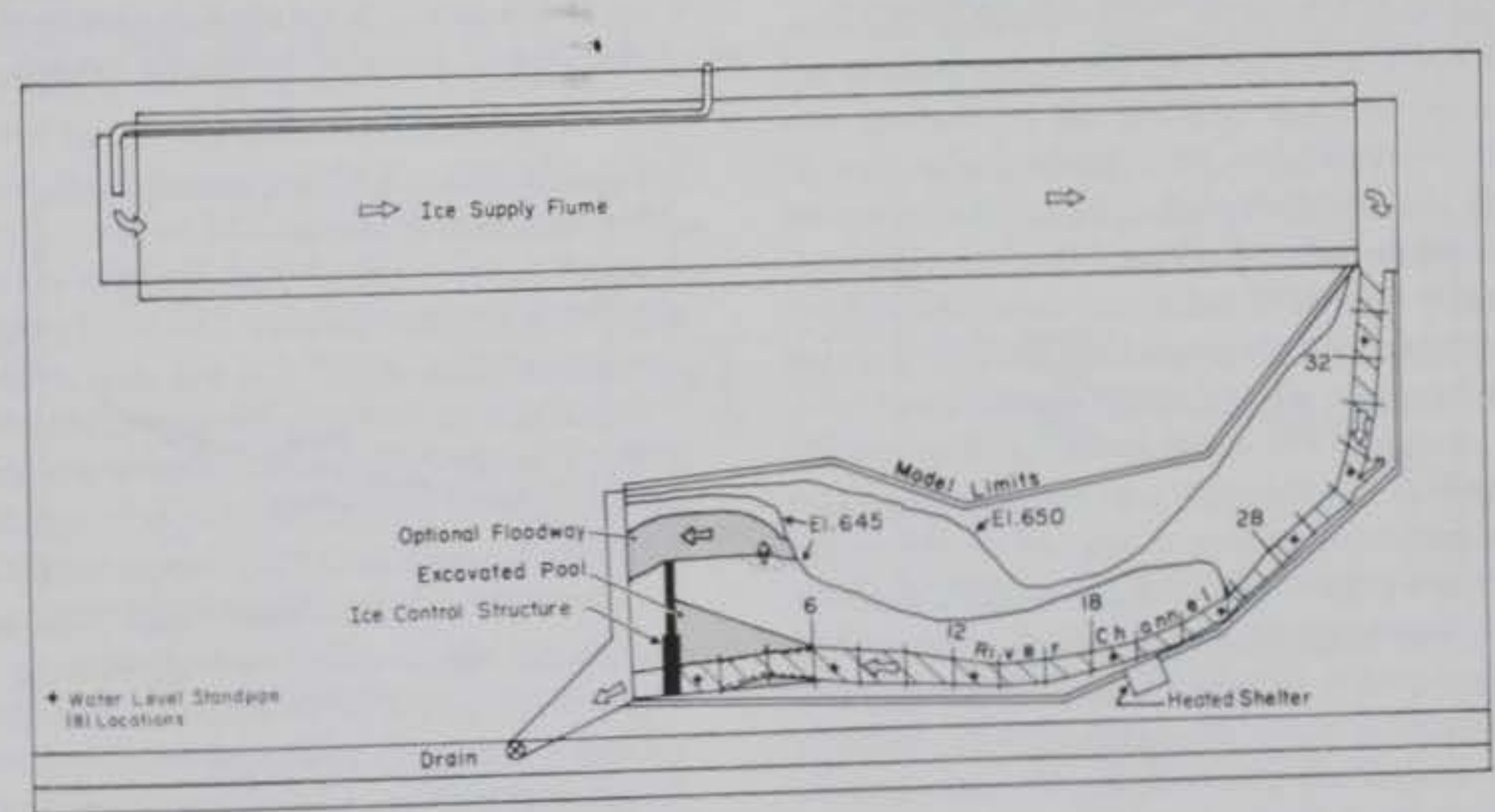

Figure 3. Plan view of Cazenovia Creek model. 


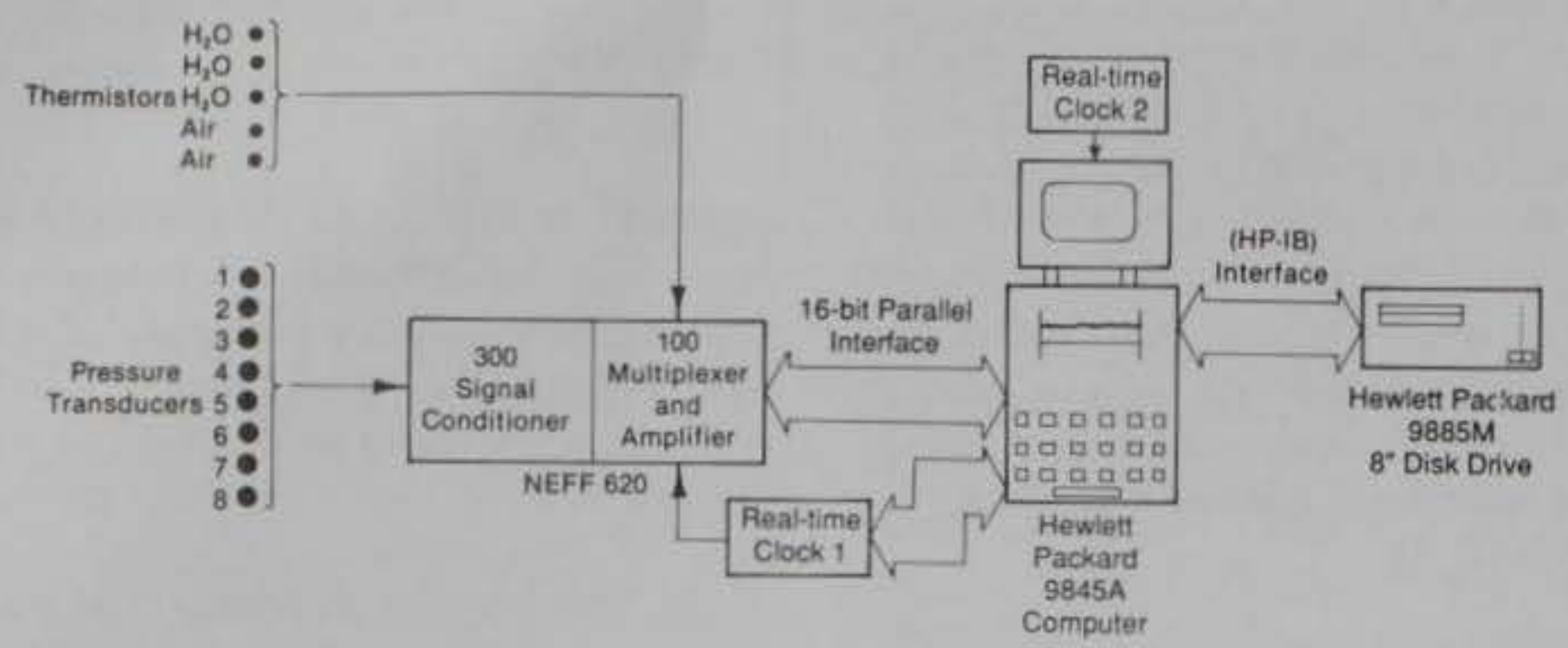

Figure 4. Schematic of data acquisition system.

\section{Data acquisition system}

The data acquisition system consisted of thermistors, with an accuracy of $0.02^{\circ} \mathrm{C}$, to monitor air and water temperatures, and 8 absolute pressure transducers to monitor water-level changes in the 8 standpipes embedded in the model. These pressure transducers, which had an accuracy of $0.3 \mathrm{~cm}(0.01 \mathrm{ft})$ of water, were necessary to evaluate the performance of the ice control structure by recording rapid water-level changes in the creek during ice-breakup simulations. The thermistors and pressure transducers were connected to a NEFF 620 signal conditioner and multiplexer controlled by an HP9845A computer. Group calibration check of the pressure transducers was accomplished by connecting all 8 transducers to a common standpipe with a known water level. The output of the transducers was checked against their calibration to detect any inaccuracies.

This data acquisition system, shown in Figure 4, has been described in detail by Bennett and Zabilansky (1985). It had three major advantages:

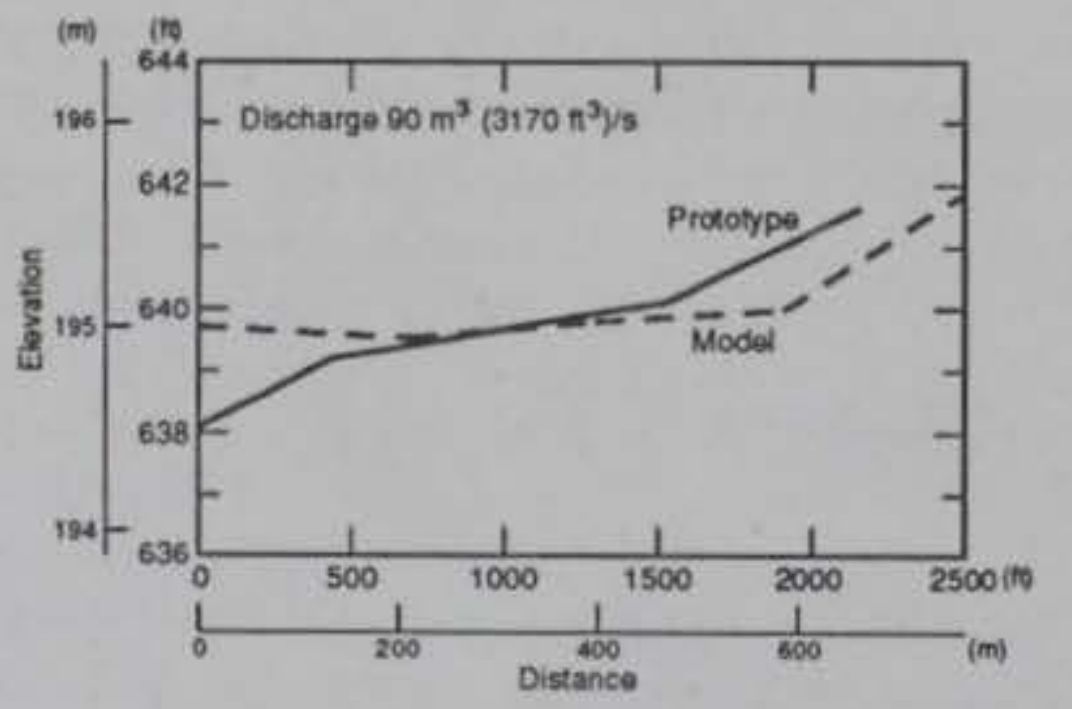

a. $Q=3170 \mathrm{ft}^{3} / \mathrm{s}$. a. It permitted real-time graphic display of water surface hydrographs at all monitoring locations. Changing water levels were recorded at 4-s intervals, permitting the ice jam to be located as it released or subsided.

b. It provided a permanent record of all measurements for subsequent analysis and interpretation.

c. The data base was calibrated and corrected through the software's initial short/shunt calibration.

\section{Model calibration}

Before conducting tests with the ICS model, the Cazenovia Creek model was hydraulically calibrated by matching in the model water surface elevations measured in the prototype at two levels of discharge. Discharges of 898 and $222 \mathrm{~m}^{3}\left(3170\right.$ and $\left.783 \mathrm{ft}^{3}\right) / \mathrm{s}$ in the prototype were scaled down to model values of 4.25 and $1.05 \mathrm{~m}^{3}$ (1124 and $\left.278 \mathrm{gal}\right) / \mathrm{min}$, respectively. As is often the case in distorted hydraulic models, the bed

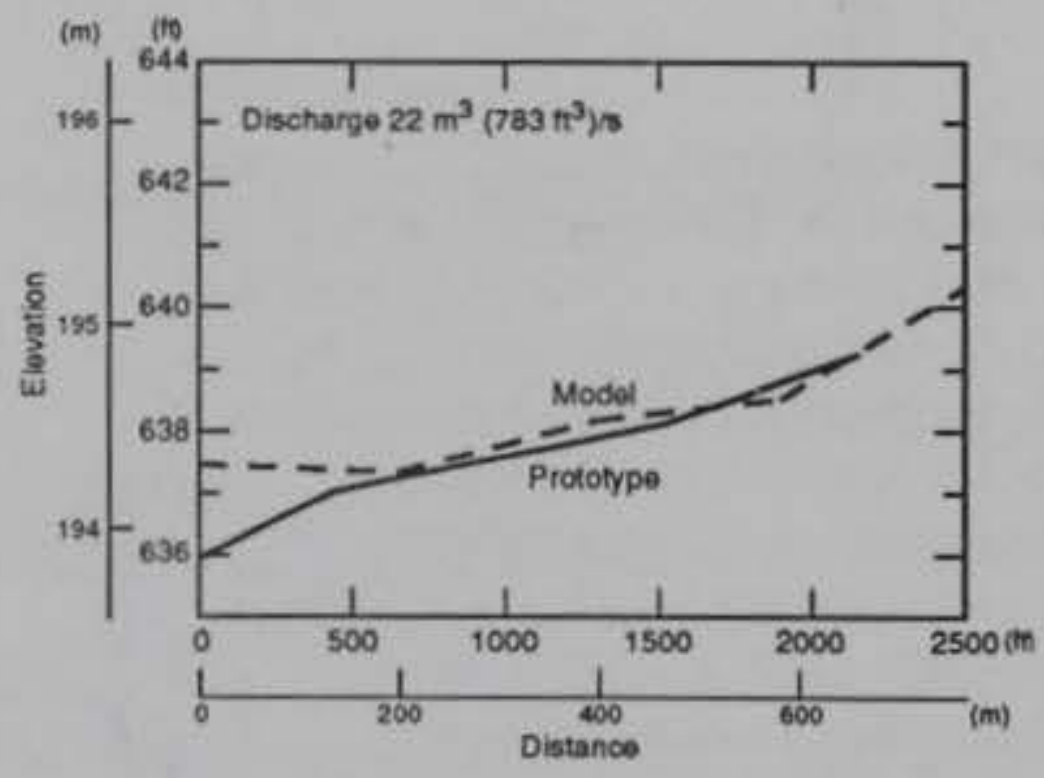

b. $Q=783 \mathrm{ft}^{3} / \mathrm{s}$.

Figure 5, Model calibration: comparison of water surface profiles between model and full-scale. 
roughness of the model had to be increased by laying a plastic fencing material on the channel surface until model water elevations were in agreement with those measured in the field. Results of the calibration are shown in Figure 5.

\section{TEST CONDITIONS AND PROCEDURES}

Since flow records for Cazenovia Creek indicated that ice breakup occured when the flow discharge reached approximately $425 \mathrm{~m}^{3}\left(1500 \mathrm{ft}^{3}\right) / \mathrm{s}$, this value was used as the base flow condition in all model tests.

The 3-hr unit hydrograph used in the model was selected as the average of two unit hydrographs that represented the following conditions:

- Known uniform rainfall and distribution

- Unfrozen ground preceding the rainfall

- Bankful peak stage.

This hydrograph (Fig. 6) was considered to be representative of extreme conditions that could be expected. To reproduce this hydrograph in the model according to the scaling factor for time in the flow direction, it was determined that the discharge in the model had to increase linearly from the base flow of $1.89 \mathrm{~m}^{3}(500$ gal)/min $\left(425 \mathrm{~m}^{3}\left[1500 \mathrm{ft}^{3}\right] / \mathrm{s}\right.$ at full scale) to the maximum possible $7.95 \mathrm{~m}^{3}(2100 \mathrm{gal}) / \mathrm{min}\left(1700 \mathrm{~m}^{3}[6000\right.$ $\mathrm{ft}^{3} \mathrm{~J} / \mathrm{s}$ full scale) in approximately 15 minutes.

The model represents a $1230-\mathrm{m}(4000-\mathrm{ft})$ reach upstream from the ICS site. However, it was estimated that at breakup ice reaching the ICS site originated as much as $12.8 \mathrm{~km}$ ( 8 miles) upstream. Therefore the shallow flume in the Hydraulic Research Area was used to supply brash ice to the model during the tests.

\section{Test conditions}

The initial ICS height was selected to be $1.8 \mathrm{mr}(6 \mathrm{ft})$ at full scale and its width to be $77 \mathrm{~m}(250 \mathrm{ft})$. The corresponding model was placed at station $0+00$ (Fig. 3 ). In addition, the upstream pool was excavated on the right bank to a width of $123 \mathrm{~m}(400 \mathrm{ft})$ at station $0+00$, returning to the original right bank at station $6+00$ as shown in Figure 1, with all material removed within this area to elevation 635 . The ICS height and pool excavation increased the cross-sectional flow area sufficiently to achieve the ice stability criteria of $0.566 \mathrm{~m}^{3}\left(2 \mathrm{ft}^{3}\right) / \mathrm{s}$ up to a discharge of approximately $906 \mathrm{~m}^{3}\left(3200 \mathrm{ft}^{3}\right) / \mathrm{s}$. A Buffalo District report (1975) had found these conditions to be economically acceptable.

To help contain the ice during higher discharges, vertical piers were mounted on the top of the structure (Fig. 7). Tests were made with 2, 3, 5, and 9 equally spaced piers to determine the optimum configuration. A few tests were conducted with the height of the weir

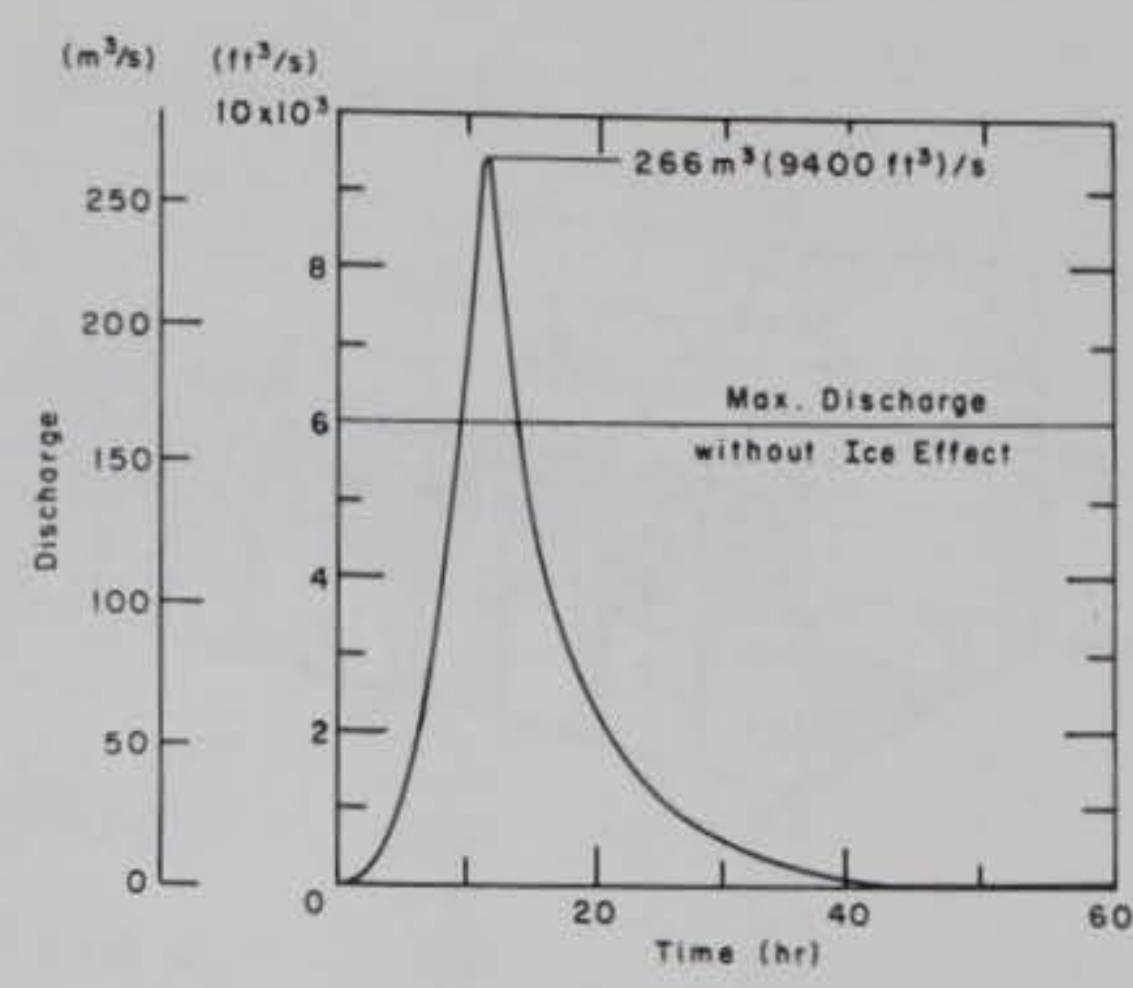

Figure 6. Three-hour unit hydrograph for Cazenovia Creek at Ebenezer.

increased to $2.5 \mathrm{~m}(8 \mathrm{ft})$, for the cases of no piers and two piers.

Finally, four tests were conducted with 9 piers on the 6-ft structure and an additional 61.5-m (200-ft)-wide bypass floodway constructed on the right bank of the creek to route water around the ICS at the higher discharges. This reduces the effective discharge passing over the weir, resulting in an ice cover stable at higher total discharge than without the floodway.

Table 3 lists the test conditions as weir height, number of piers, ice thickness, and ice strength.

\section{Test procedure}

Before each test, the base flow of $1.89 \mathrm{~m}^{3}$ (500 gal)/ min was established in the model, and the room temperature was set at $-10^{\circ} \mathrm{C}$. When the water temperature had reached nearly the freezing point, a fine water mist was sprayed in the air. The droplets froze into ice crystals, which settled on the water surface to initiate the ice cover in the model and in the ice supply flume. The ice was grown until it reached the desired thickness. The room temperature was raised to about $+1^{\circ} \mathrm{C}$ to temper the ice until the desired ice strength was reached. The ice sheet in the supply flume and the upstream end of the model was then broken into small fragments. The data acquisition program was started, the flow discharge was increased in steps, and ice was released from the supply flume into the model. The flow was increased until the ice sheet in the pool immediately upstream from the ICS broke up and the accumulated ice started to spill over the structure. The discharge and stage at which this final breakup occurred was recorded, and the test was terminated. 


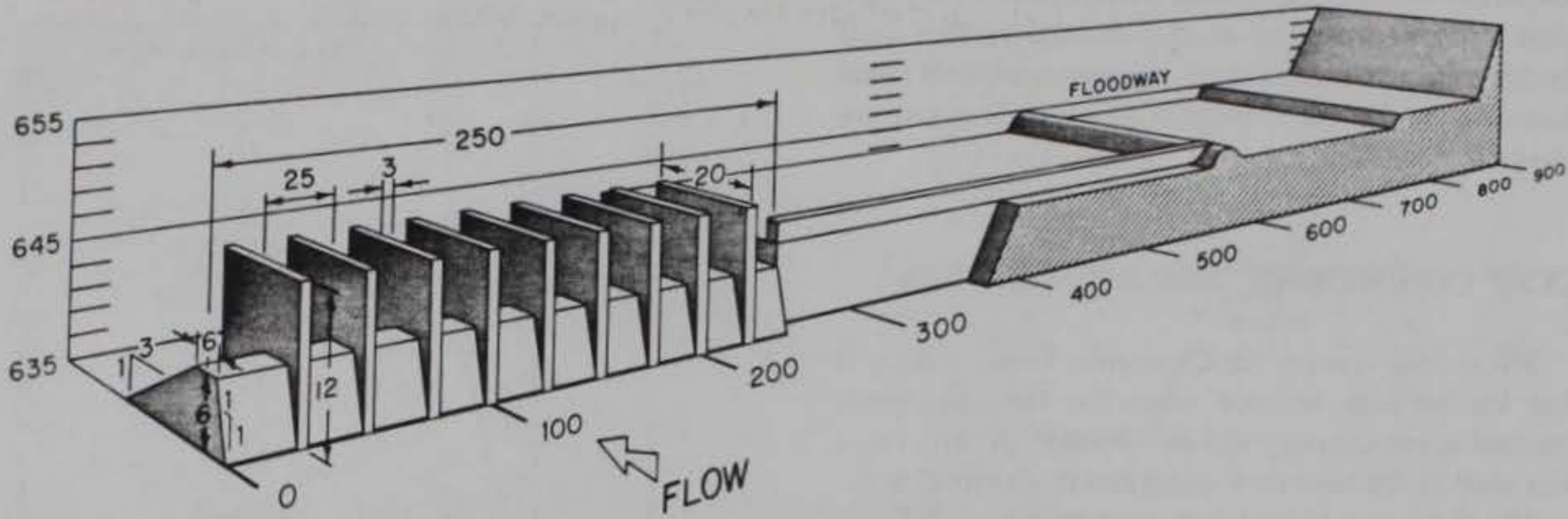

a. Isometric drawing.

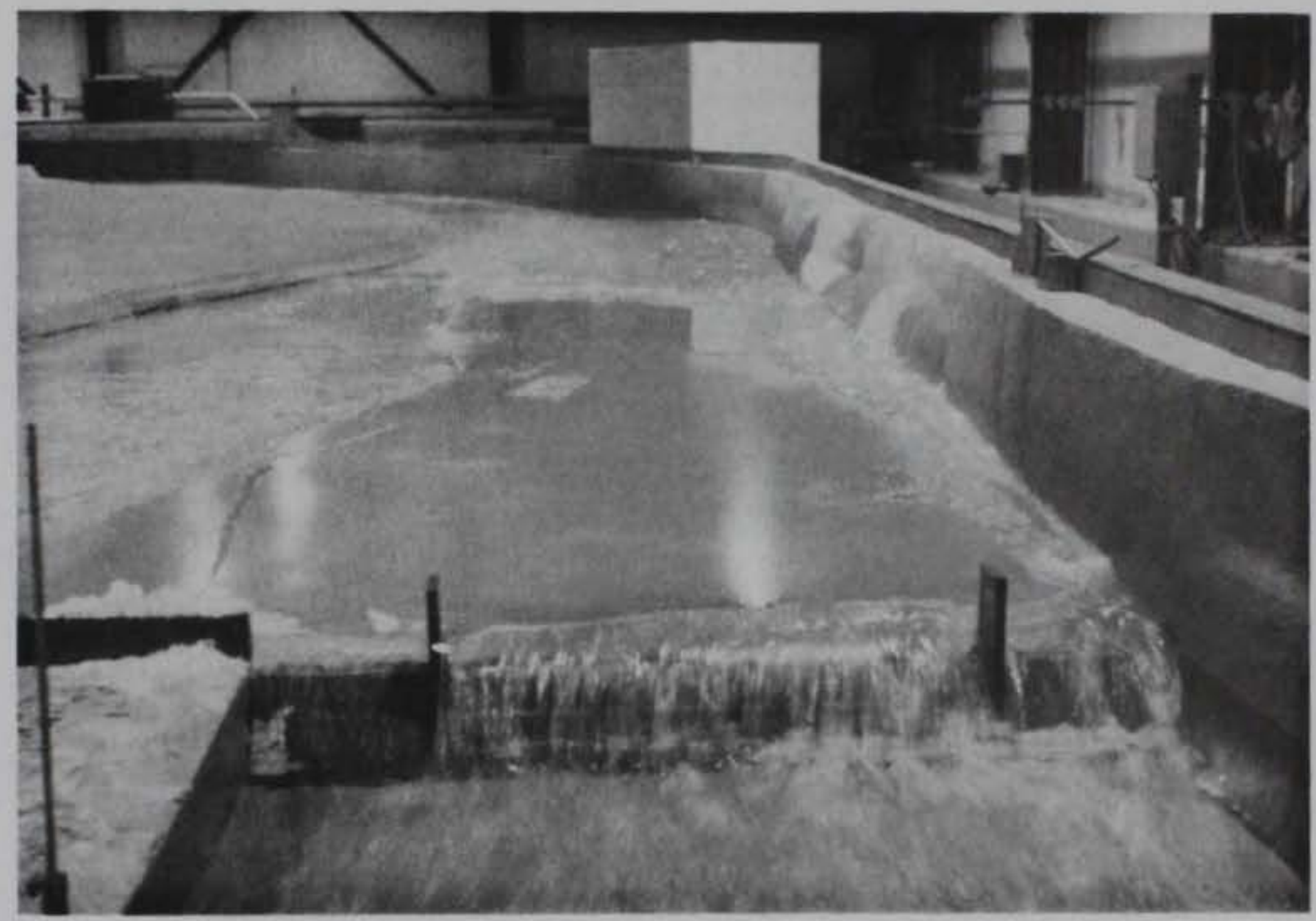

b. Photo of model test of 6-ft structure with 2 piers.

Figure 7. The Cazenovia Creek ice control structure. 
Table 3. Test conditions for Cazenovia Creek model.

\begin{tabular}{|c|c|c|c|c|c|}
\hline Test & & $\begin{array}{c}\text { Prototype } \\
\text { structure height (fI) }\end{array}$ & $\begin{array}{c}\text { Ice } \\
\text { strength } \\
(k P a)\end{array}$ & $\begin{array}{l}\text { Sid } \\
\text { dev }\end{array}$ & $\begin{array}{c}\text { lce } \\
\text { thickness } \\
\text { (mm) }\end{array}$ \\
\hline AA & 6 & \multirow[t]{5}{*}{ Withoutpiers } & 17.8 & 7.9 & 14.3 \\
\hline $\begin{array}{l}\mathrm{BB} \\
\mathrm{CC}\end{array}$ & $\begin{array}{l}6 \\
6\end{array}$ & & 20.7 & 5.1 & 24.9 \\
\hline $\begin{array}{l}C C \\
D D\end{array}$ & $\begin{array}{l}6 \\
6\end{array}$ & & - & - & - \\
\hline $\begin{array}{l}\mathrm{DD} \\
\mathrm{EE}\end{array}$ & $\begin{array}{l}6 \\
6\end{array}$ & & 16.6 & 1.0 & 18.4 \\
\hline $\begin{array}{l}\text { EE } \\
\text { GG }\end{array}$ & $\begin{array}{l}6 \\
6\end{array}$ & & 19.1 & 2.0 & $\begin{array}{l}22.9 \\
28.3\end{array}$ \\
\hline $\mathrm{HH}$ & 6 & \multirow[t]{6}{*}{ Two piers } & 23.2 & & 33.1 \\
\hline II & 6 & & $\begin{array}{l}19.2 \\
22.2\end{array}$ & $\overline{6.2}$ & $\begin{array}{l}35.1 \\
21.9\end{array}$ \\
\hline JJ & 6 & & $\begin{array}{l}22.2 \\
27.3\end{array}$ & $\begin{array}{l}0.2 \\
7.6\end{array}$ & 26.0 \\
\hline LL. & 6 & & $\begin{array}{l}27.3 \\
19.0\end{array}$ & 3.6 & 23.0 \\
\hline MM & 6 & & $\begin{array}{l}19.0 \\
22.6\end{array}$ & 2.1 & 22.6 \\
\hline NN & 6 & & 24.5 & 2.8 & 22.5 \\
\hline KK & 6 & (fragmented ice) & - & - & - \\
\hline 00 & 8 & \multirow[t]{6}{*}{ Without piers } & 20.5 & 3.2 & 25.4 \\
\hline PP & 8 & & 28.7 & 4.0 & 29.3 \\
\hline$Q Q$ & 8 & & 20.1 & 1.2 & 22.8 \\
\hline RR & 8 & & 17.7 & 1.4 & 25.8 \\
\hline SS & 8 & & 20.5 & 2.2 & 19.8 \\
\hline $\mathrm{TT}$ & 8 & & 19.3 & & 24.5 \\
\hline UU & 8 & \multirow[t]{2}{*}{ Two piers } & 22.7 & 2.1 & 28.5 \\
\hline VV & 8 & & 26.8 & 4.6 & 29.7 \\
\hline A1 & 6 & \multirow{3}{*}{ Without piers } & 23.3 & 1.9 & 27.1 \\
\hline$A 2$ & $\begin{array}{l}6 \\
6\end{array}$ & & 11.8 & 1.2 & 26.6 \\
\hline & 6 & & 16.4 & 4.1 & 25.8 \\
\hline $\begin{array}{l}\text { A4 } \\
\text { A6 }\end{array}$ & $\begin{array}{l}6 \\
6\end{array}$ & \multirow{2}{*}{ Two piers } & 20.7 & 2.0 & 24.5 \\
\hline $\begin{array}{l}\text { A6 } \\
\text { A5 }\end{array}$ & $\begin{array}{l}6 \\
6\end{array}$ & & 26.4 & 2.8 & 19.0 \\
\hline A7 & & (fragmented ice) & - & - & - \\
\hline A7 & $\begin{array}{l}6 \\
6\end{array}$ & \multirow{3}{*}{ Three piers } & 30.0 & 6.5 & 13.6 \\
\hline A9 & 6 & & 22.8 & 7.8 & $\begin{array}{l}25.8 \\
15.9\end{array}$ \\
\hline BI & 6 & & $\begin{array}{l}25.3 \\
25.4\end{array}$ & $\begin{array}{l}4.2 \\
2.1\end{array}$ & $\begin{array}{l}15.9 \\
19.8\end{array}$ \\
\hline B2 & 6 & \multirow[t]{3}{*}{ Five piers } & 26.6 & 5.7 & \\
\hline B3 & 6 & & 38.2 & 3.1 & 28.8 \\
\hline B4 & 6 & & 40.3 & 7.7 & 26.4 \\
\hline B5 & 6 & . & 28.0 & 3.3 & 17.6 \\
\hline B6 & 6 & \multirow[t]{4}{*}{ Nine piers } & 34.1 & 4.3 & 24.2 \\
\hline B7 & 6 & & - & - & - \\
\hline B8 & 6 & & - & - & - \\
\hline B9 & 6 & & - & - & - \\
\hline $\mathrm{Cl}$ & 6 & \multirow{4}{*}{$\begin{array}{l}\text { Nine piers and } \\
\text { floodway }\end{array}$} & - & - & - \\
\hline $\mathrm{C2}$ & 6 & & - & - & - \\
\hline $\mathrm{C} 3$ & 6 & & - & - & - \\
\hline C4 & 6 & & - & - & - \\
\hline
\end{tabular}

\section{TEST RESULTS AND DISCUSSION}

The model hydrographs for the tests run with the 6ft ICS are shown in Figure 8 for the various test configurations. In particular, Figure $8 \mathrm{f}$ shows the hydrographs for the tests with nine piers and the additional floodway. On these figures it is indicated when ice-out occurred or whether ice was still retained at the end of the test. The corresponding stages at station $0+96$ are shown in Figure 9a-c.

The test results (see the Appendix) indicate that although the holding time for ice was increased when additional piers were mounted along the top of the ICS, ice continued to pass through until the number of piers 


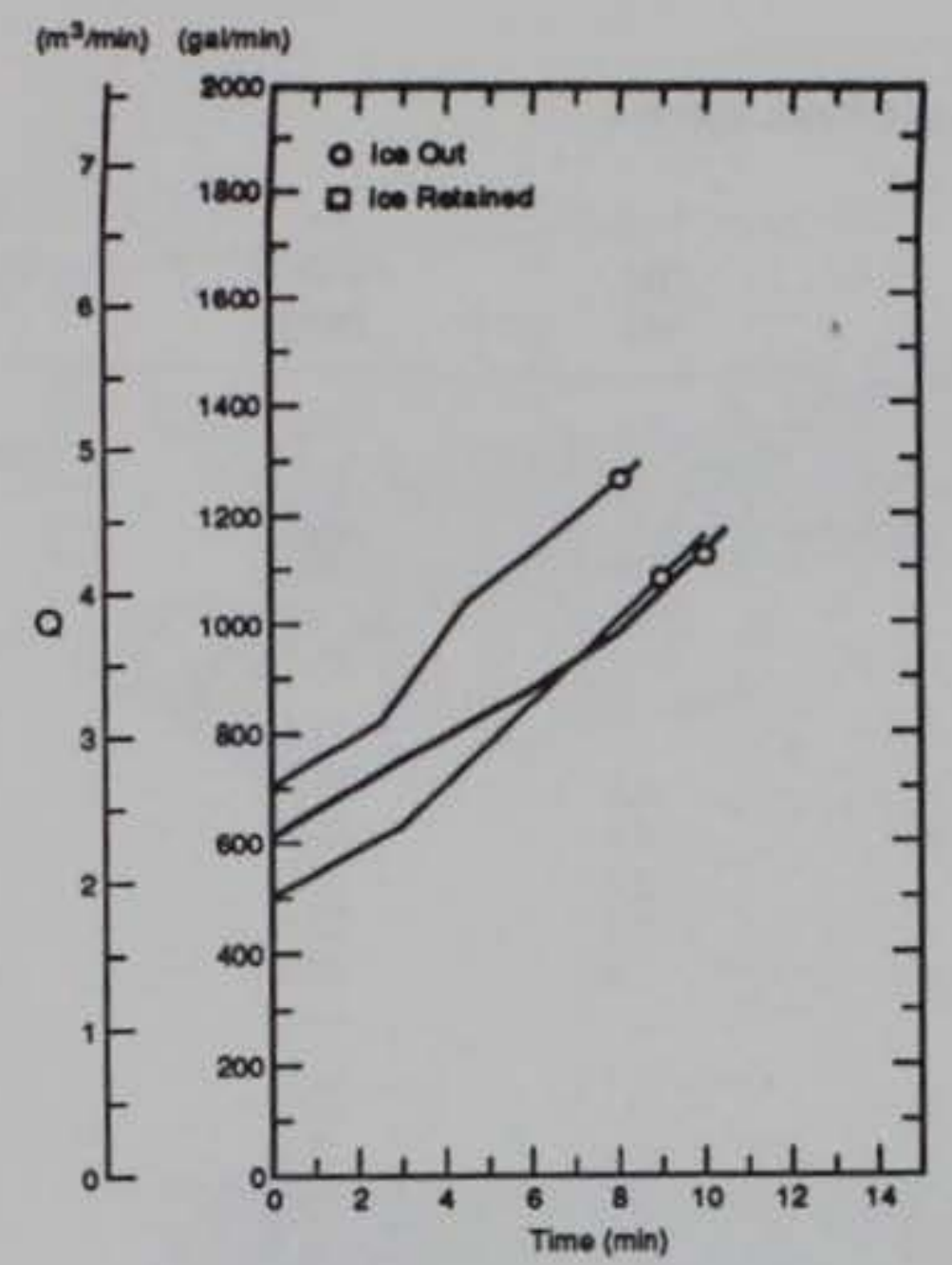

a. No piers.
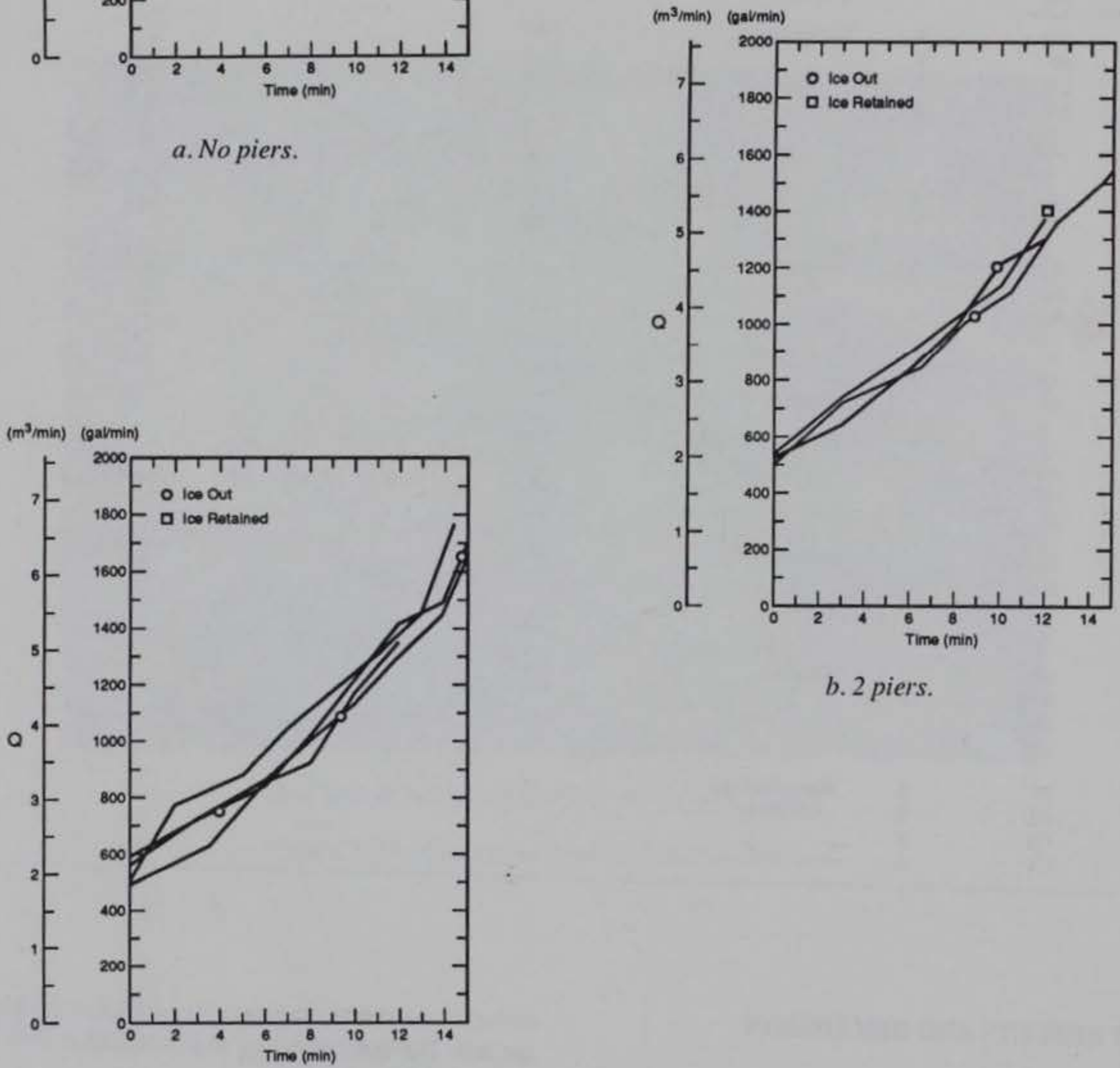

b. 2 piers.

c. 3 piers.

Figure 8. Hydrographs in model tests with 1.8-m (6-ft) ICS. 


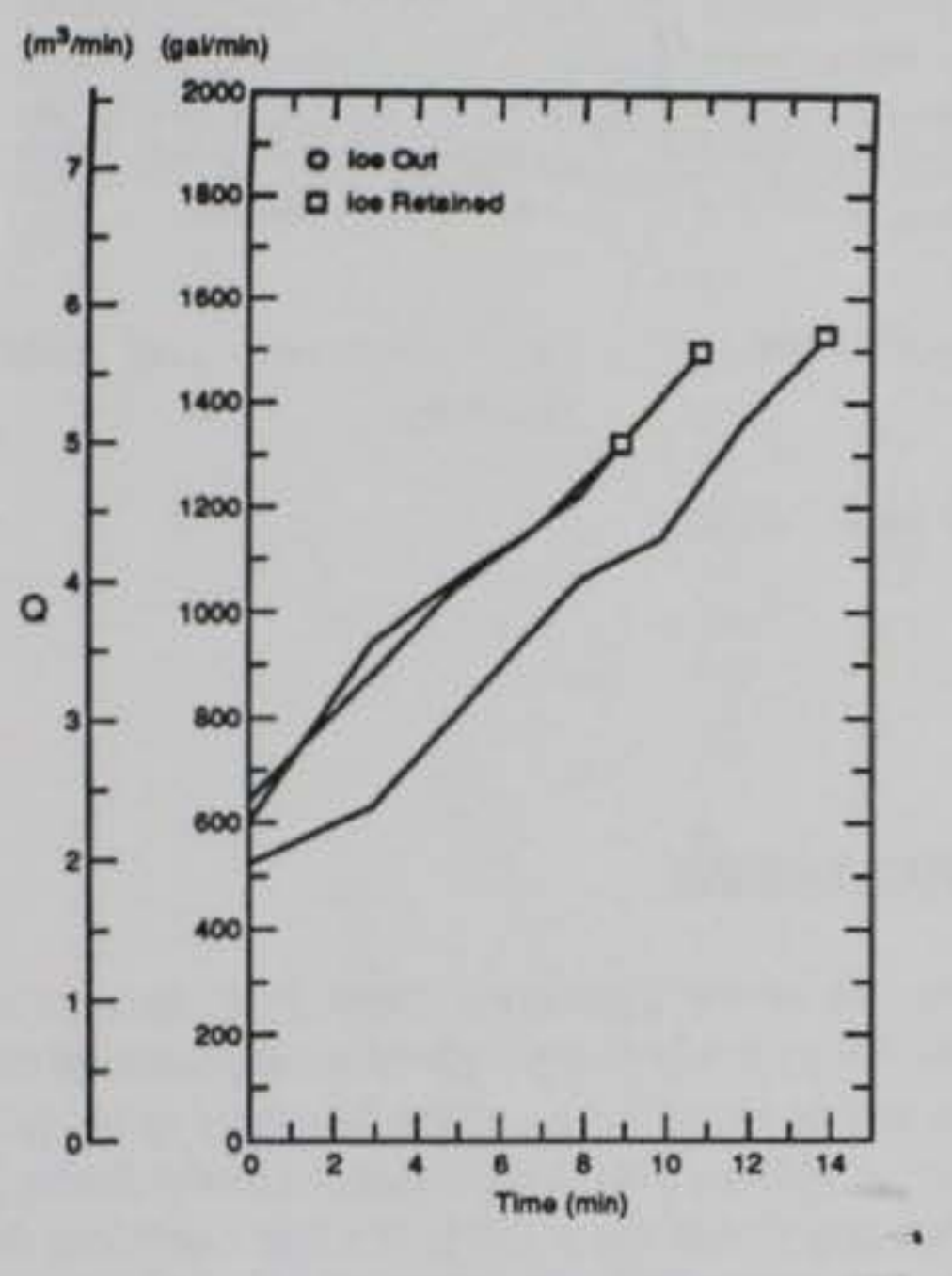

e. 9 piers.
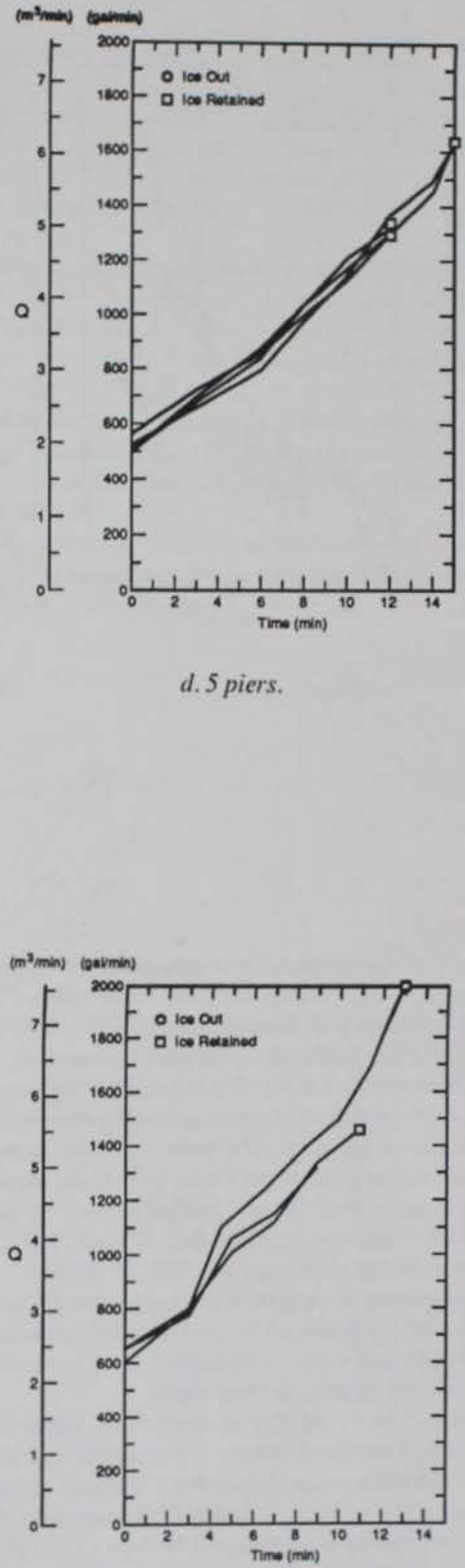

f. 9 piers and floodway.

Figure 8 (cont'd). Hydrographs in model tests with 1.8-m (6-ft) ICS. 


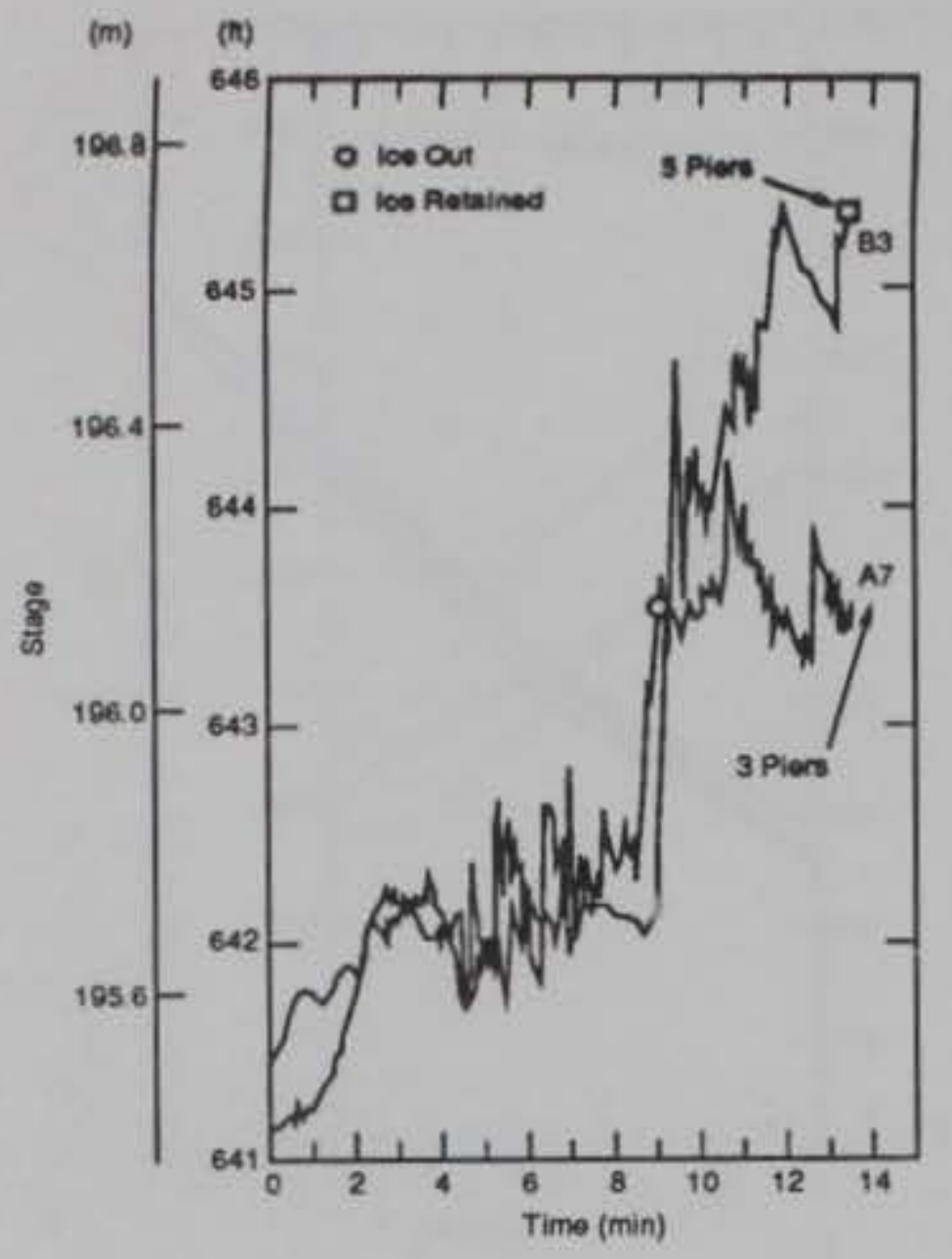

a. 3 and 5 piers.

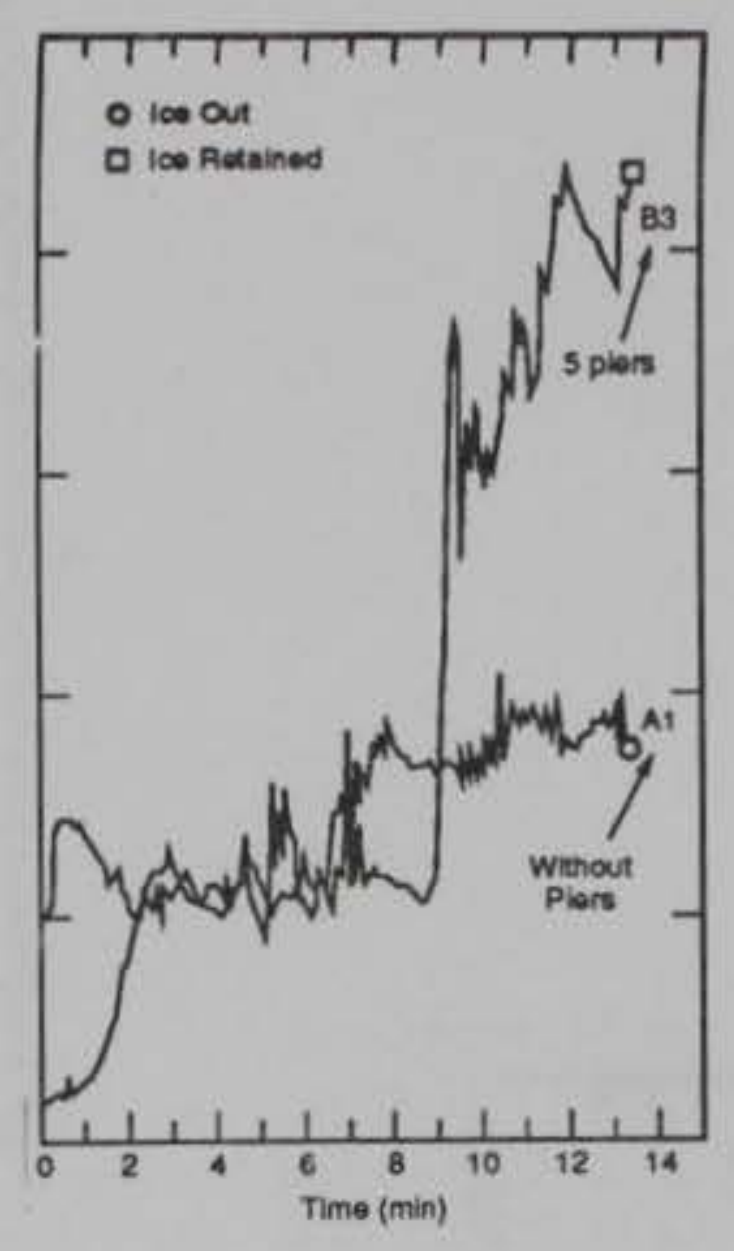

b. No piers and 5 piers.

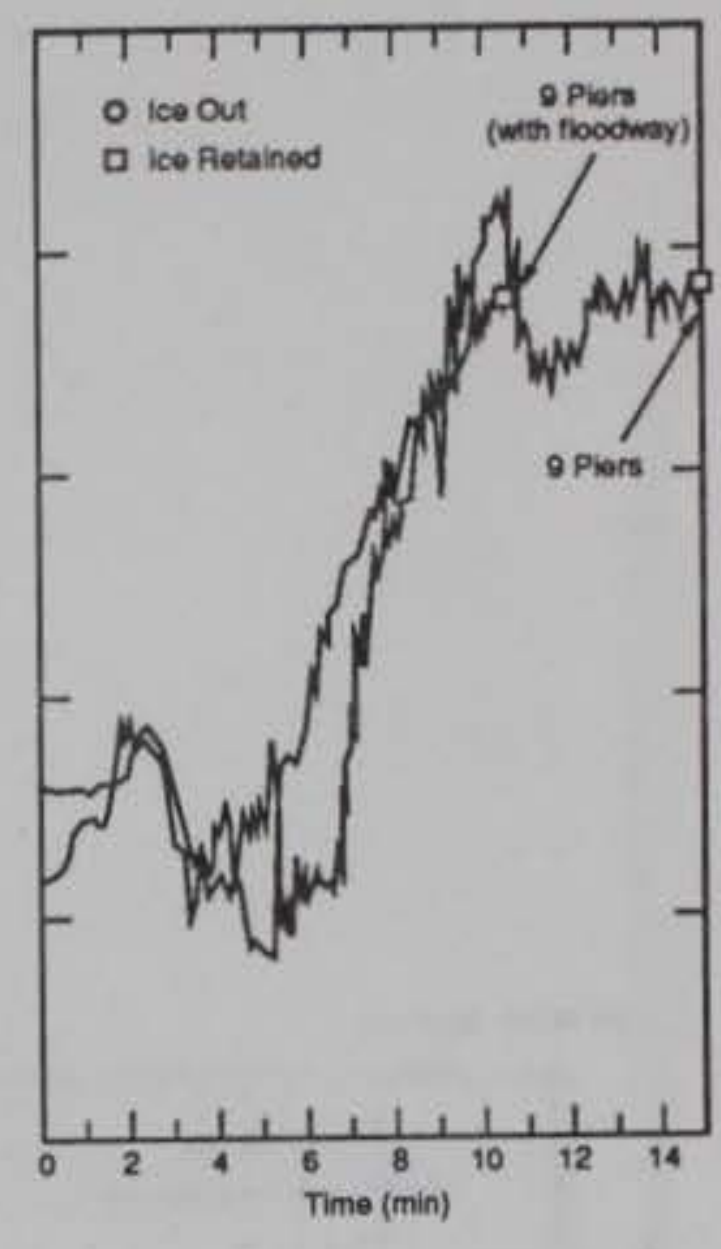

c. 9 piers with and without floodway.

Figure 9. Stage variations at station $0+96$.

reached 5 . At this point, ice was repeatedly held behind the structure at flow rates greater than those reported for the last seven ice-jam floods (Table 2). The test series using nine piers produced no apparent benefit over the five-pier configuration, possibly because the discharges required for ice-out could not be reached because of the limited pump capacity. The tests with the bypass floodway showed that water began to enter the bypass when a mean flow of $934 \mathrm{~m}^{3}\left(3300 \mathrm{ft}^{3}\right) / \mathrm{s}$ was reached. The flow through the bypass reached $382 \mathrm{~m}^{3}\left(1350 \mathrm{ft}^{3}\right) /$ $\mathrm{s}$ at the peak test discharge of $1707 \mathrm{~m}^{3}\left(6030 \mathrm{ft}^{3}\right) / \mathrm{s}$, thereby reducing the effective discharge over the weir by $22 \%$. The maximum water level recorded behind the ICS was 647 , and water above the 645 level is rerouted to the existing right-bank flood plain.

It should be noted that in those tests where the maximum available discharge was reached, approximately $50 \%$ of the ice had been melted by the time of the maximum flow of $1700 \mathrm{~m}^{3}\left(6000 \mathrm{ft}^{3}\right) / \mathrm{s}$ because of the heat input to the water by the pump. However, this effect was not considered detrimental to the test results since it implies weakening of the ice cover and therefore less resistance to breakup, and because a similar process occurs naturally during high runoff at ice breakup.

\section{CONCLUSIONS}

Results of the Cazenovia Creek ICS model study showed that a $1.8-\mathrm{m}$ (6-ft)-high weir equipped with nine piers and bordered by a bypass floodway is likely to retain ice well beyond the maximum recorded discharge for ice-jam fioods since 1971. We feel confident that such a structure will prevent future ice-jam flooding of West Seneca and Buffalo, New York.

This design was accepted by the U.S. Army Corps of Engineers, Buffalo District, and the structure is currently scheduled for completion by 1990 .

Once the structure is built, field data will need to be obtained in the following areas:

- Freeze-up and breakup conditions over several winters

- Ice loads on the structure

- Water levels immediately upstream of the ICS

These data are necessary for comparison with the results of the model study, and for future improvements in the design and techniques of hydraulic models involving ice processes. 


\section{LITERATURE CITED}

Bennett, B.M. and L.J. Zabilansky (1985) Cazenovia Creek model data acquisition system. In Pro. ceedings, ASCE Specialty Conference, Hydraulies and Hydrology in the Small Computer Age Conference, Orlando, 12-17 August. Vol. 2, p. 1424 1429.

Deck, D.S. (1985) Cazenovia Creek physical ice model study. Report to U.S. Army Corps of Engineers, Buffalo District, Cold Regions Research and Engineering Laboratory.

Hirayama, K. (1983) Properties of urea-doped ice in the CRREL test basin. Cold Regions Research and Engineering Laboratory, CRREL Report 83-8.

Predmore, S.R. (1986) A structure to control ice formation and ice jam flooding on Cazenovia Creek. New York. In Proceedings, Cold Regions Hydrology Symposium. American Water Resources Association,
Fairbanks, Alaska, 22-25 July, p. 565.

Timco, G.W. (1979) The mechanical and morphological properties of doped ice: A search for a better structurally simulated ice for model test basins. In Proceedings, 5th International Port and Ocean Engineering under Arctic Conditions (POAC), Trondheim, p. 719-739.

USA Corps of Engineers Buffalo District (1966) Flood plain information. Cazenovia Creek, N.Y., in the City of Buffalo and Town of West Seneca. Buffalo District, U.S. Army Corps of Engineers (reprinted June 1971).

USA Corps of Engineers Buffalo District (1985) Draft detailed project report and environmental impact statement for Cazenovia Creek, West Seneca, N.Y., Section 205.

Wuebben, J.L. (in preparation) Physical modeling. Ice Jams Monograph, Chapter 6, National Research Council of Canada, Ottawa. 


\section{APPENDIX: TEST DATA FOR CAZENOVIA CREEK MODEL STUDY}

Plots of experimental data at Standpipe 1

1. Stage vs time

2. Stage vs discharge

Note: ${ }^{*}$ indicates data at 1 -min intervals.

IST TEST SERIES WITH GHFT ICS - NO PIERS

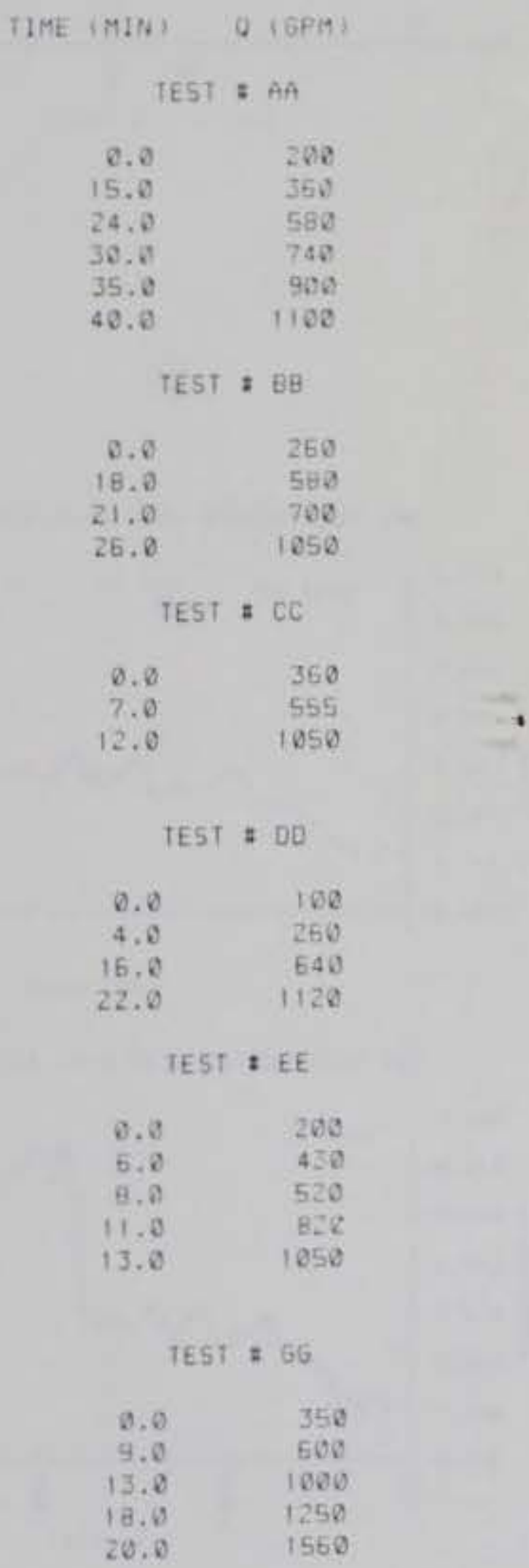

ISt TEST SERIES HITH 6-ft ICS - NO PIERS

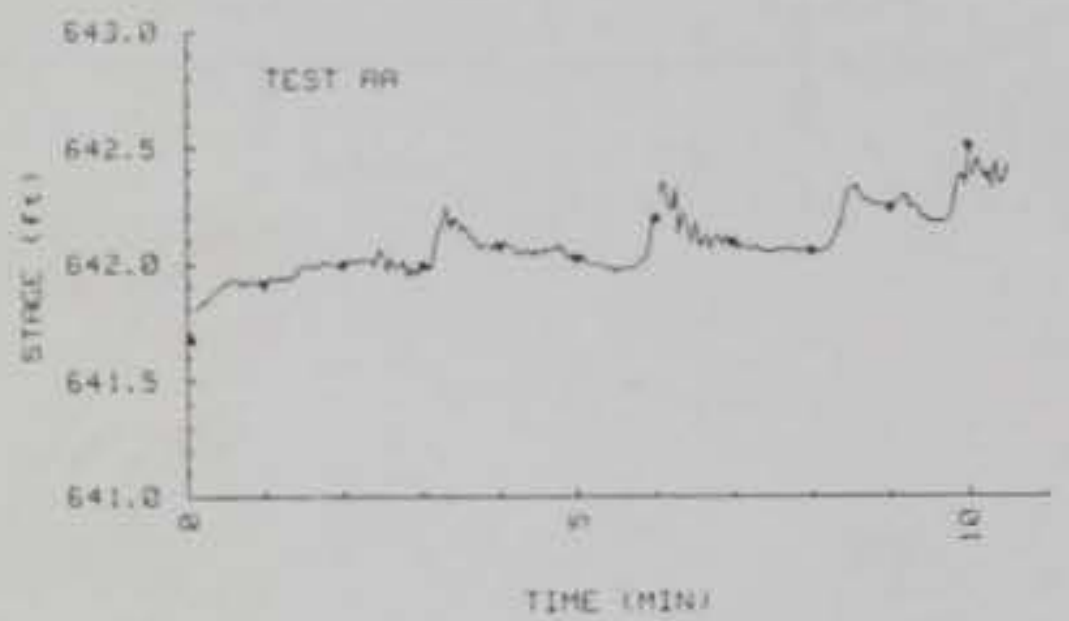

IN: TEST SERIES HITH $6-t$ t TCS - NO PIERS

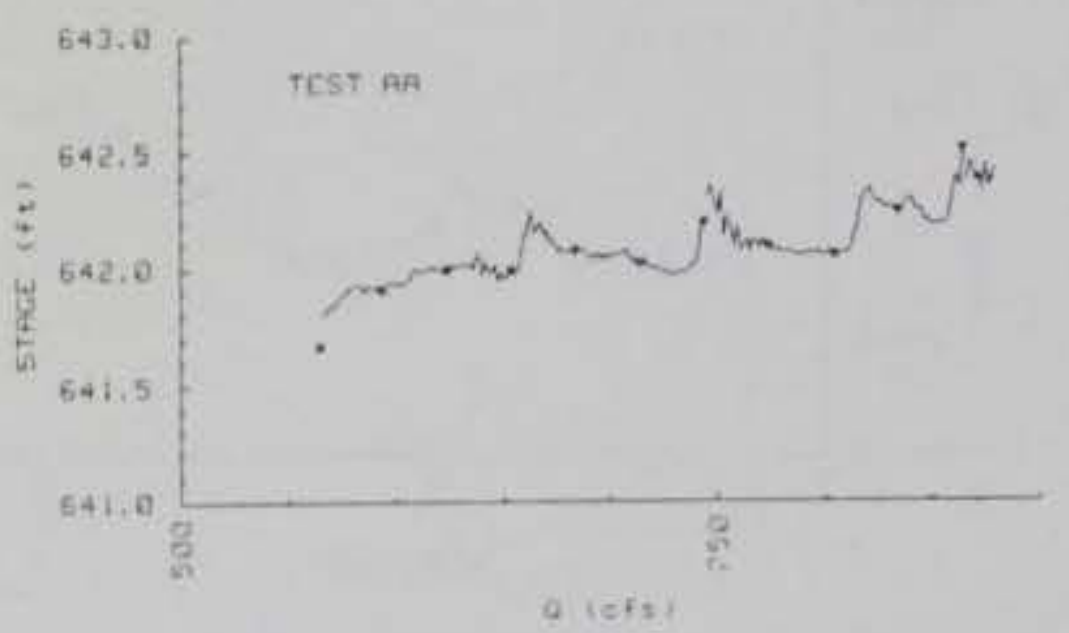


Ist test sertes WrTH 6 -ft tCS - No pIERS

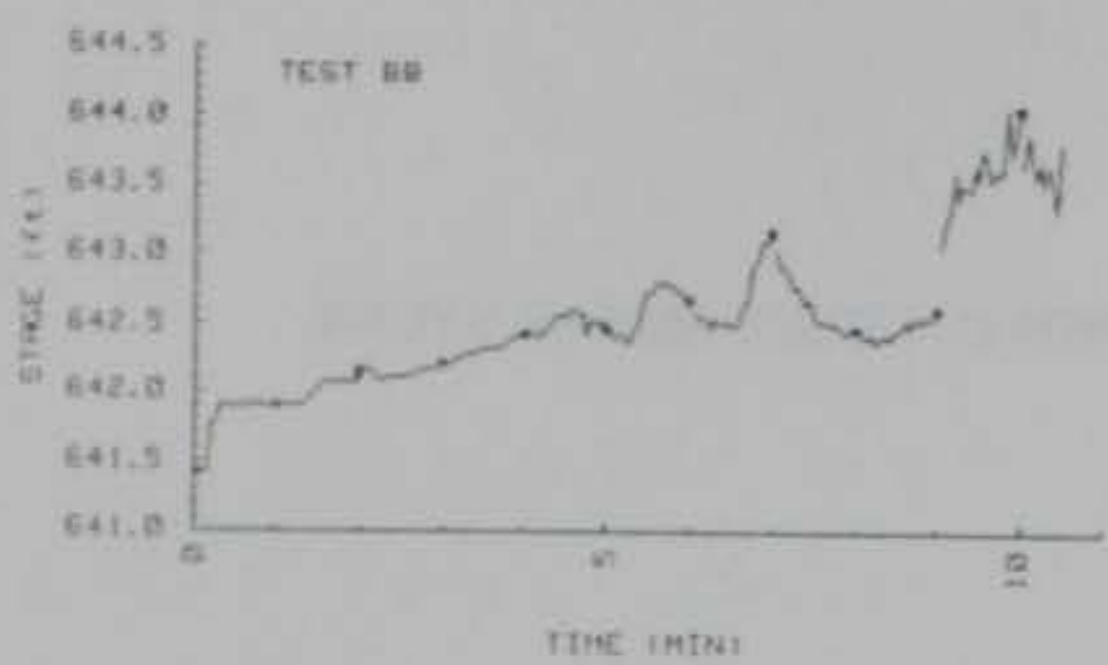

lat TEST BERIES WITH GMT LCS - No ptCos

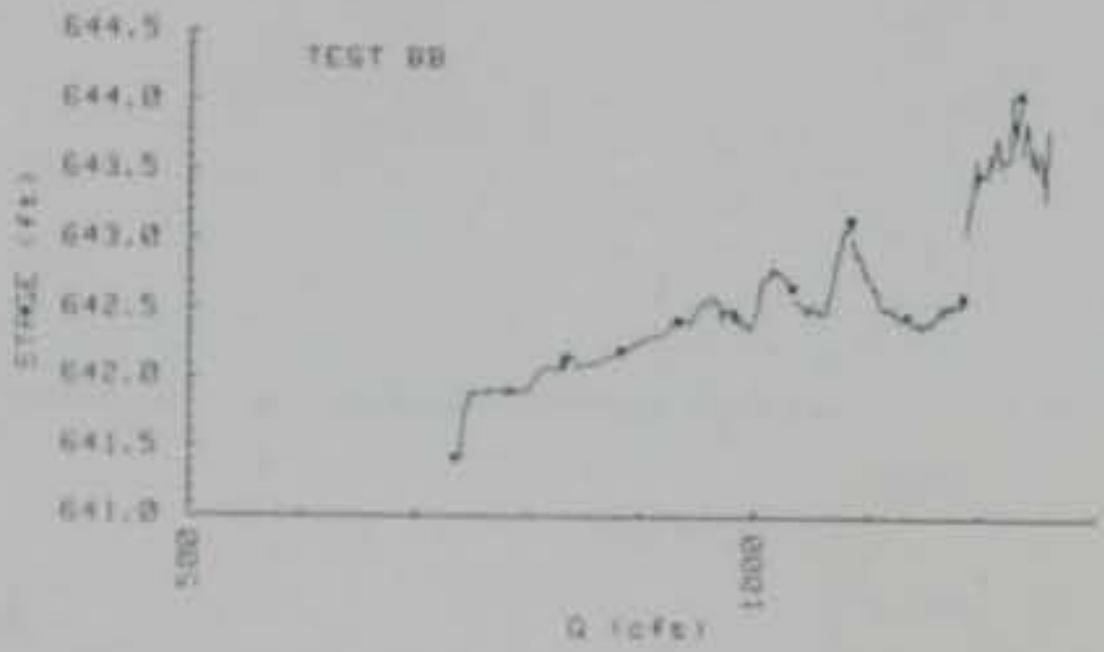

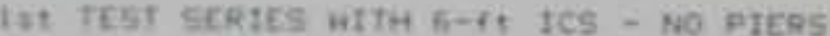

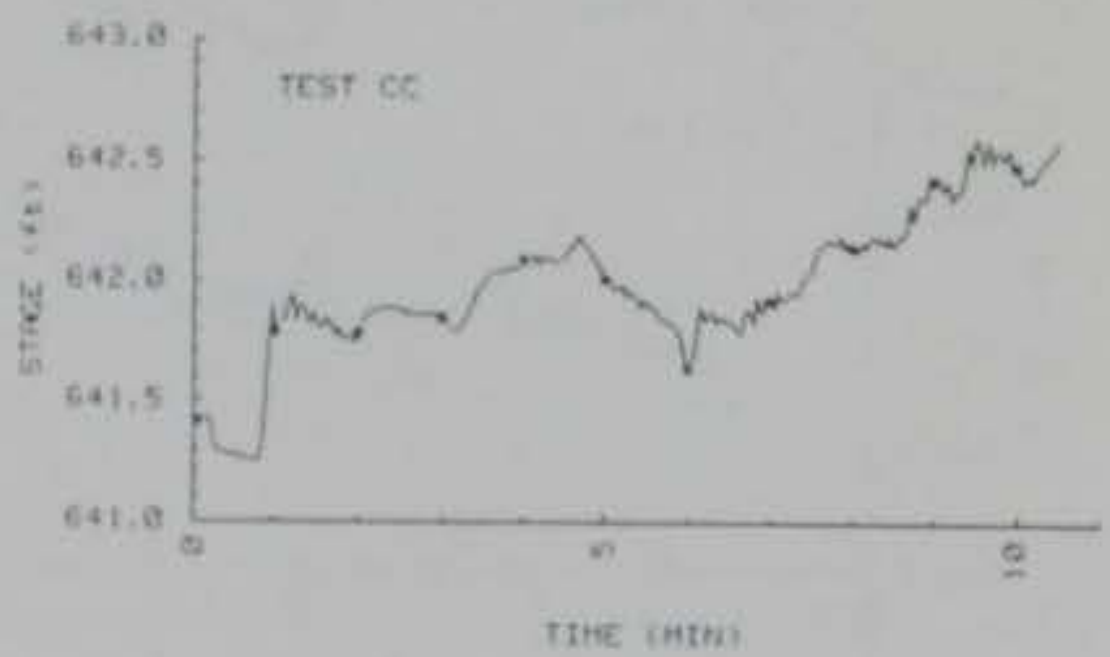

in test septes wth $6-1$ t tCS - no ptces

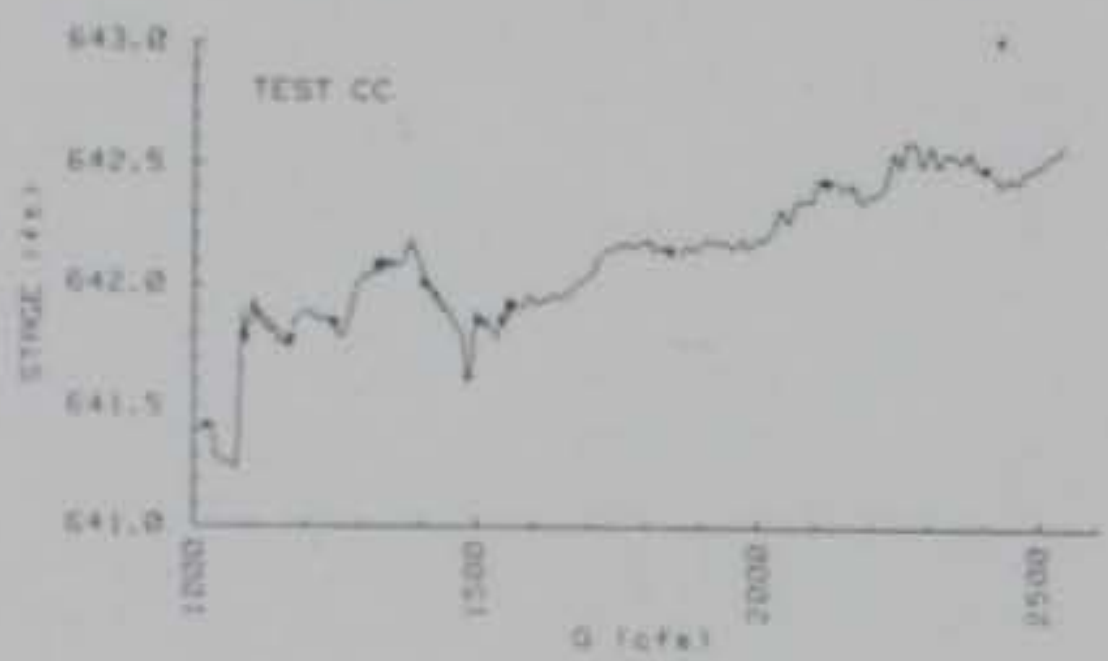

Ist TEST SERIES wITH 6-ft ICS - No PIERS

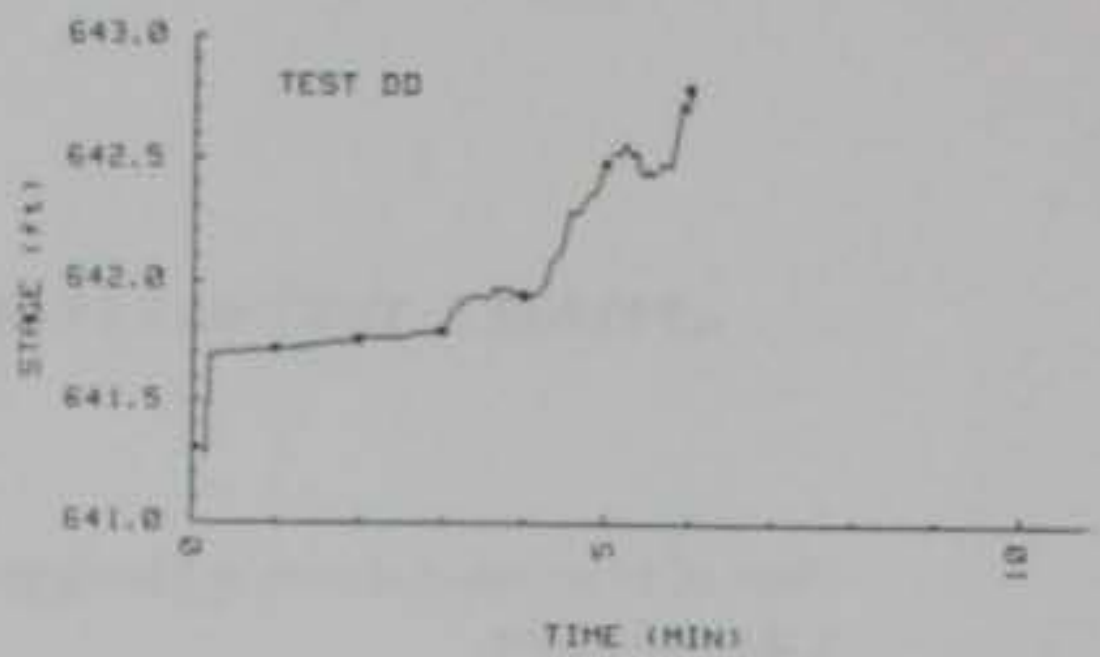

Ist TEST SERIES WITH $5-\mathrm{Ft}$ tCS - NO PIERS

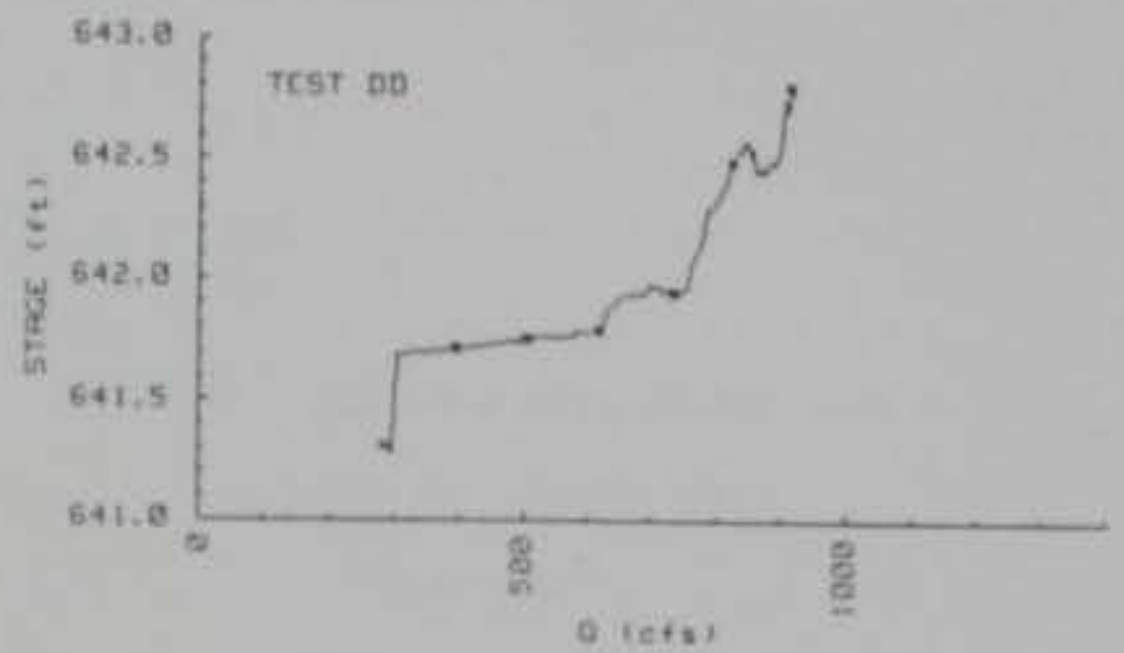

Ist TEST SERIES WITH 6-Ft ICS - NO PIERS

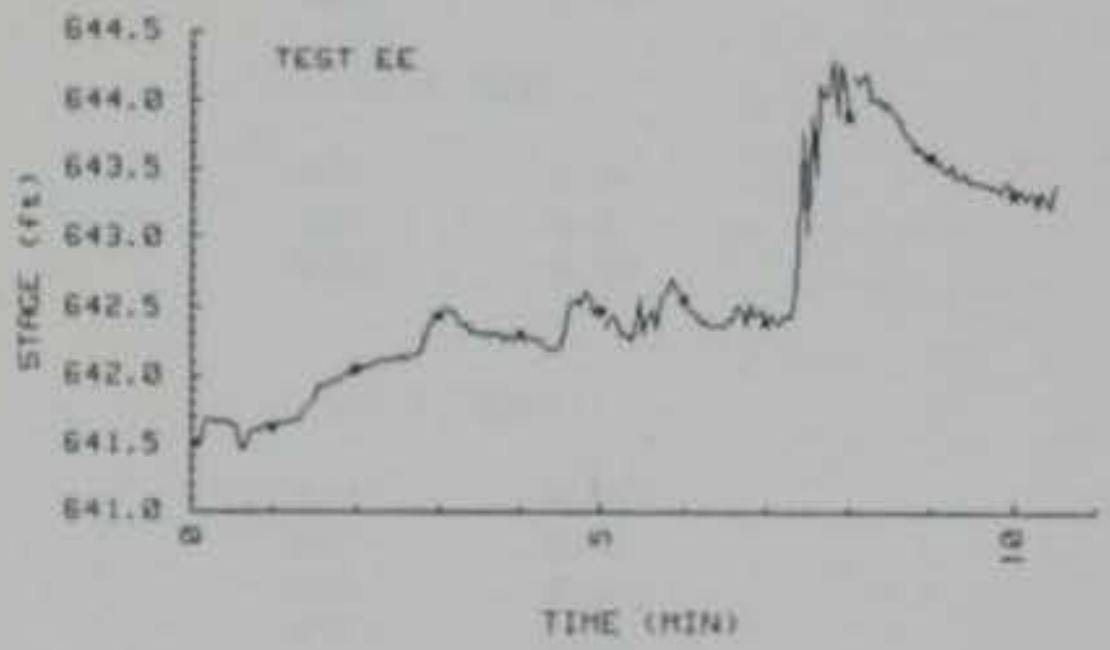

Ist TESI SERTES WITH $5-1 \mathrm{t}$ ICS - No PIERS

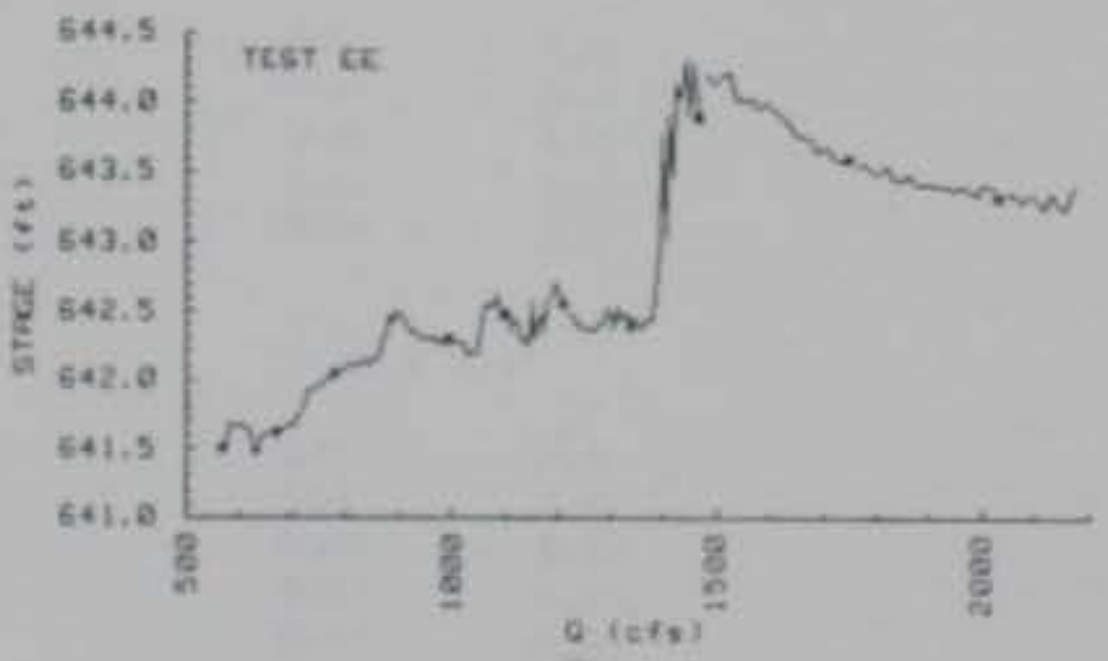




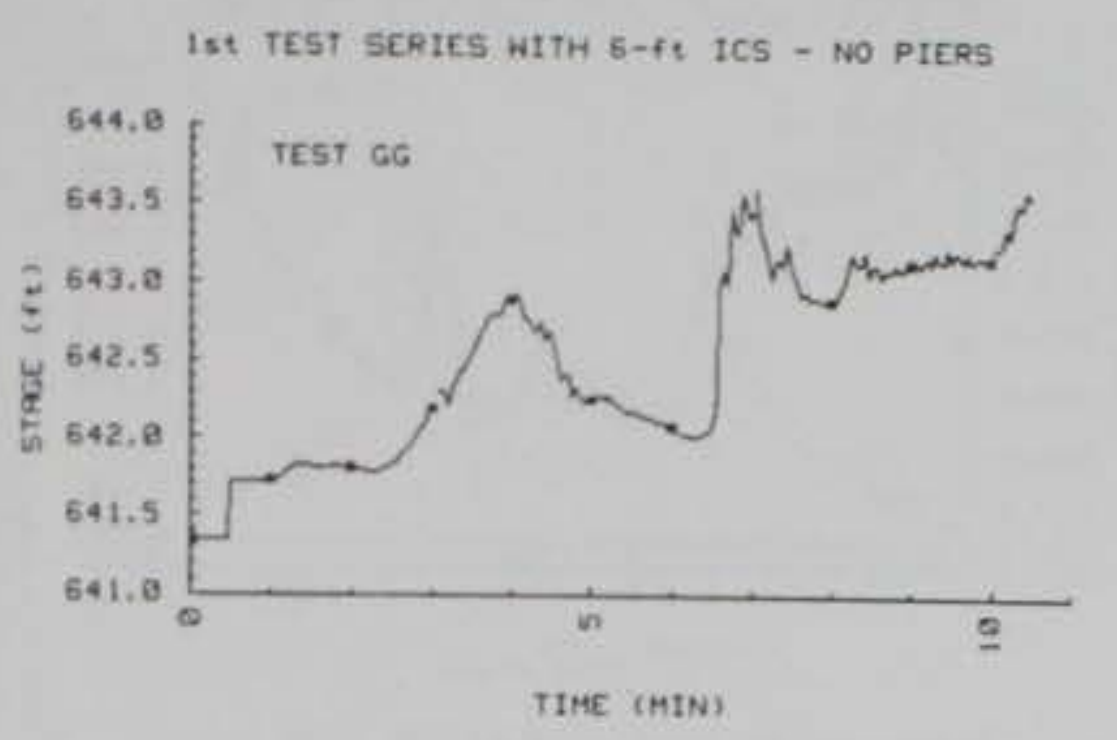

IST TEST SERTES WITH $6-\mathrm{ft}$ ICS - NO PIERS

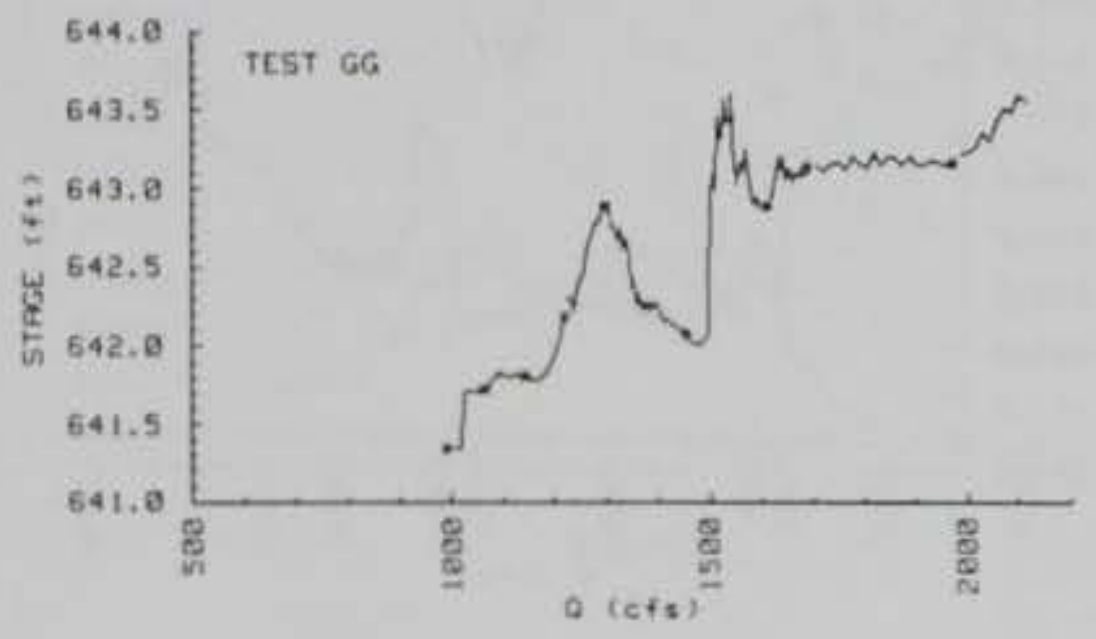

17 
ist TEST SERIES WITH GOFT ICS - 2 PIER5

\begin{tabular}{|c|c|c|c|}
\hline TIME $(\mathrm{MIN}$ & & 0 & $16 P M$ \\
\hline & TEST & $z$ & net \\
\hline 0.0 & & & 450 \\
\hline 4.8 & & & 580 \\
\hline B. 8 & & & 910 \\
\hline 11.2 & & & 1168 \\
\hline 13.0 & & & 1260 \\
\hline 16.0 & & & 1350 \\
\hline 18.0 & & & 1590 \\
\hline & TEST & : & II \\
\hline a. 3 & & & 500 \\
\hline 3.0 & & & 800 \\
\hline 8.8 & & & 1050 \\
\hline 10.0 & & & 1240 \\
\hline & TEST & 8 & Jנ \\
\hline 0.0 & & & 620 \\
\hline 4.0 & & & 940 \\
\hline 6.0 & & & 1200 \\
\hline 9.8 & & & 1400 \\
\hline 13.0 & & 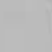 & 1720 \\
\hline
\end{tabular}

TEST $:$ LL.

$\begin{array}{ll}0.0 & 180 \\ 1.0 & 720 \\ 3.5 & 1840 \\ 4.5 & 1460 \\ 5.0 & 1720 \\ 6.8 & 2050\end{array}$

TEST : $\mathrm{MM}$

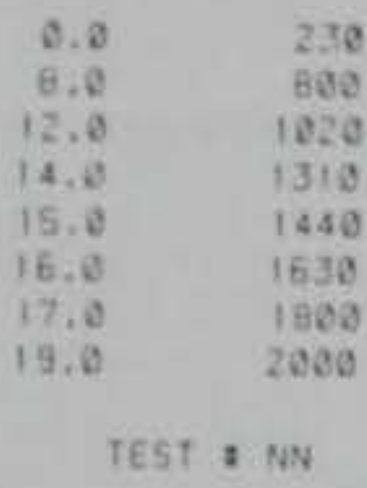

8.9 360

$1 \mathrm{H.9}=500$

$19.0 \quad 689$

2.. 1120

25.61596

$28.9-1000$

TEST : KK

$\begin{array}{rr}0.0 & 640 \\ 3.0 & 920 \\ 5.0 & 1978 \\ 6.8 & 1200 \\ 8.0 & 1370 \\ 18.0 & 1540\end{array}$

ist TEST SERTES WITH $6-f$ t ICS - 2 PIERS

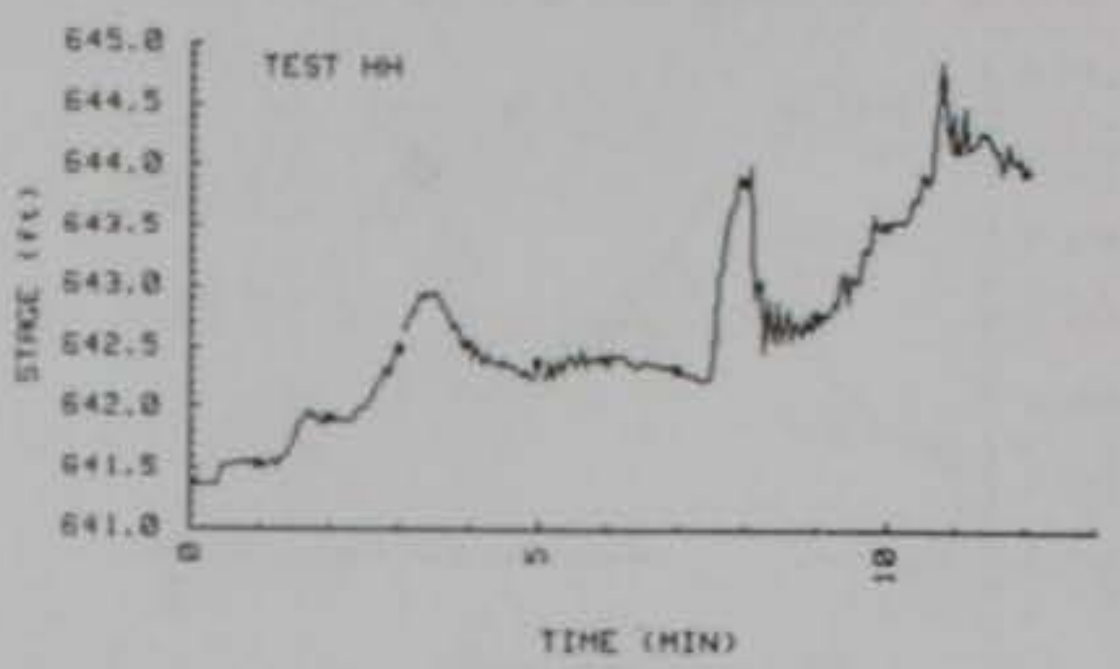

Ist TEST SERIES WITH $6-1 \mathrm{t}$ ICS - 2 PIERS

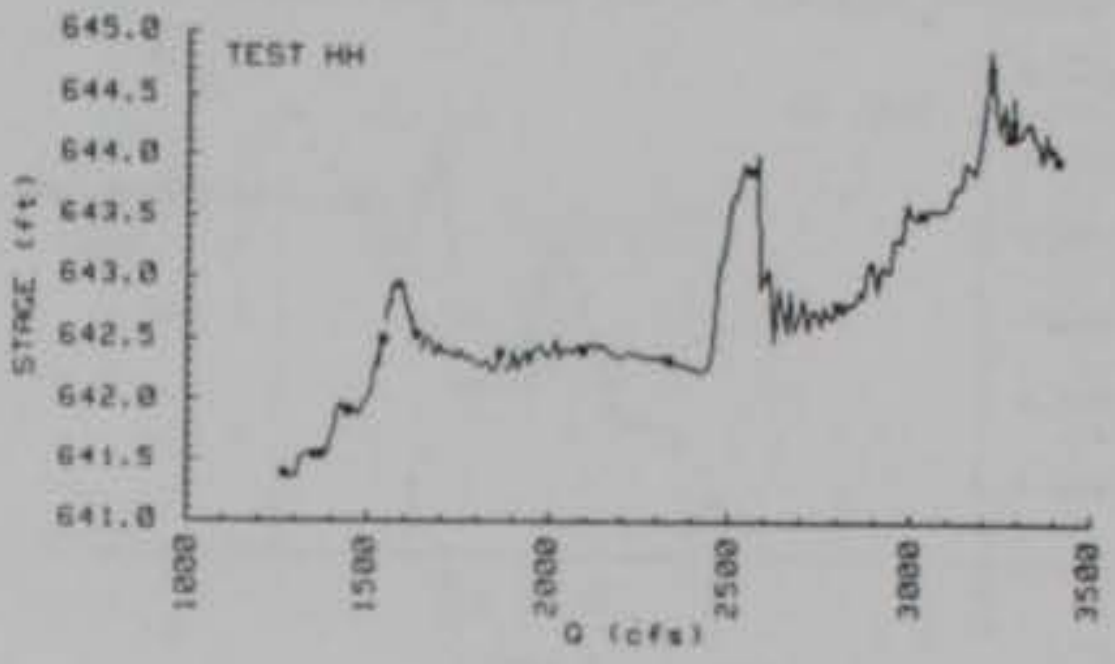

ist TLST SCRIES WITH $6-7 \mathrm{t}$ tCS - 2 PIERS

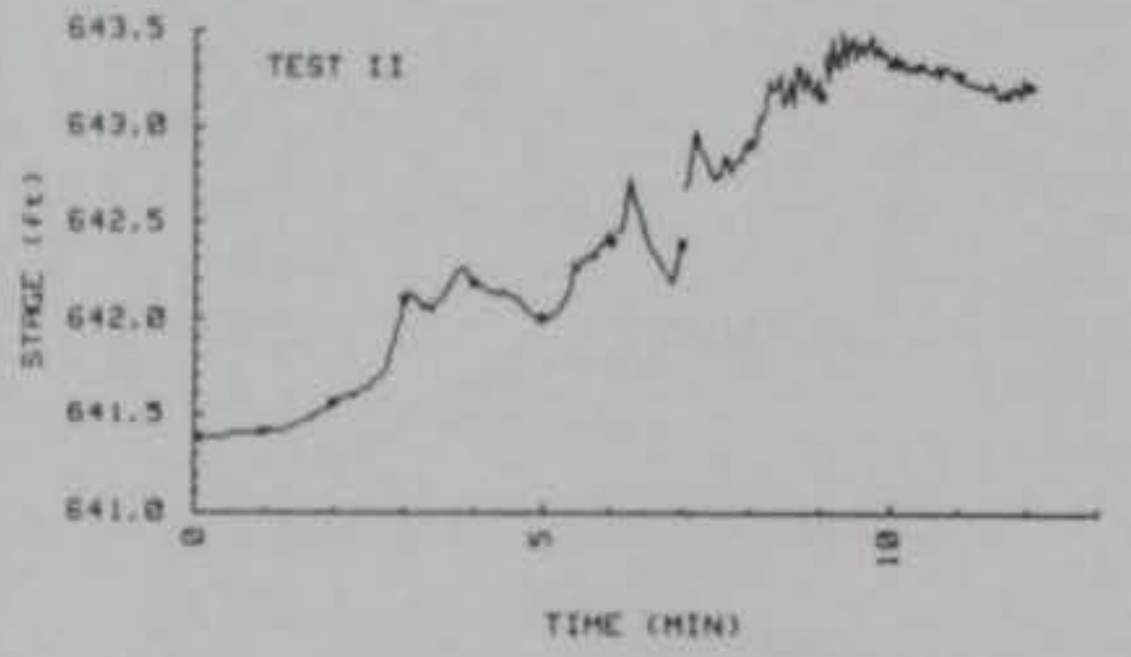

Ist TESt SERIES wtTH 5 -fs ICS - 2 PIERS

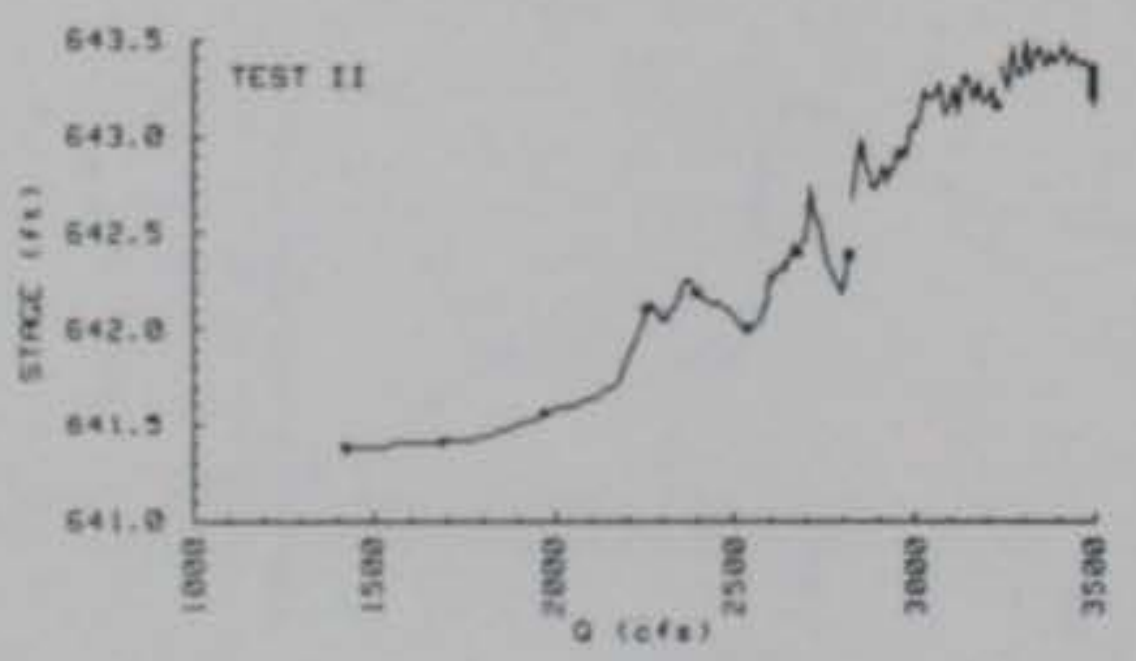


Ist TEST SERIES WITH $6-1 \mathrm{t}$ ICS - 2 PIERS

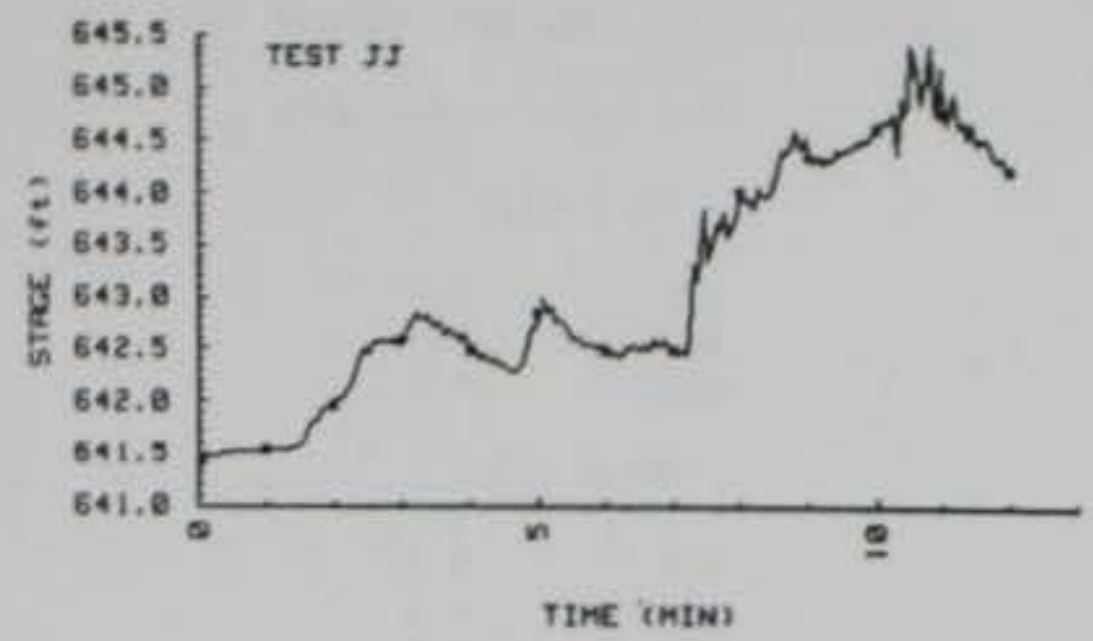

Ist TEST SERICS WITH G -fE ICS - I PICRS

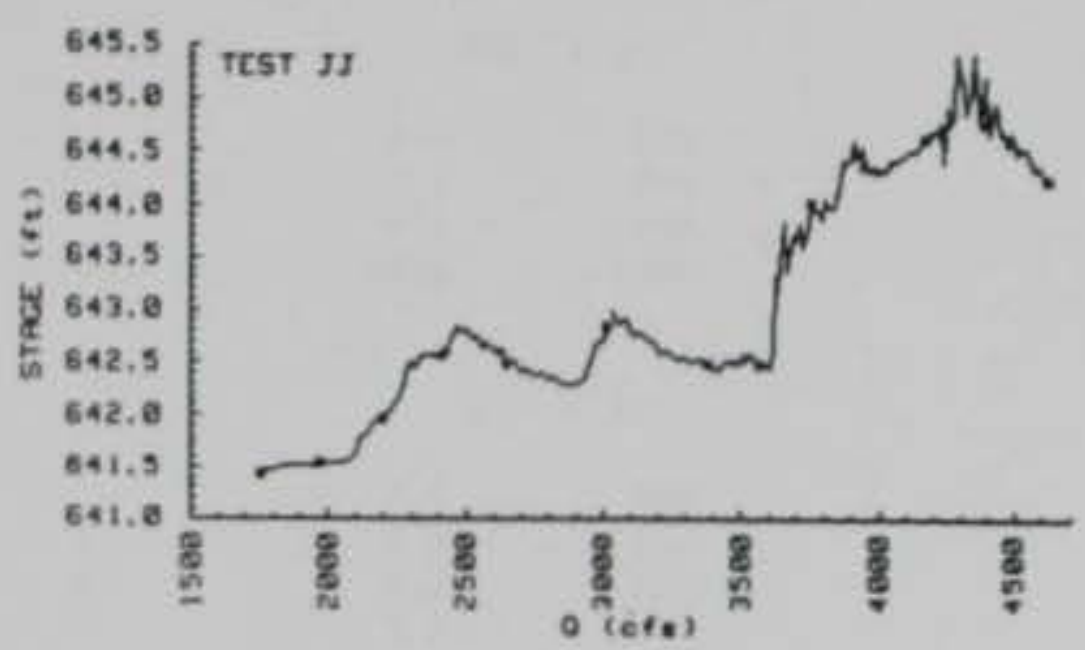

I T T TEST SERIES WITH $6-1 \mathrm{f}$ TCS -2 PIERS

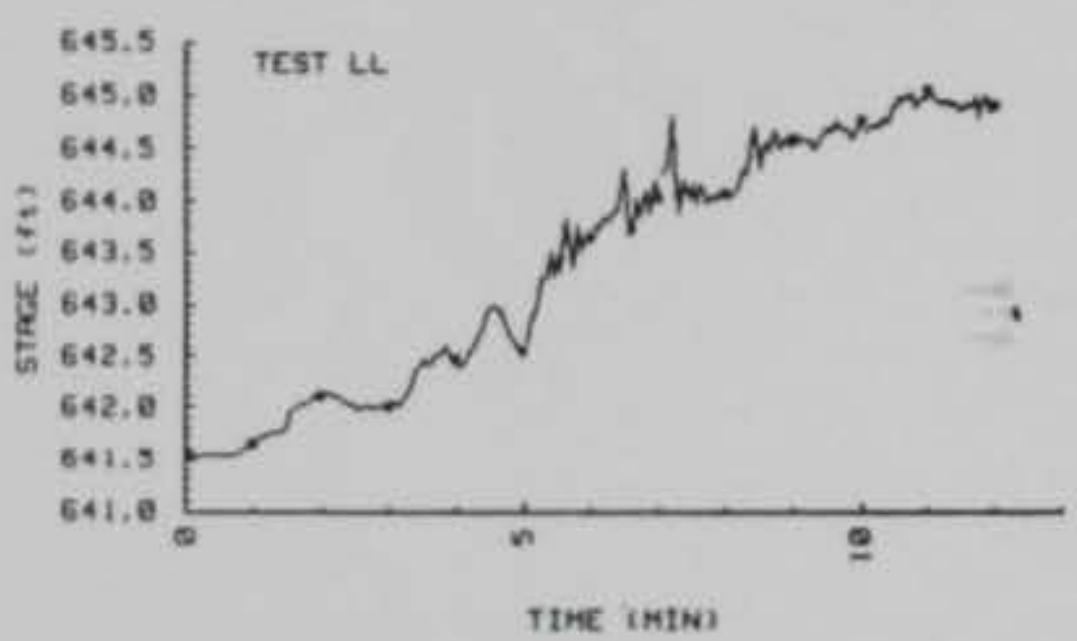

Ist TEST SERICS WITH $6-1 \mathrm{t}$ ICS - 2 PICRS

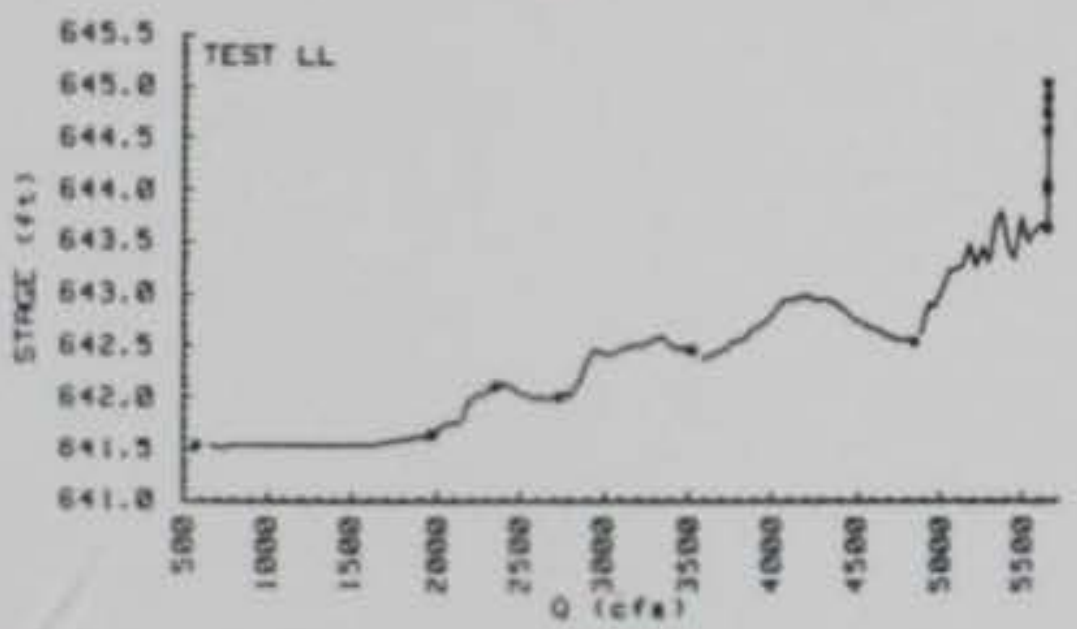

ist Test series wtTh s -1 t ICS - z pteas

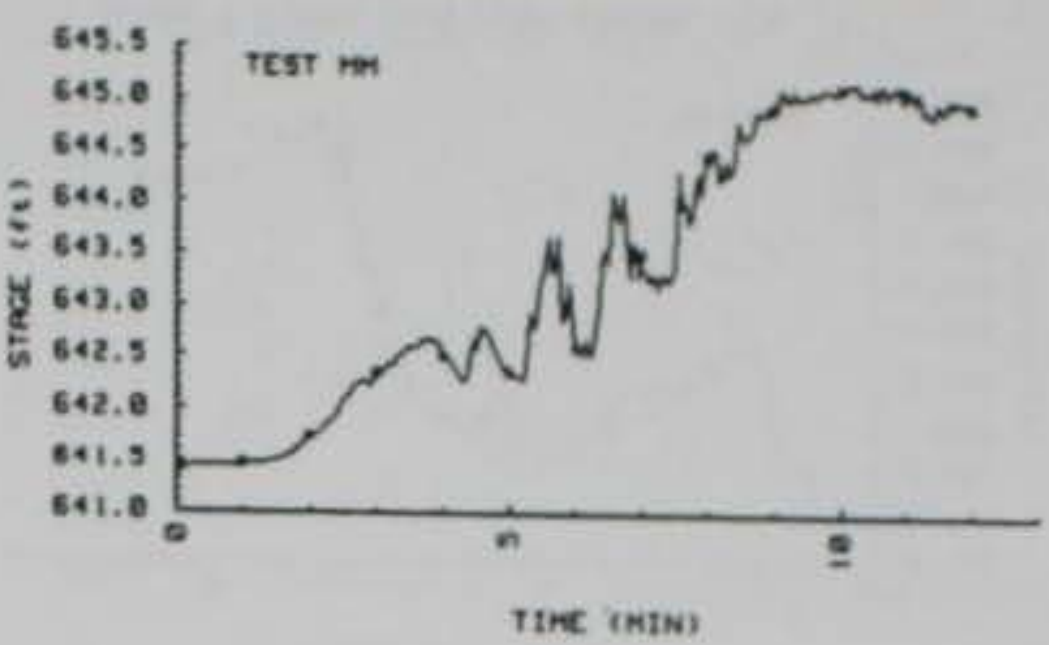

Ist TEST SCRICS wITH $6-t$ t ICS - 2 pICES

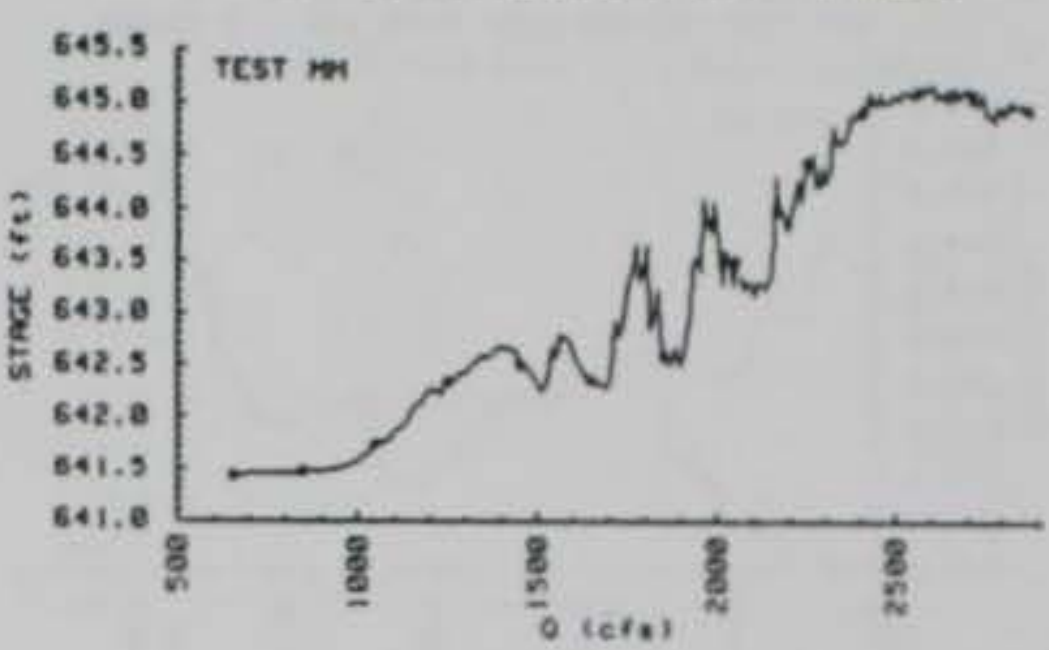

Ist Test sCatrs with $5-1$ t tCS - 2 pICRS

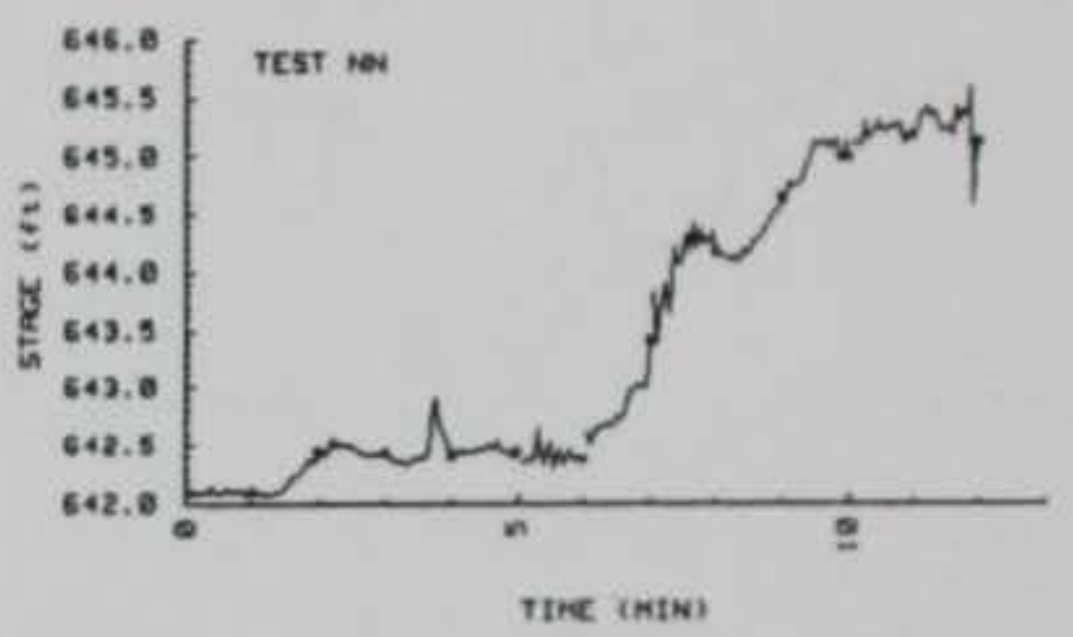

Int Test series wIT $6-1 \mathrm{t}$ ICS - 2 piras

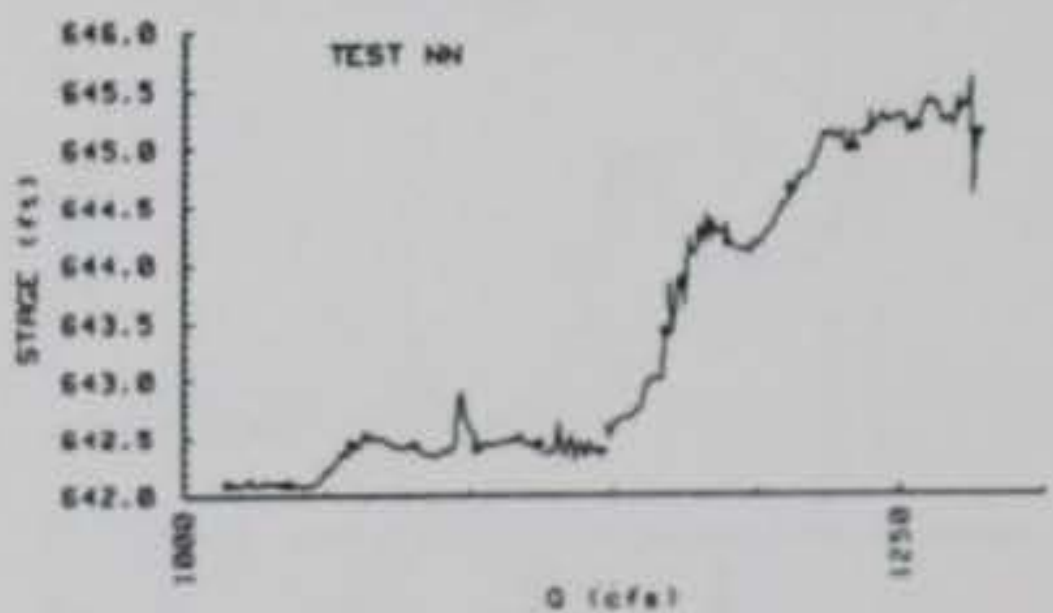


1 st TEST SERIES WITH 6-ft ICS - 2 PIERS
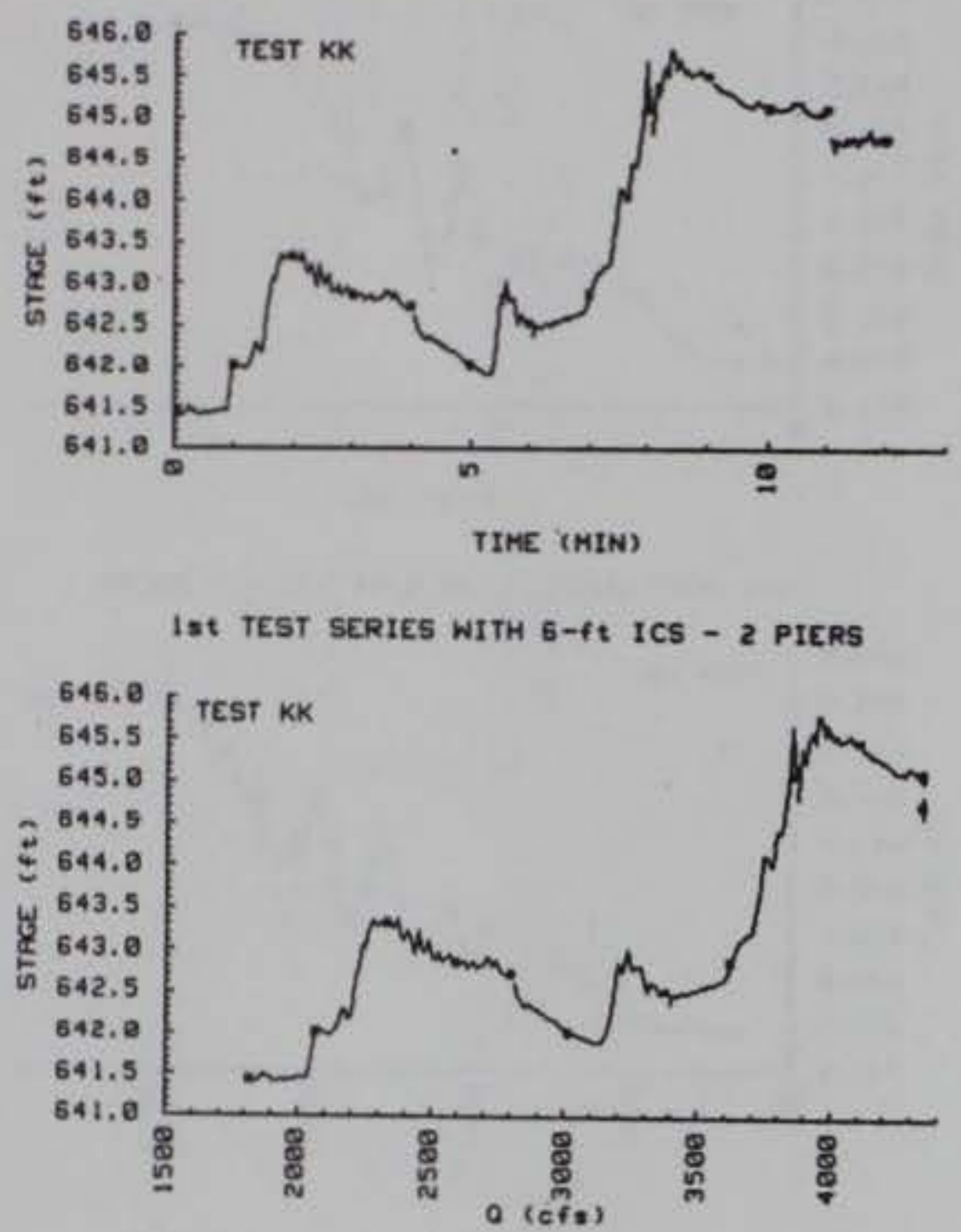
Is TEST SERIES WITH B-FT ICS - NO PIERS

TIME (MIN) Q (GPM)

TEST \& 00

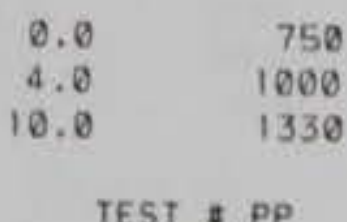

$$
\begin{array}{rr}
0.0 & 720 \\
5.0 & 1020 \\
8.0 & 1320 \\
11.0 & 1500 \\
\text { TEST } \approx & 00
\end{array}
$$

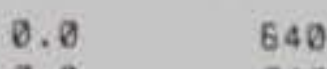

$3.0 \quad 940$

$7.5 \quad 1030$

$10.5 \quad 1300$

TEST \# 55

$$
\begin{array}{rr}
0.0 & 350 \\
3.0 & 820 \\
9.0 & 1850 \\
13.0 & 1320 \\
\text { TEST = TT }
\end{array}
$$

$\begin{array}{rr}0.0 & 600 \\ 2.0 & 840 \\ 12.0 & 1070 \\ 18.0 & 1460 \\ 19.0 & 1500 \\ 23.0 & 1420\end{array}$

IST TEST SERIES WITH B -1T ICS - NO PIERS

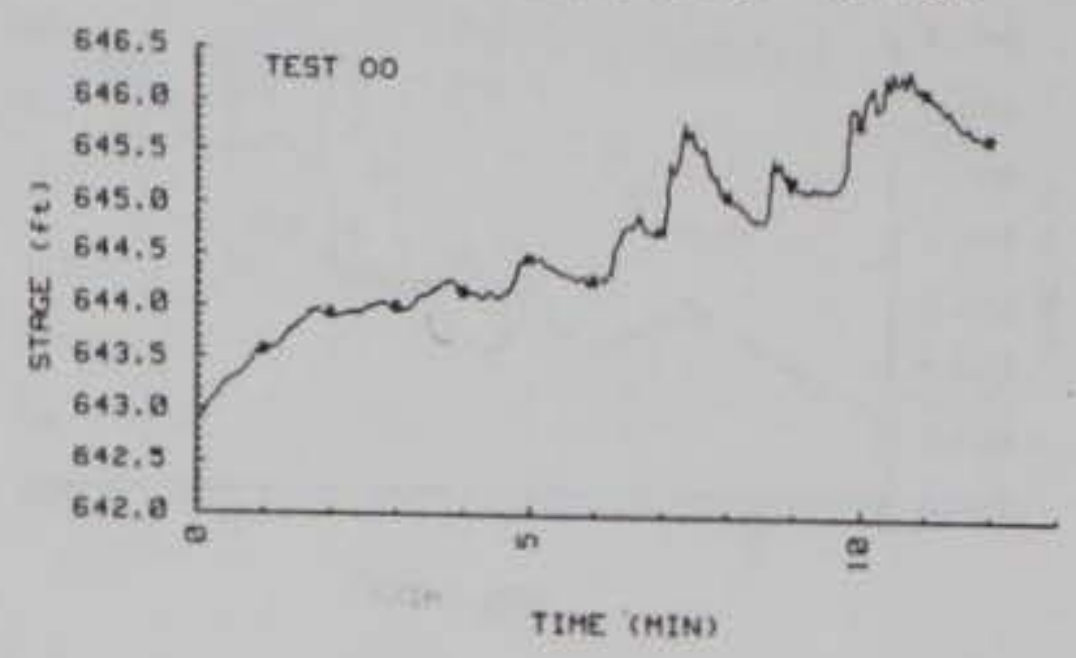

Ist TEST SERIES WITH B-ft ICS - NO PIERS

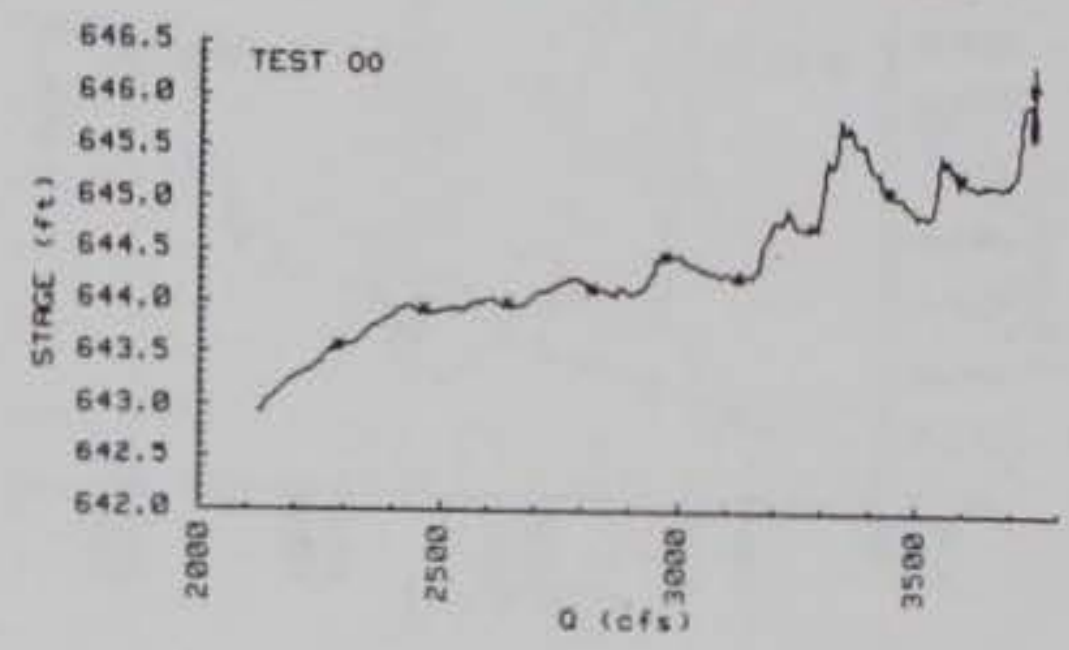

I $=2$ TEST SERIES WITH $g-f t$ ICS - NO PIERS

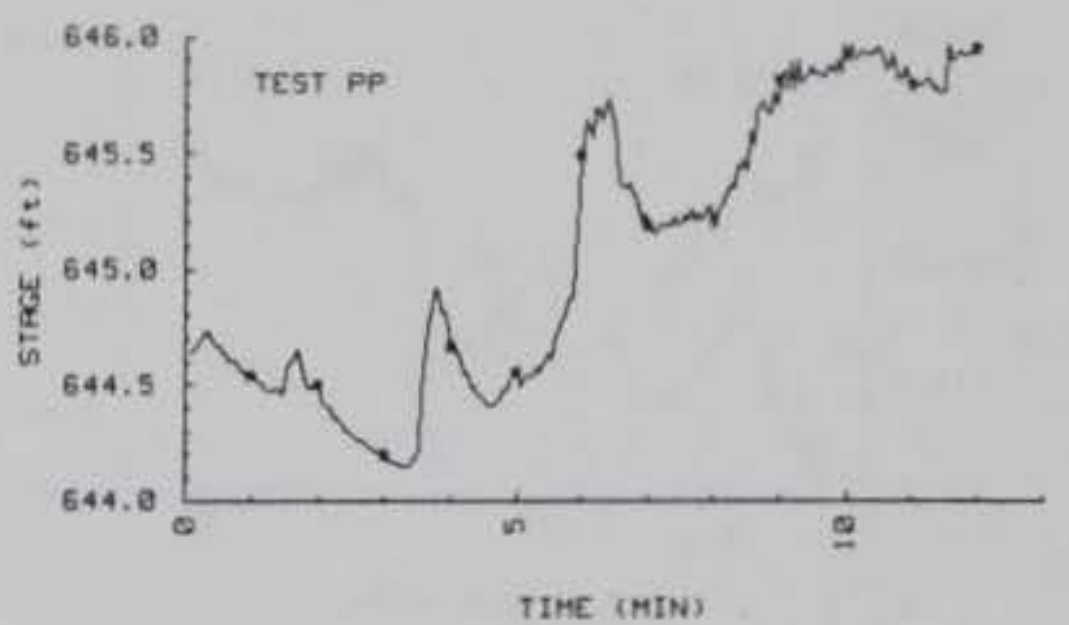

1st TEST SERIES WITH $8-f$ I ICS - NO PIERS

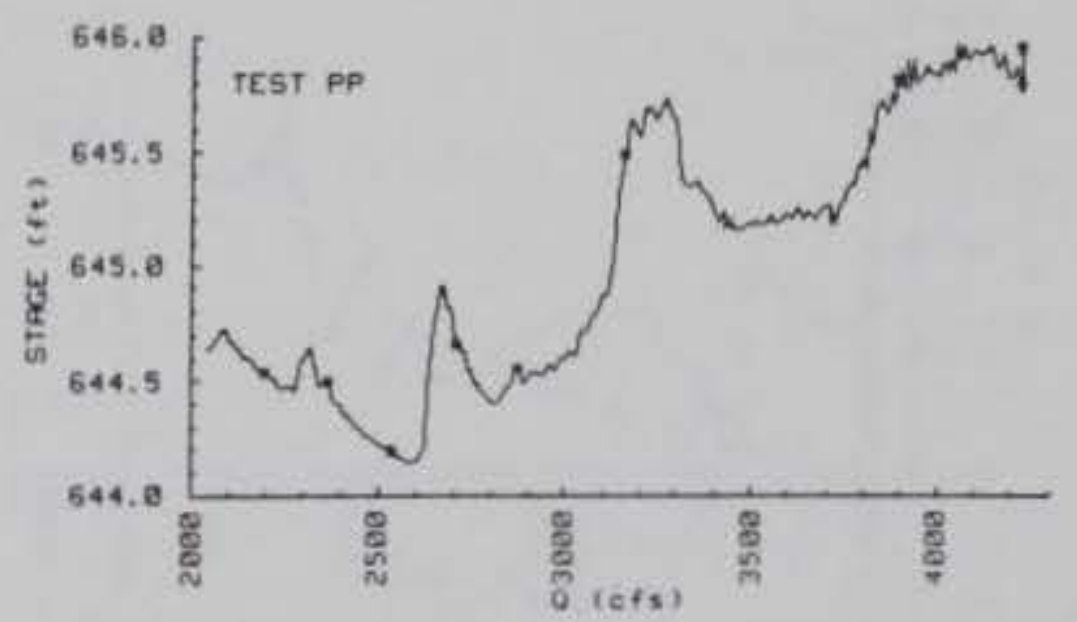


Ist TEST SERIES WITH $8-\mathrm{ft}$ ICS - NO RIERS

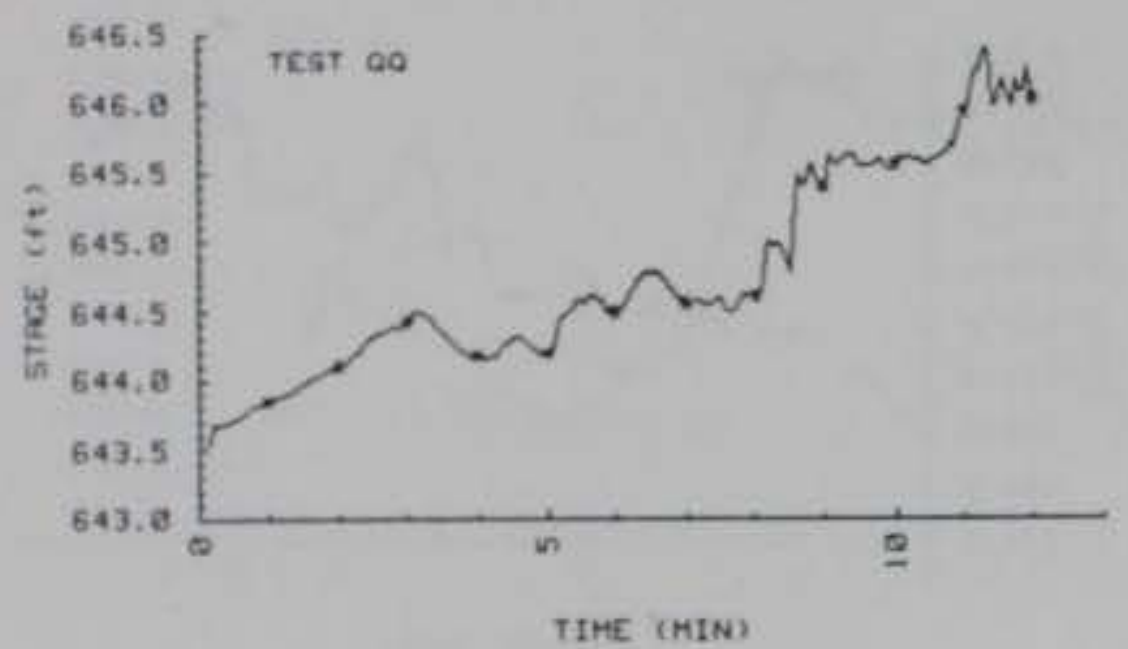

ist TEST SERIES WITH 8 -ft ICS - NO PIERS

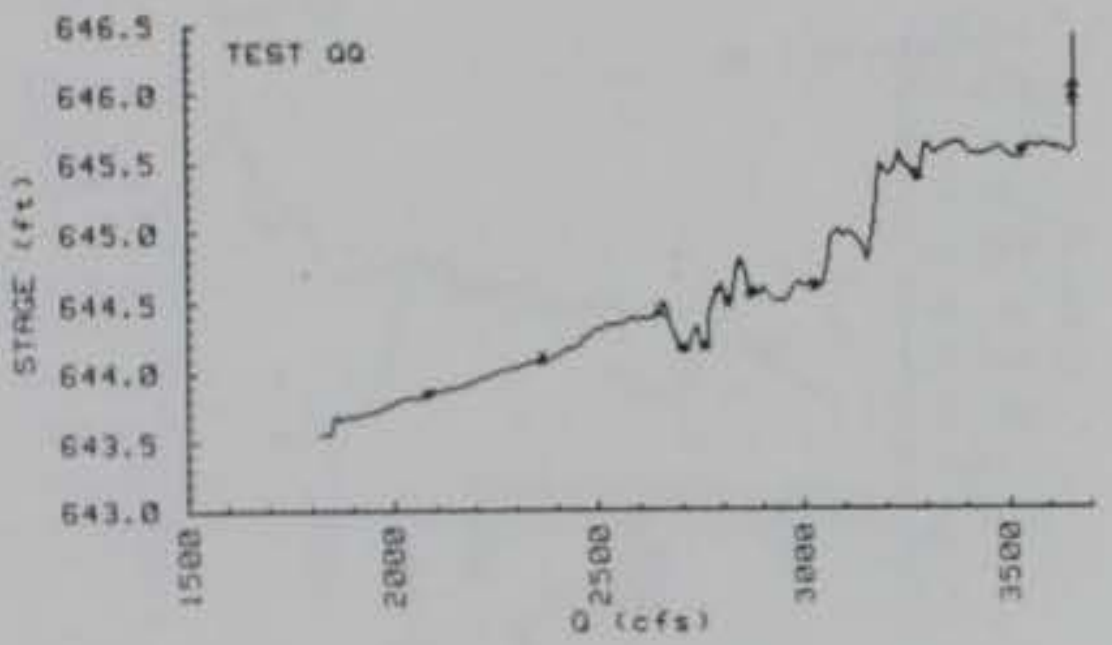

Ist TEST SERIES WITH $8-f t$ ICS - NO PIERS

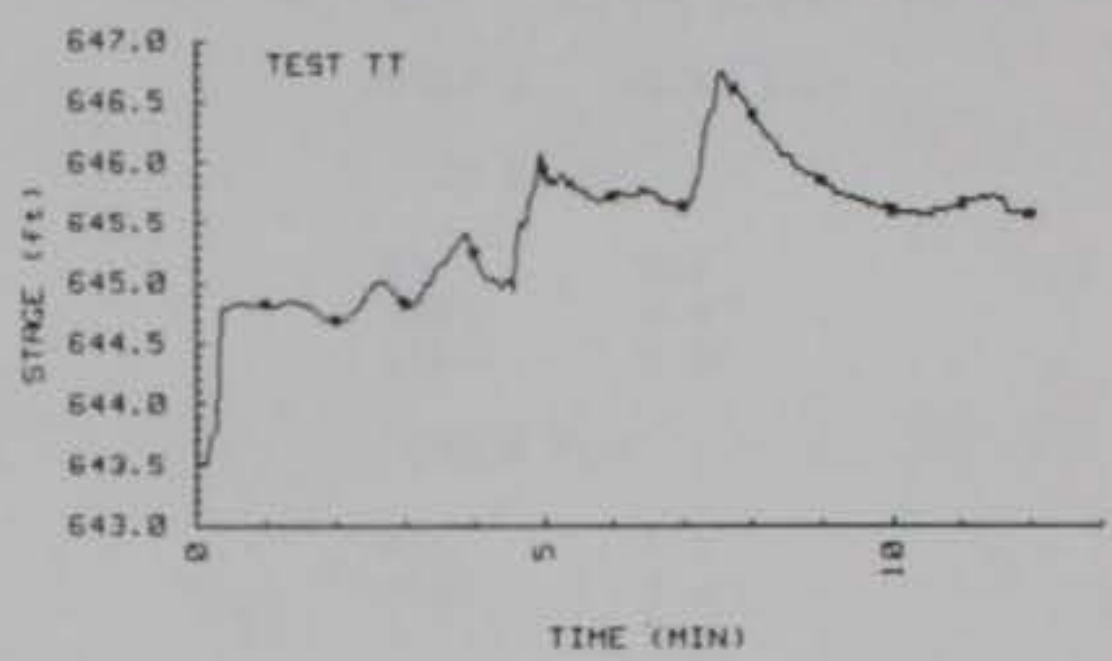

Ist TEST SERIES WITH B-fE ICS - NO PIERS

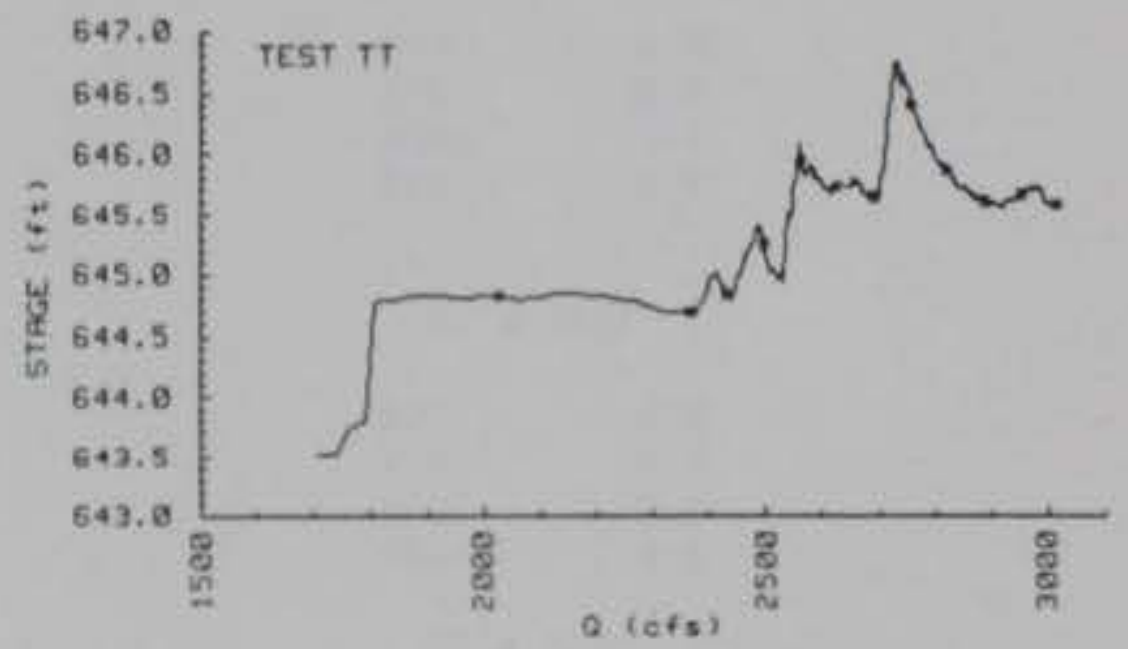

1st TEST SERIES W1TH 8 -ft ICS - NO PIERS

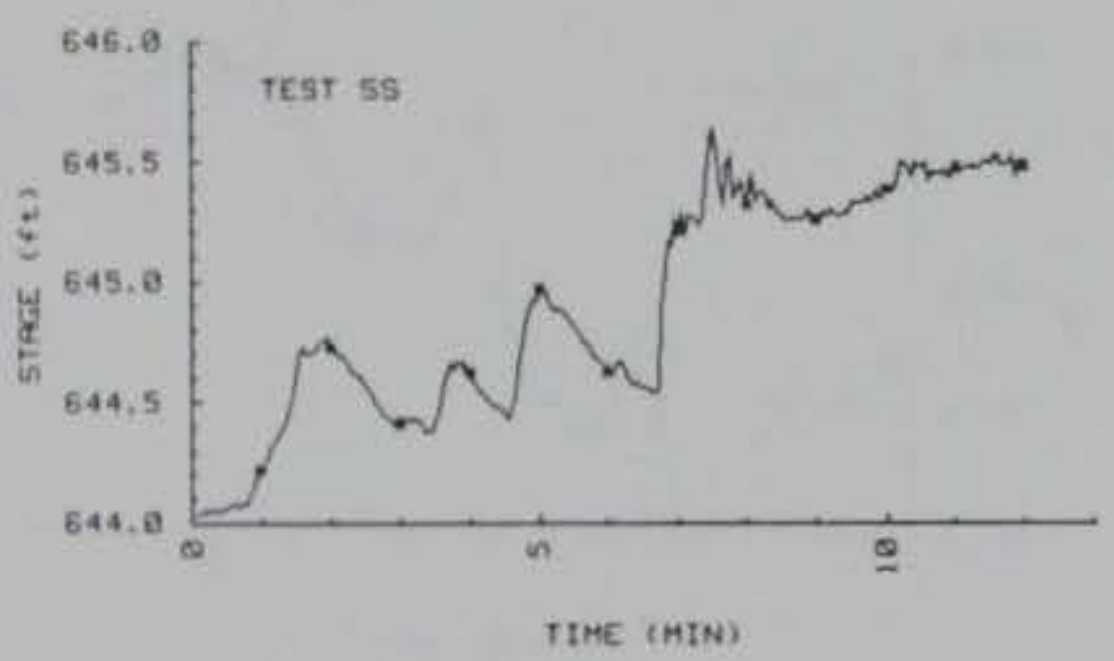

Ist TEST SERIES WITH $\$-f t$ ICS - NO PIERS

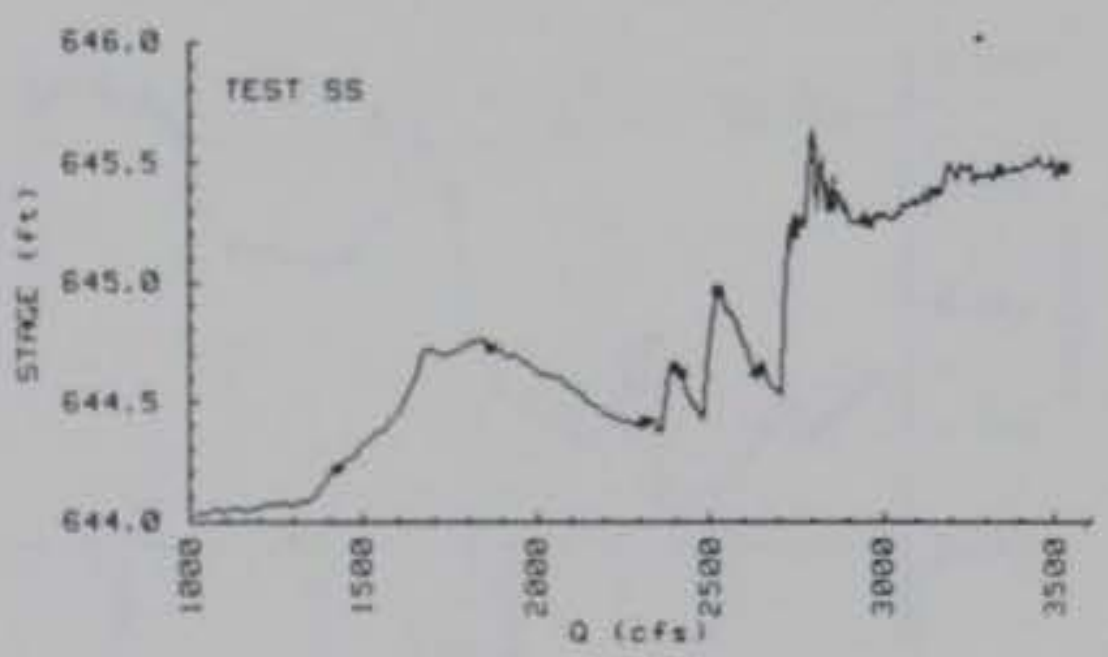


Ist TEST SERIES WITH 8-FT ICS - 2 PIERS TIME (MIN) 0 (GPM)

TEST * UU

\begin{tabular}{rr}
0.0 & 580 \\
9.0 & 1050 \\
15.0 & 1320 \\
\multicolumn{2}{c}{ TEST = VU } \\
0.0 & 710 \\
4.0 & 1140 \\
10.0 & 1370
\end{tabular}

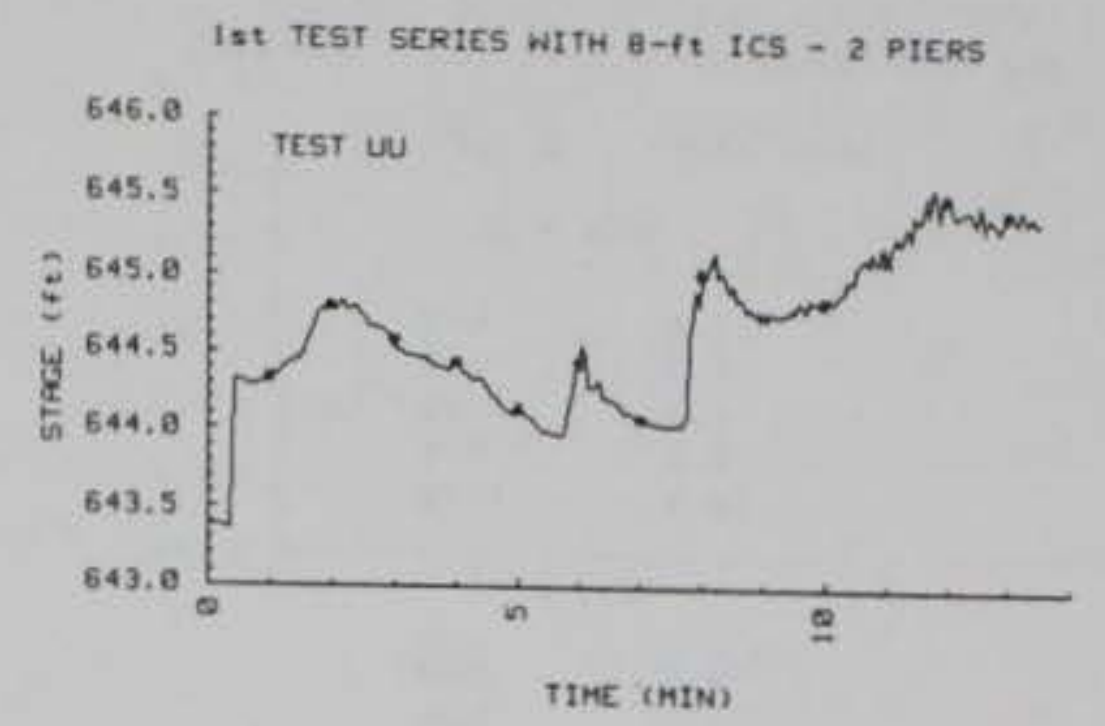

IsT TEST SERIES WITH $8-f$ ICS - 2 PIERS

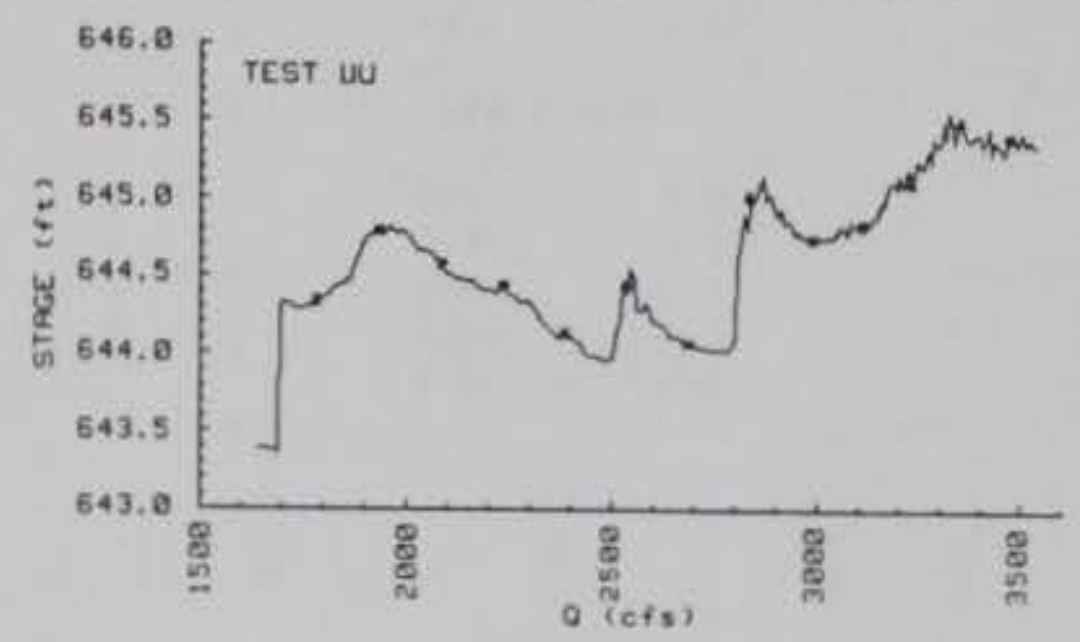

1st TEST SERIES WITH $8-f t$ ICS -2 PIERS

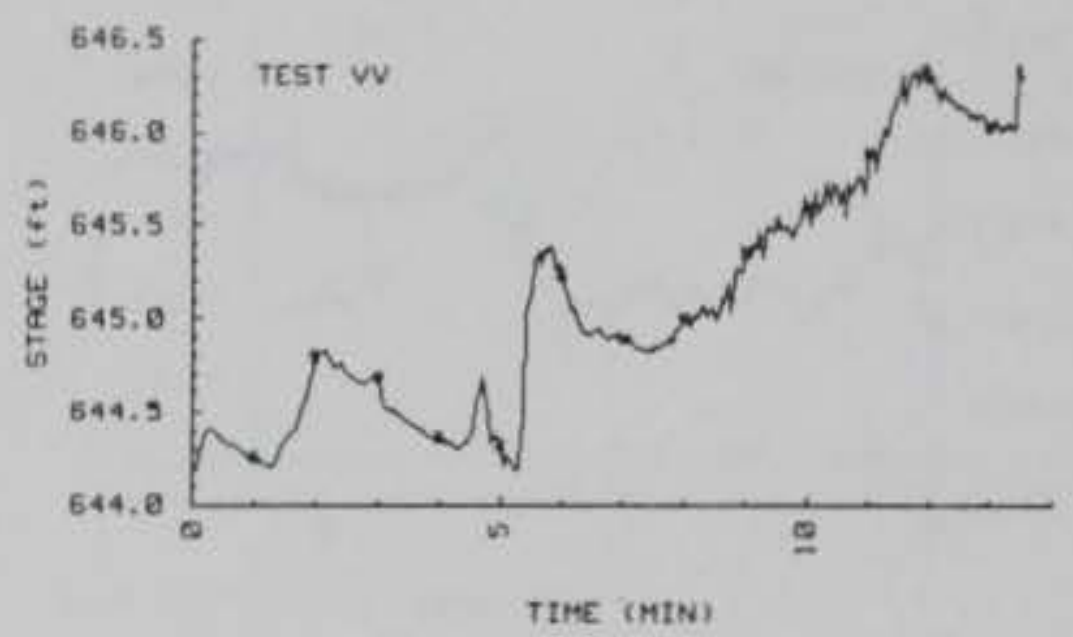

1st TEST SERIES WITH $\theta-f$ t TCS - 2 PIERS

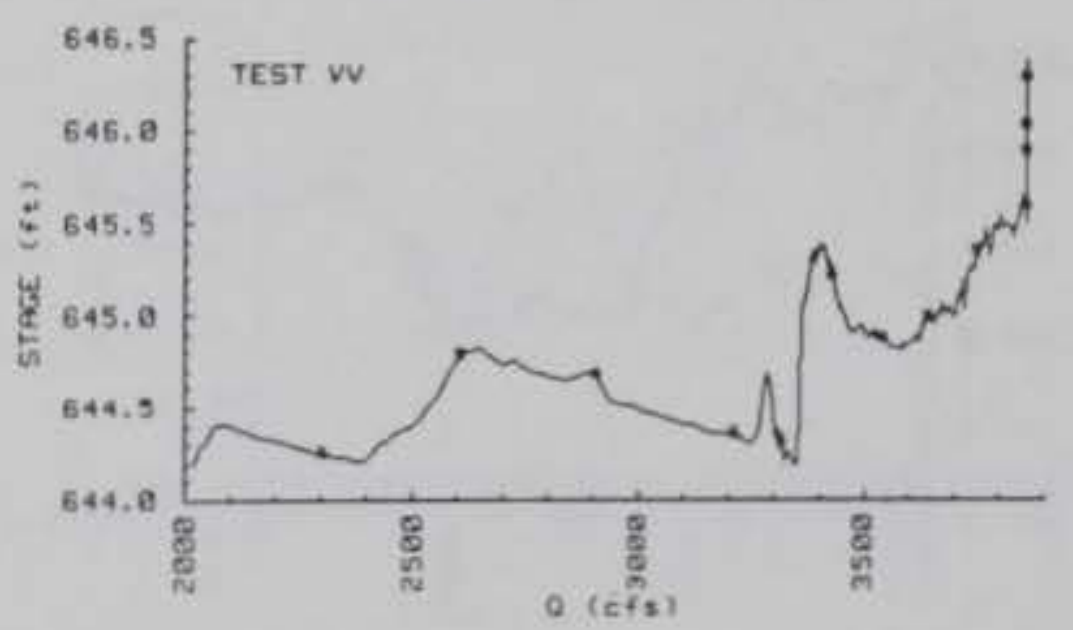


2nd TEST SERIES WITH G-FT ICS - NO PIERS

$\begin{array}{cc}\text { TIME (MIN) O (GPM) } \\ \text { TEST = A1 } \\ 0.0 & 610 \\ 3.0 & 750 \\ 6.0 & 880 \\ 8.0 & 980 \\ 10.5 & 1170 \\ & \text { TEST = A2 } \\ 0.0 & 500 \\ 3.0 & 625 \\ 6.5 & 895 \\ 8.0 & 995 \\ 10.0 & 1160 \\ & \text { TEST } \approx A 3 \\ 0.0 & 700 \\ 2.5 & 815 \\ 4.5 & 1040 \\ 6.5 & 1160 \\ 8.5 & 1295\end{array}$

2nd TEST SERIES WITH 6-f: ICS - NO PIERS

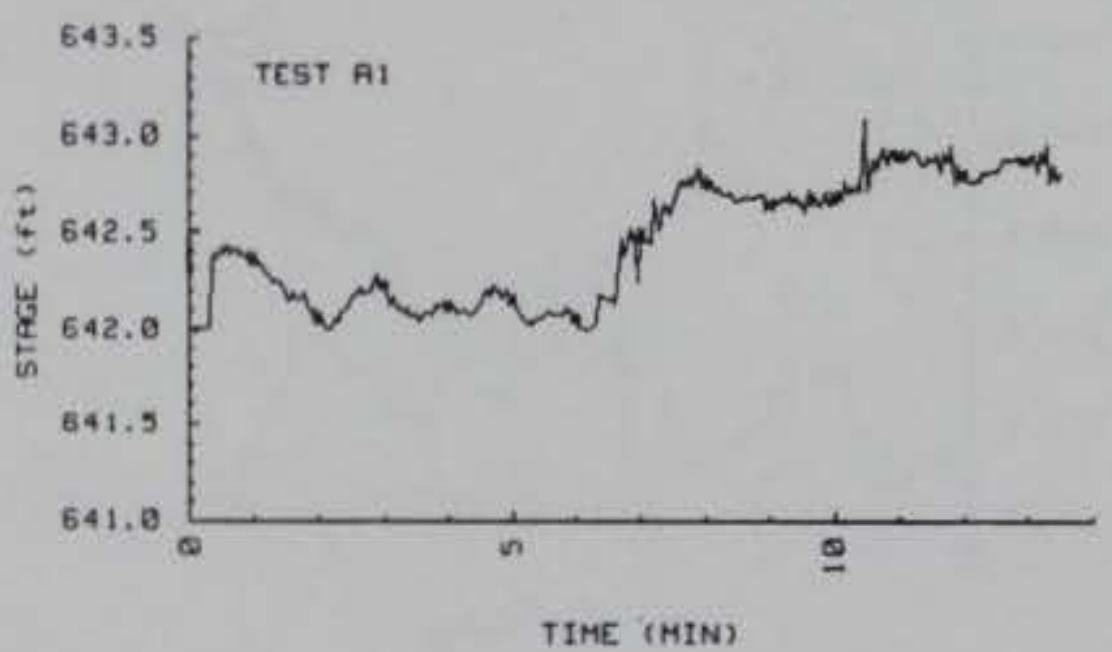

2nd TEST SERIES WITH $6-\mathrm{ft}$ ICS - NO PIERS

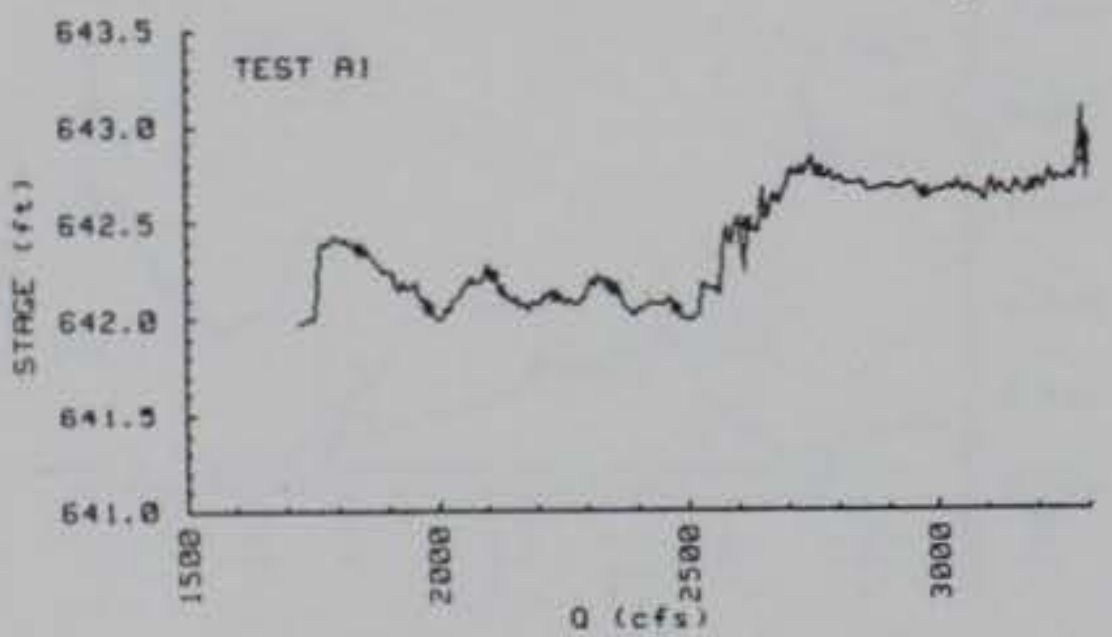

2nd TEST SERIES WITH $6-f \mathrm{t}$ ICS - NO PIERS
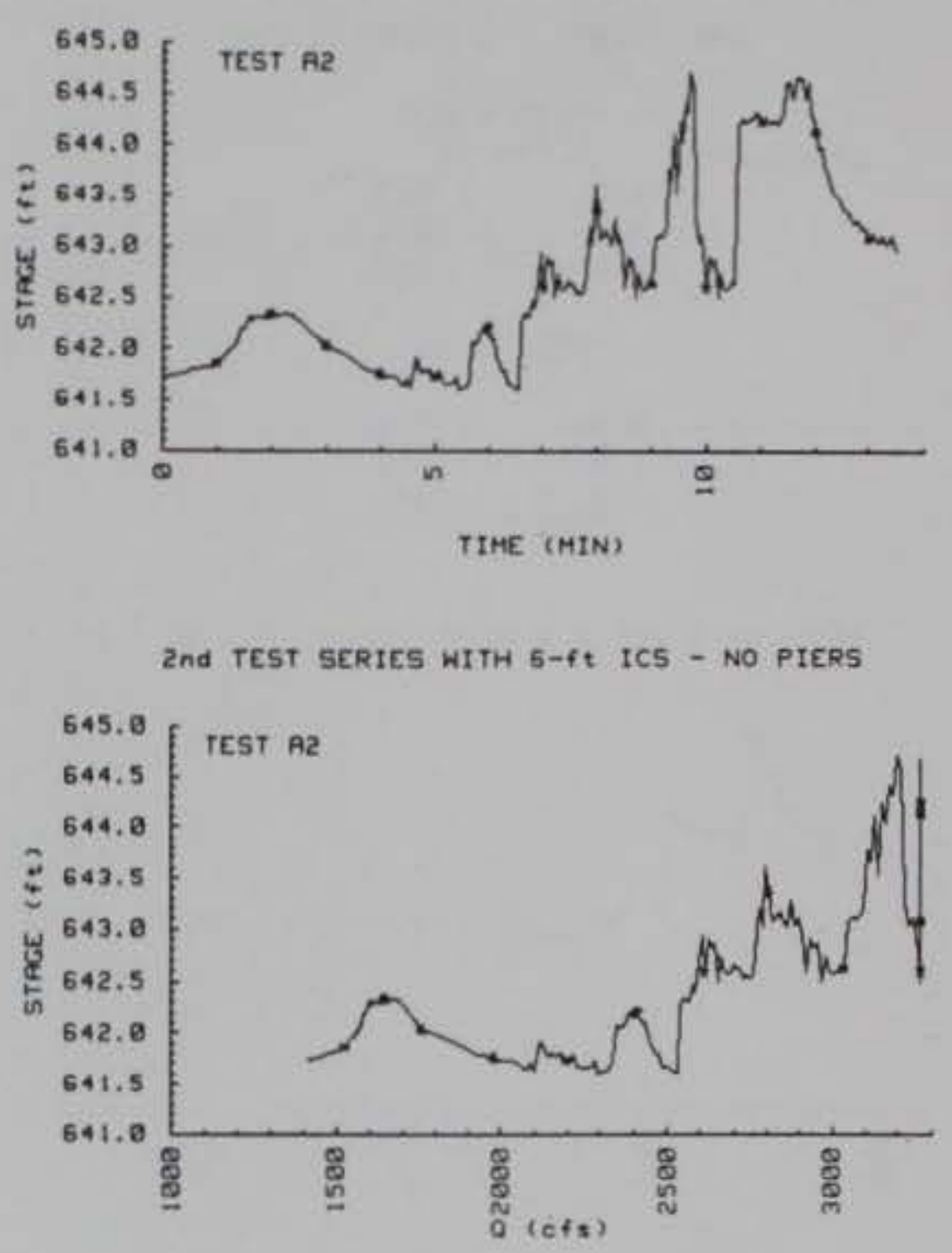

2nd TEST SERIES WITH 6-ft ICS - NO PIERS

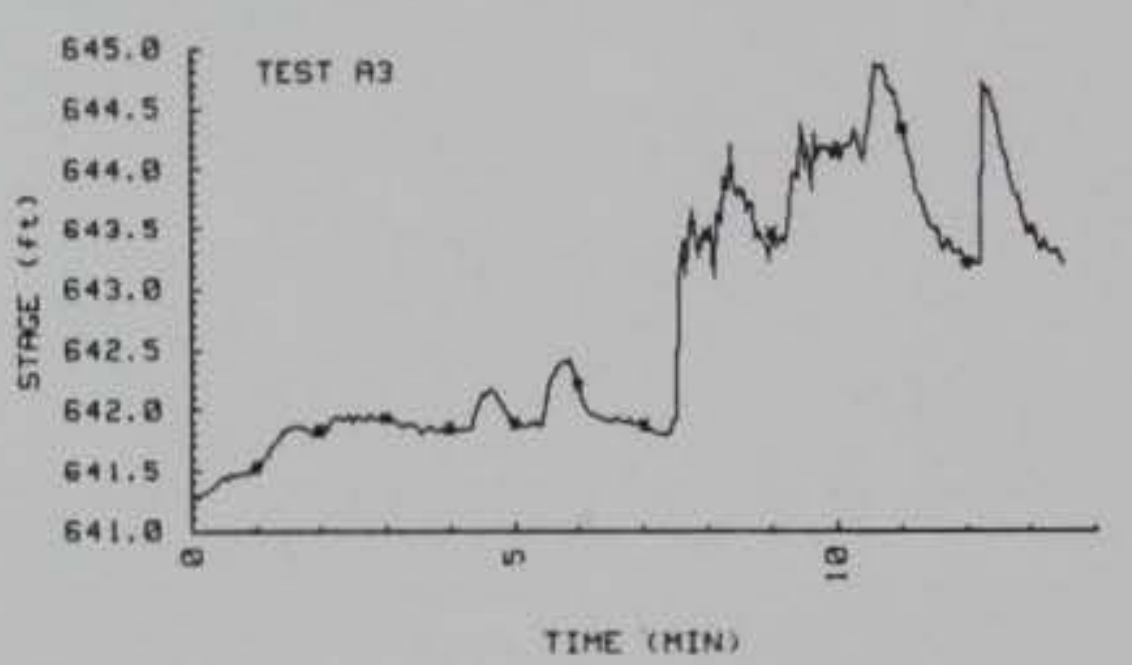

2nd TEST SERIES WITH 6-ft ICS - NO PIERS

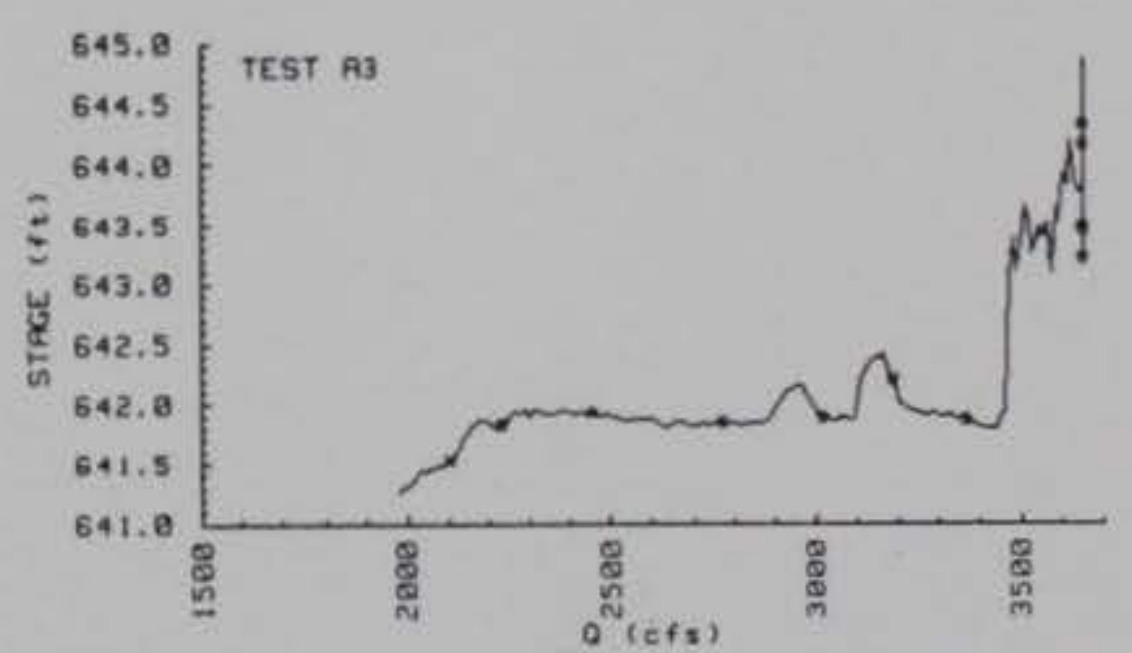


2nd TEST SERIES WITH 6-FT ICS - 2 PIERS

TIME (MIN) Q (GPM)

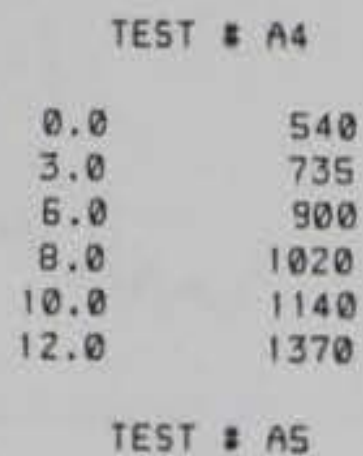

$\begin{array}{rr}0.0 & 500 \\ 3.0 & 720 \\ 6.5 & 850 \\ 8.5 & 1010 \\ 10.5 & 1120 \\ 12.5 & 1360 \\ 14.5 & 1500 \\ 16.5 & 1685 \\ \text { TEST } \approx & \text { A6 }\end{array}$

$\begin{array}{rr}0.0 & 525 \\ 3.0 & 640 \\ 6.0 & 840 \\ 8.0 & 990 \\ 10.0 & 1215 \\ 12.0 & 1300\end{array}$

2nd TEST SERIES WITH $6-f \mathrm{t}$ ICS - 2 PIERS

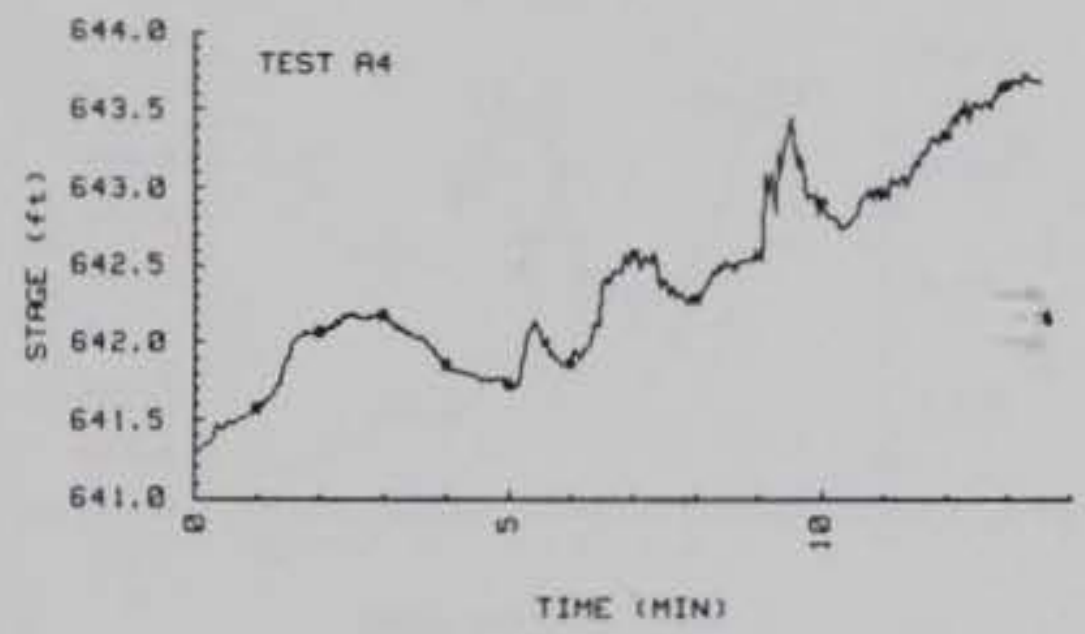

2nd TEST SERIES WITH $6-\mathrm{ft}$ ICS -2 PIERS

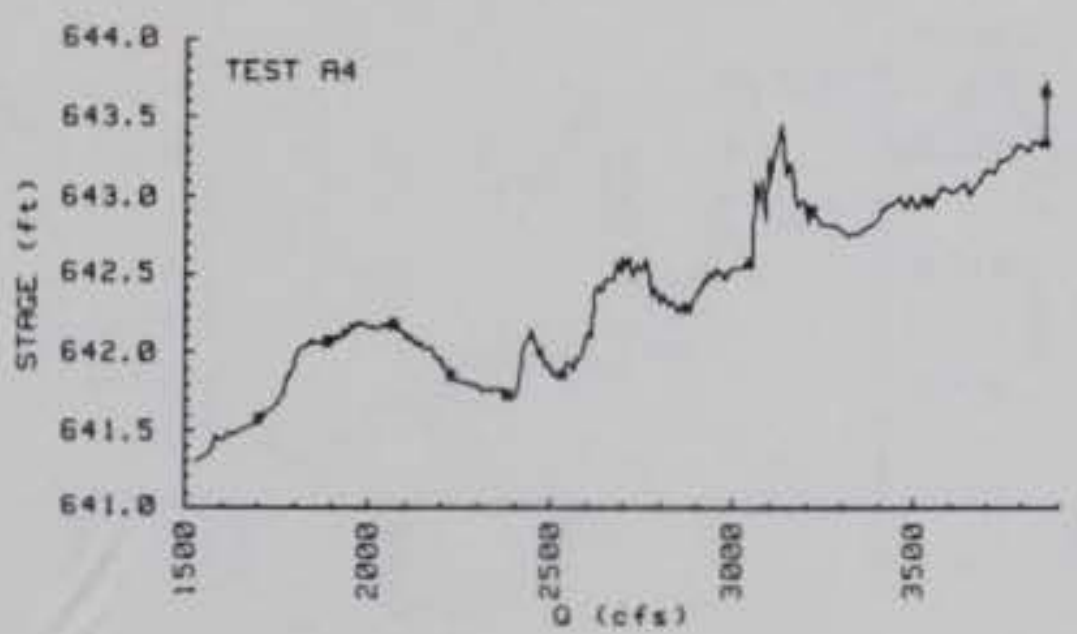

2nd TEST SERIES WITH $6-f$ t ICS - 2 PIERS

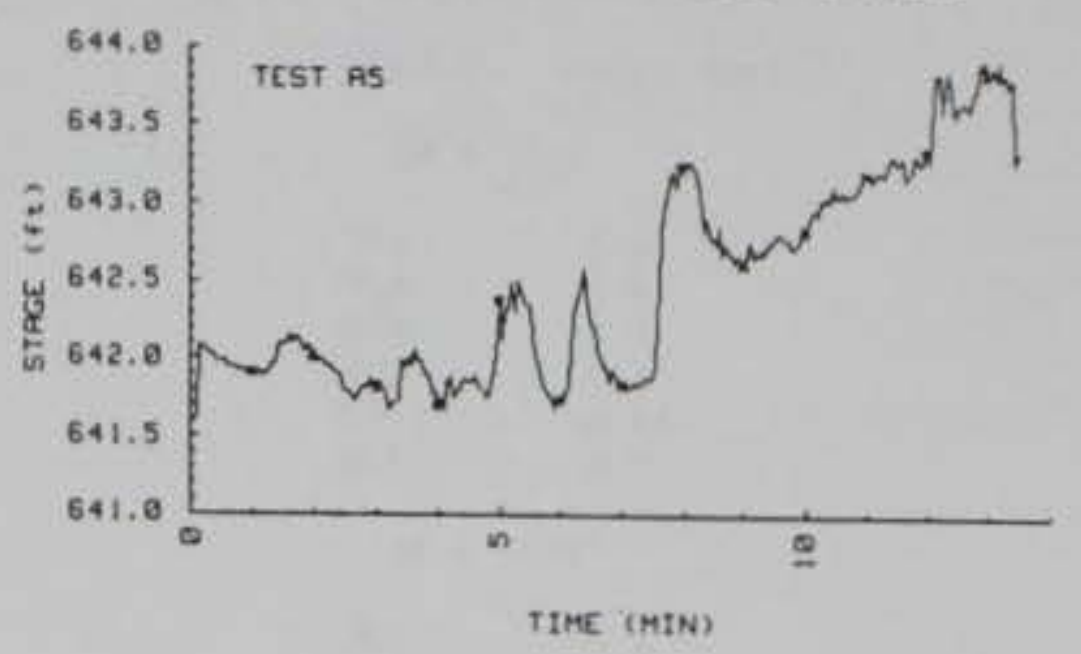

2nd TEST SERIES WITH $6-7 \mathrm{t}$ ICS - 2 PIERS

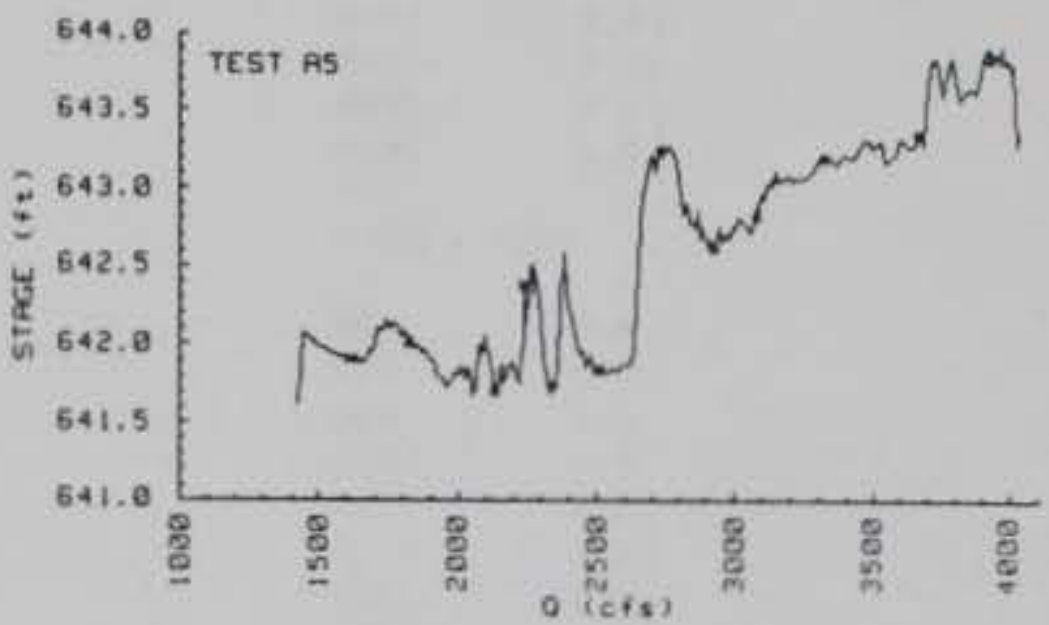

2Nd TEST SERIES WITH $6-f$ t ICS - 2 PIERS

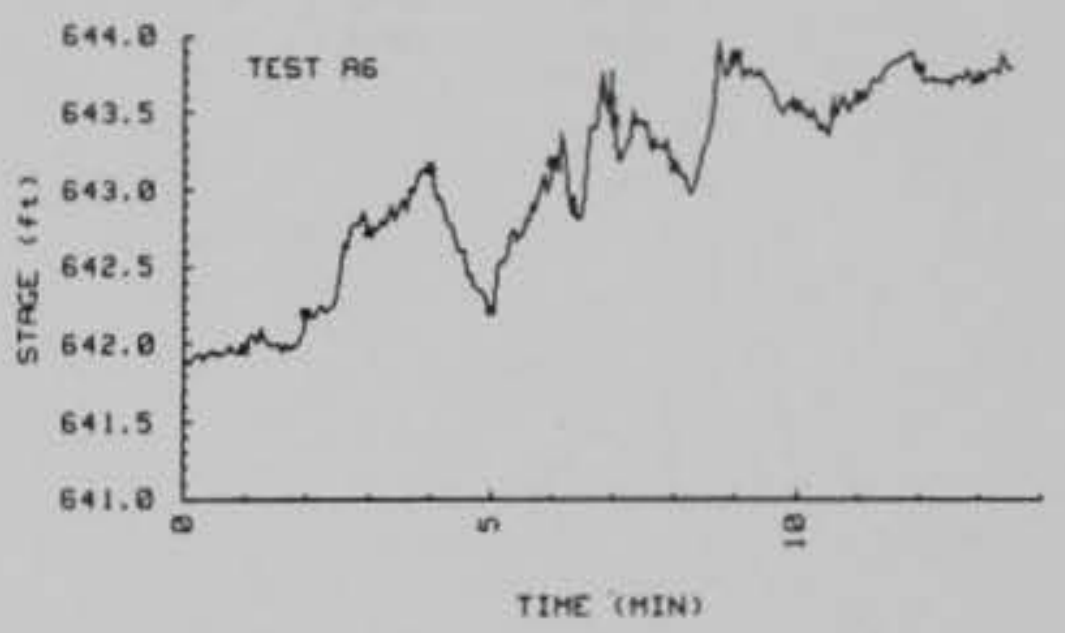

2nd TEST SERIES WITH $6-\mathrm{ft}$ ICS - 2 PIERS

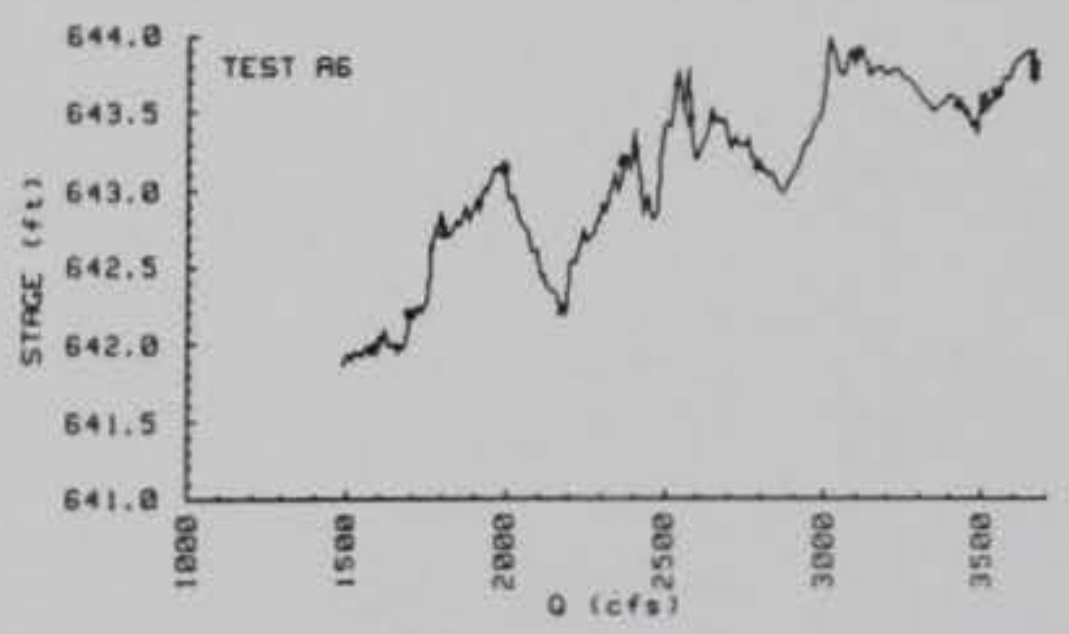


TEST SERIES WITH 6-FT ICS - 3 PIERS

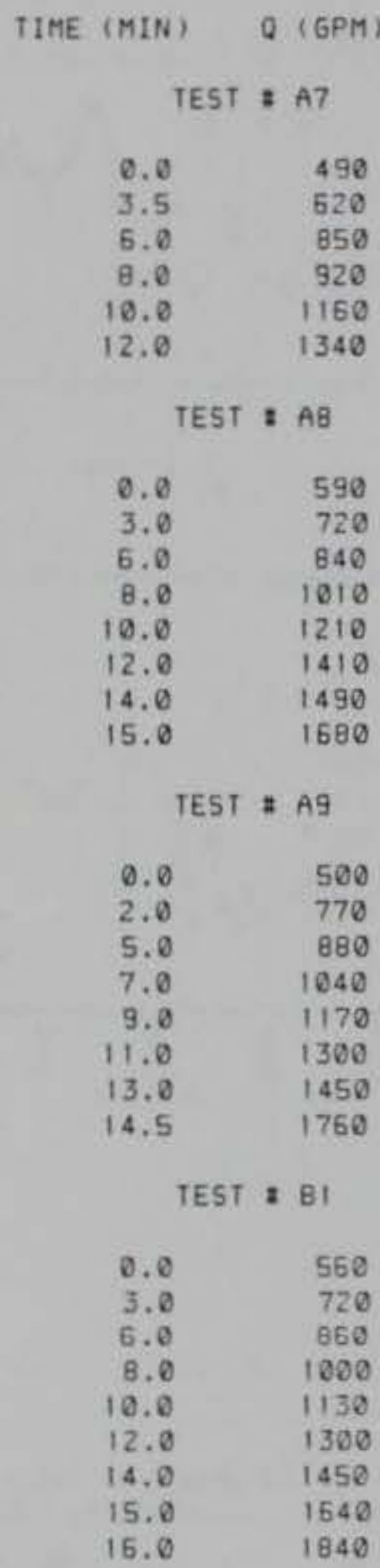

TESTS WITH $6-f \mathrm{t}$ ICS - 3 PIERS

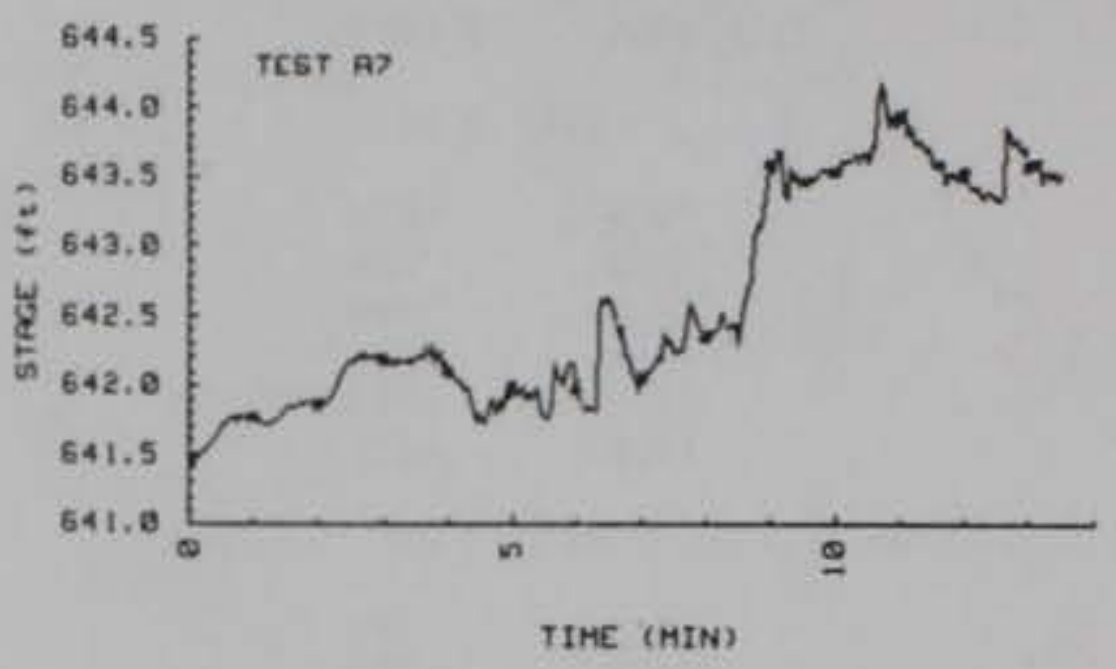

TESTS WITH $6-f \mathrm{t}$ ICS - 3 PIERS

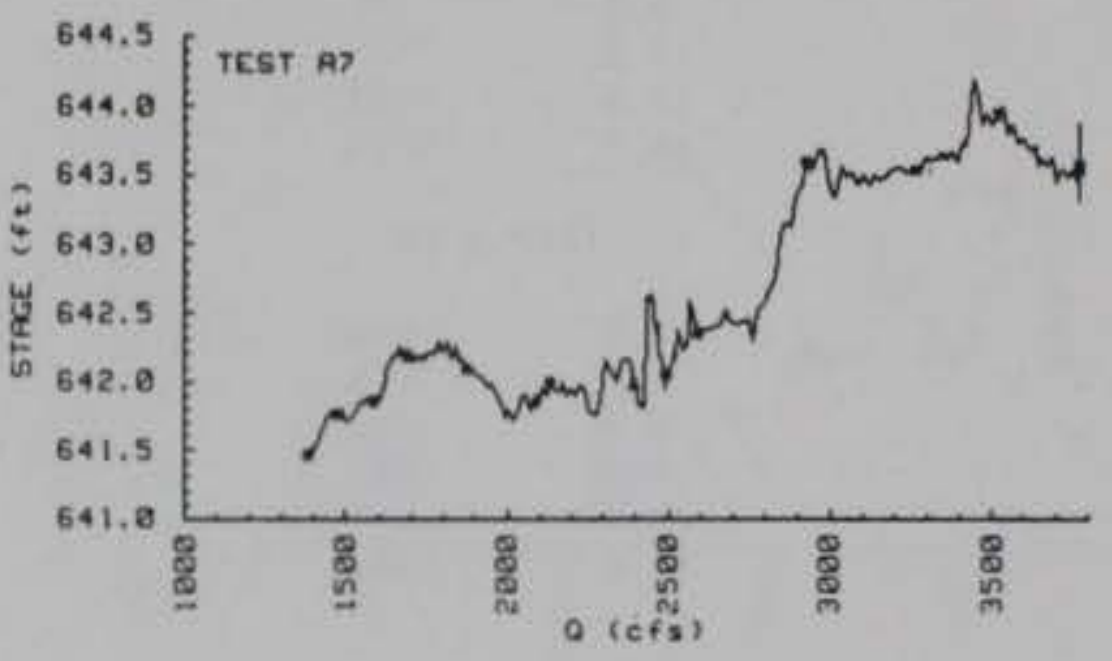

TESTS WITH $5-\mathrm{ft}$ : 1 CS - 3 PIERS

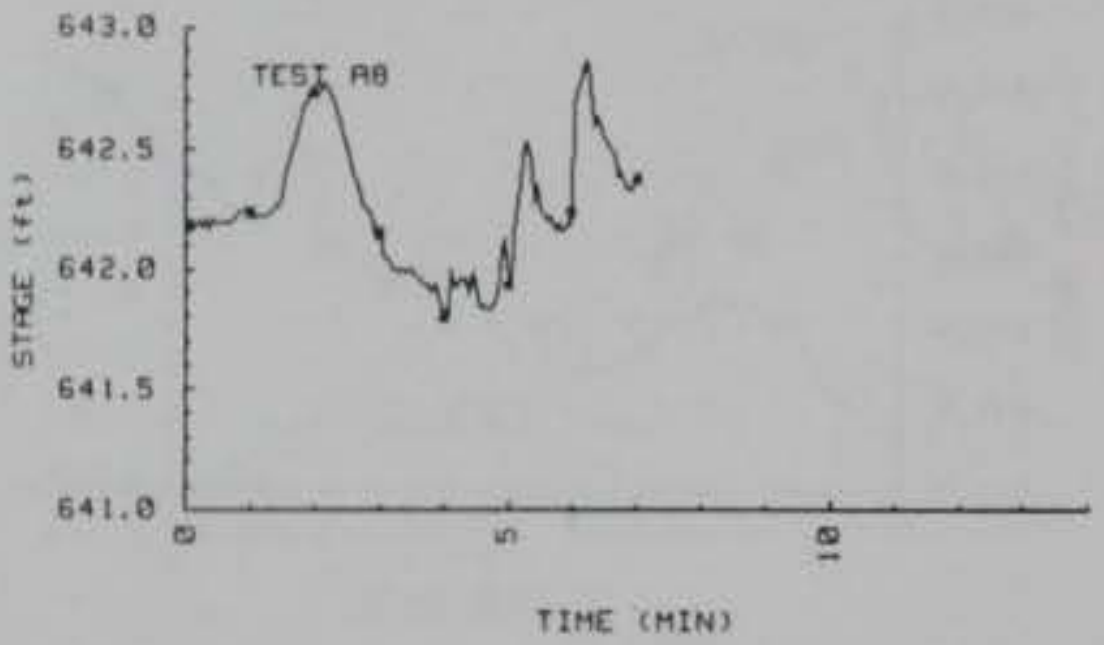

TESTS WITH 6 -ft ICS - 3 PIERS

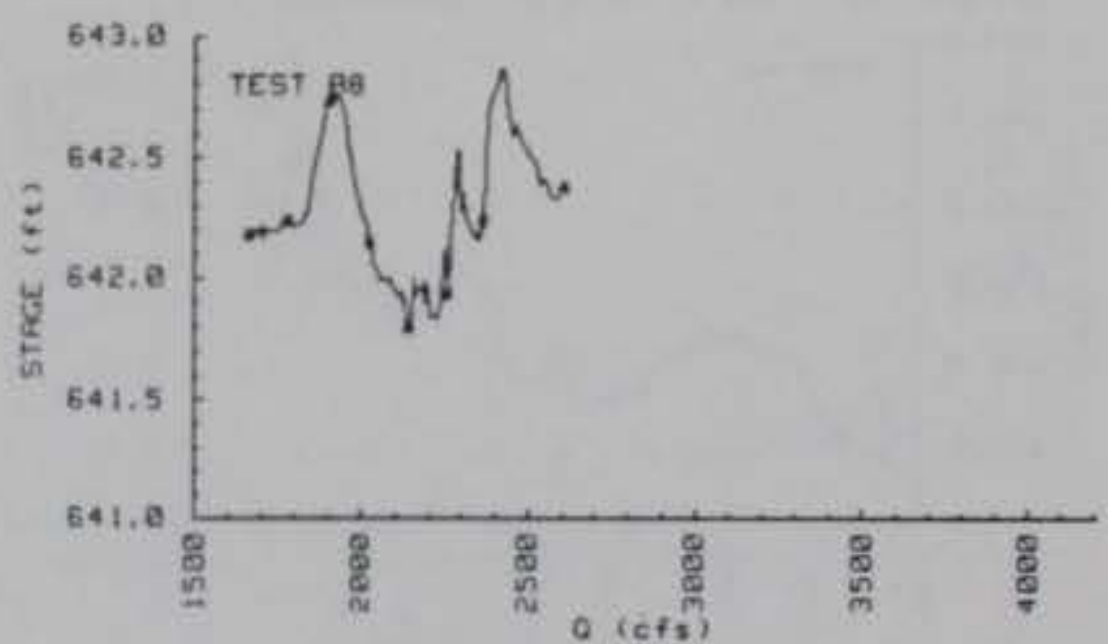



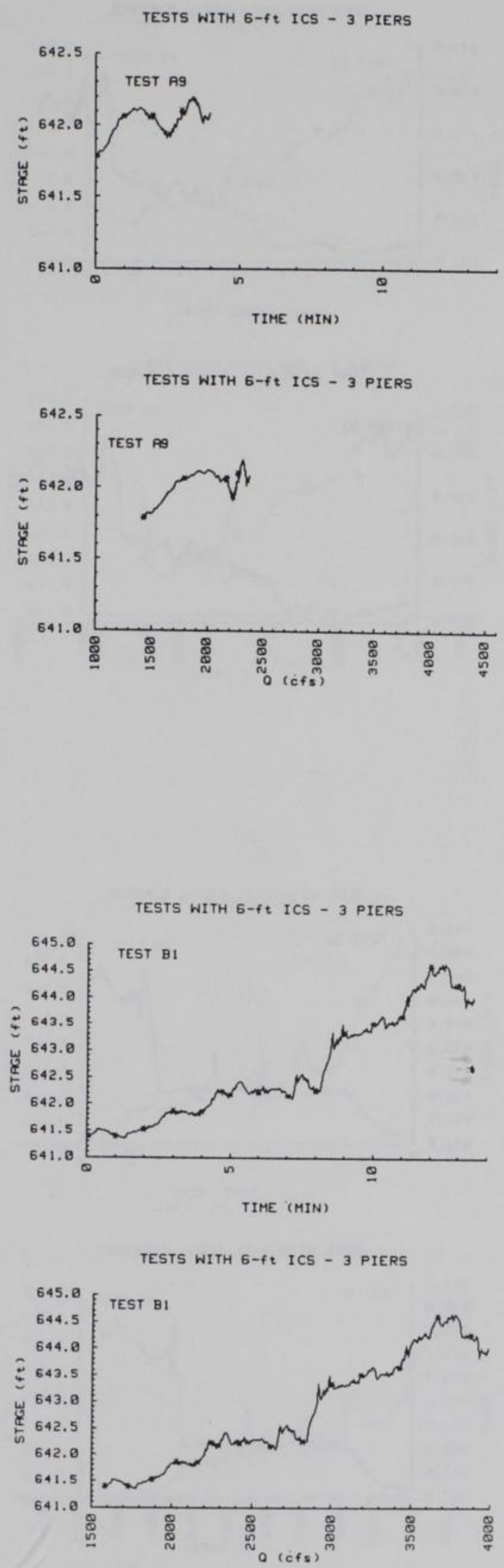
TEST SERIES WITH 6-FT ICS - 5 PIERS

\begin{tabular}{|c|c|c|}
\hline TIME (MIN) & $Q$ & (GPM \\
\hline \multicolumn{2}{|c|}{ TEST $:$} & 82 \\
\hline 0.0 & & 560 \\
\hline 3.0 & & 720 \\
\hline 6.0 & & 860 \\
\hline 8.0 & & 1000 \\
\hline 10.0 & & 1130 \\
\hline 12.0 & & 1300 \\
\hline 14.0 & & 1450 \\
\hline 15.0 & & 1640 \\
\hline 16.8 & & 1840 \\
\hline \multicolumn{2}{|c|}{ TEST : } & 83 \\
\hline 0.0 & & 535 \\
\hline 3.0 & & 720 \\
\hline 5.0 & & 820 \\
\hline 8.0 & & 1040 \\
\hline 10.0 & & 1130 \\
\hline 12.0 & & 1350 \\
\hline 14.0 & & 1490 \\
\hline \multicolumn{2}{|c|}{ TEST $:$} & 84 \\
\hline 0.0 & & 520 \\
\hline 3.0 & & 660 \\
\hline 6.0 & & 800 \\
\hline 8.0 & & 980 \\
\hline 10.0 & & 1140 \\
\hline 12.0 & & 1370 \\
\hline 14.0 & & 1490 \\
\hline 15.0 & & 1630 \\
\hline \multicolumn{2}{|c|}{ TEST: } & 85 \\
\hline 0.0 & & 500 \\
\hline 3.0 & & 680 \\
\hline 6.0 & & 845 \\
\hline 8.0 & & 1040 \\
\hline 10.0 & & 1170 \\
\hline 12.0 & & 1295 \\
\hline
\end{tabular}
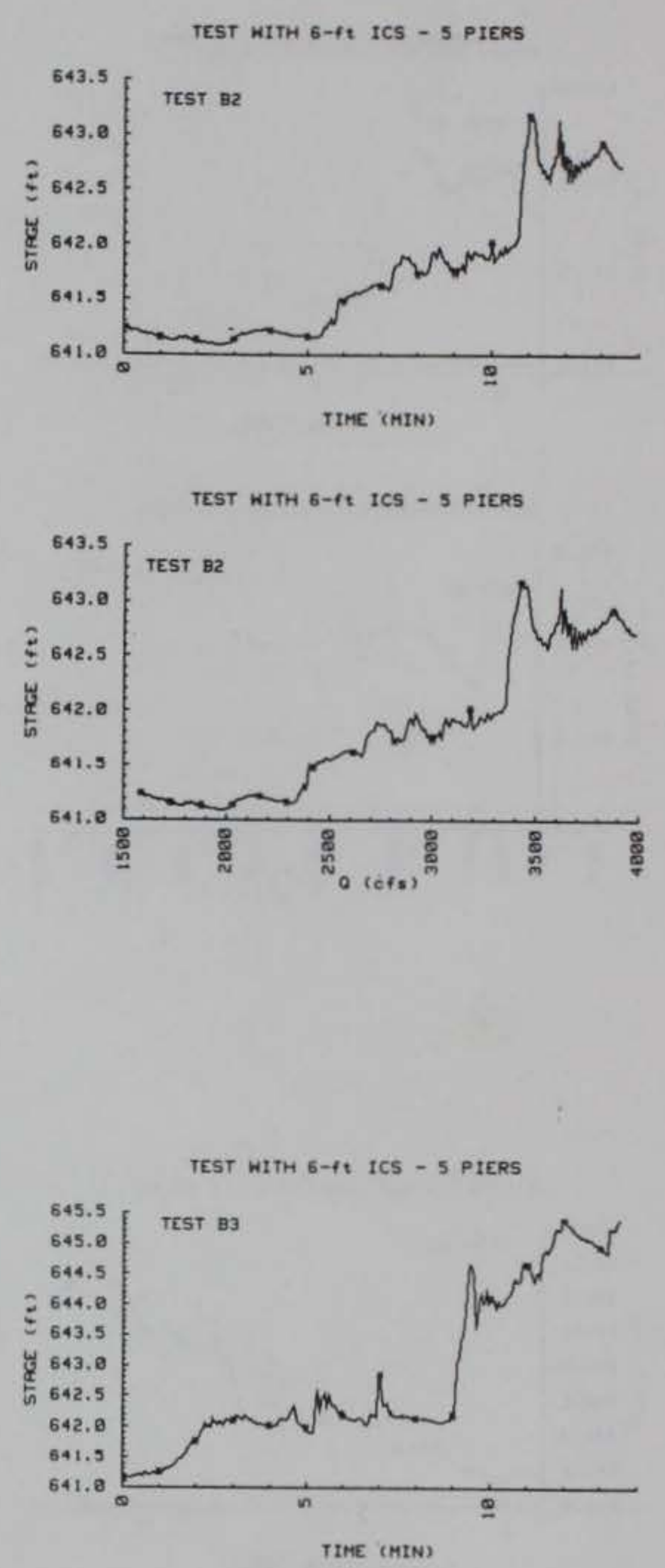

TEST WITH 6-ft ICS - 5 PIERS

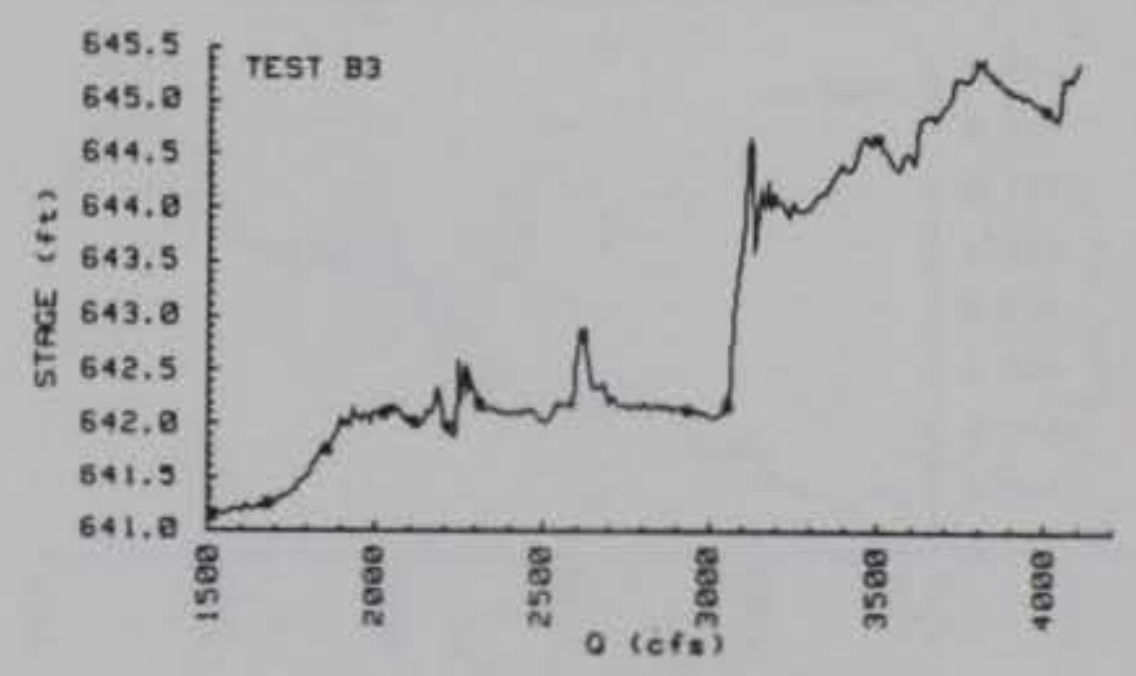


TEST WITH 6-fT ICS - 5 PIERS

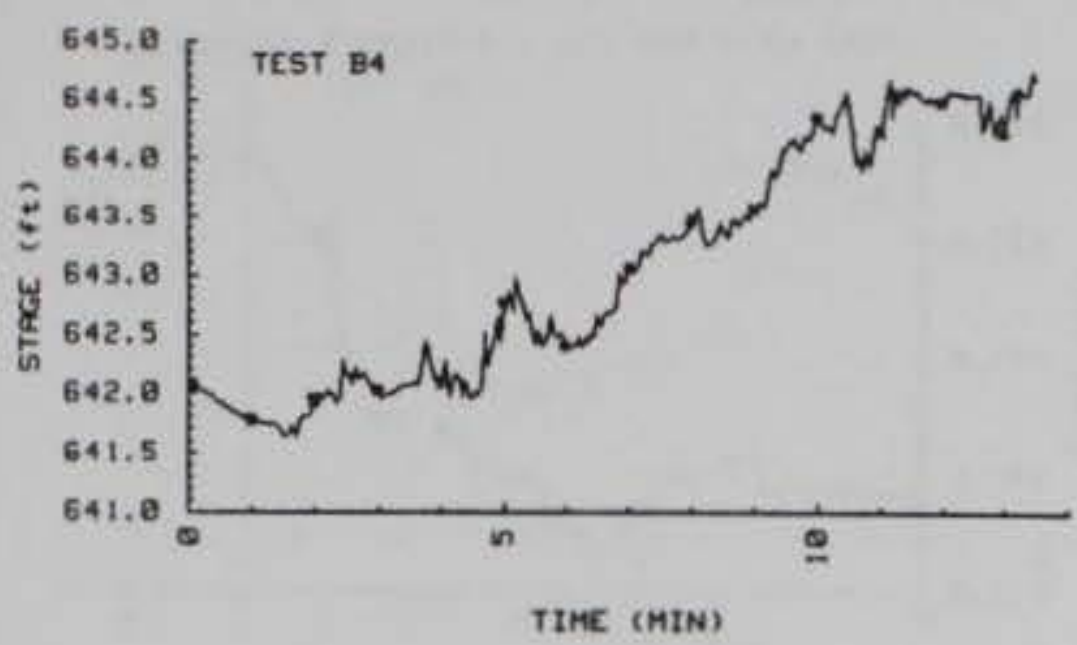

TEST WITH 6-1T ICS - 5 PIERS

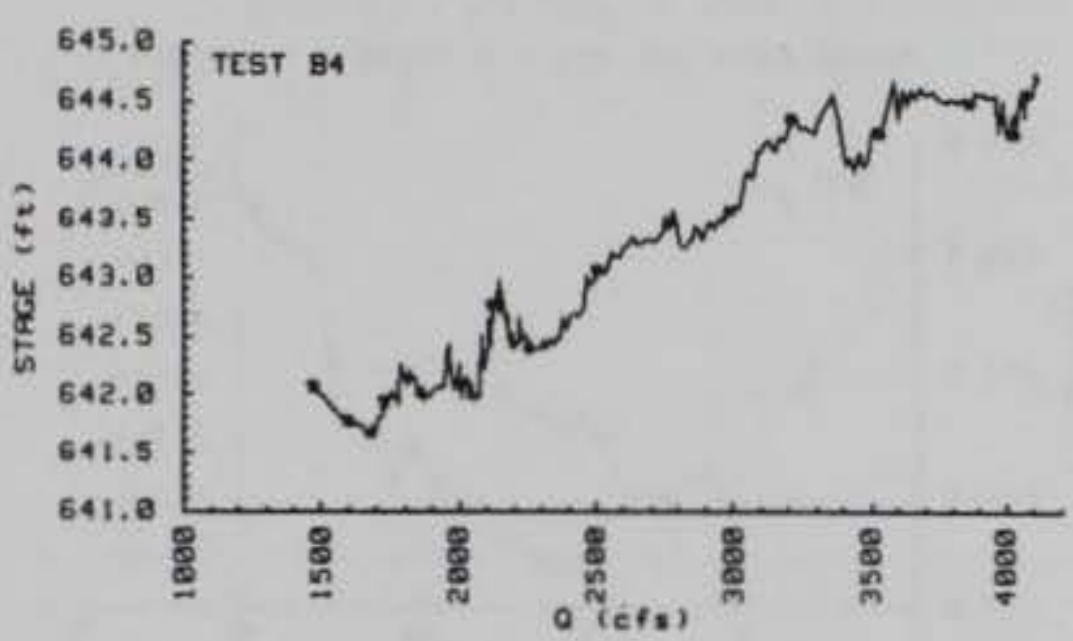

TEST WITH 6-ft ICS - 5 PIERS

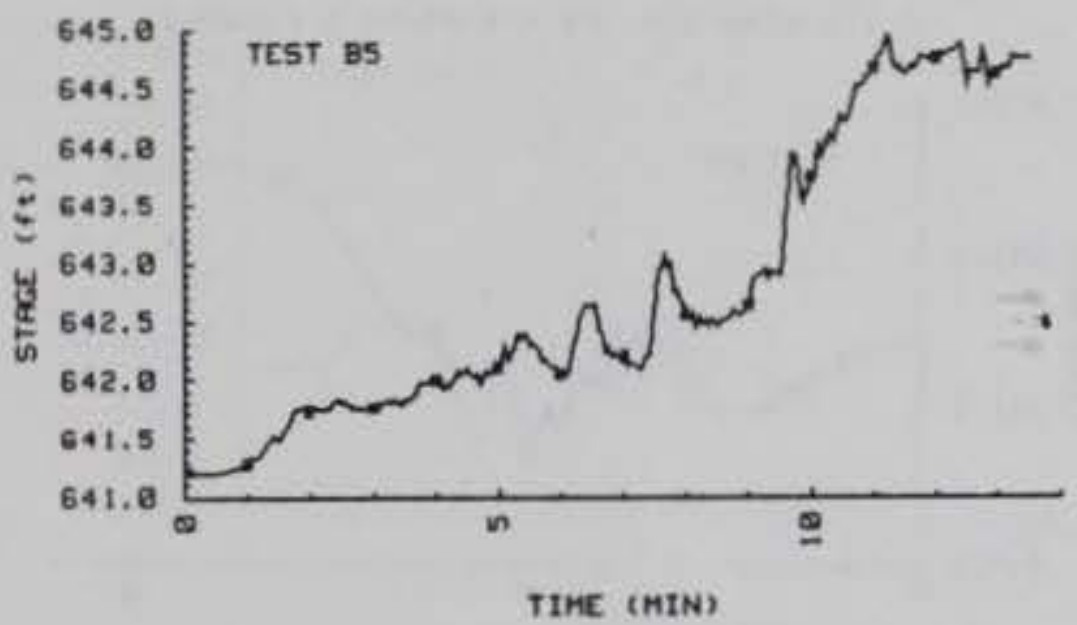

TEST WITH 6-ft ICS - S PIERS

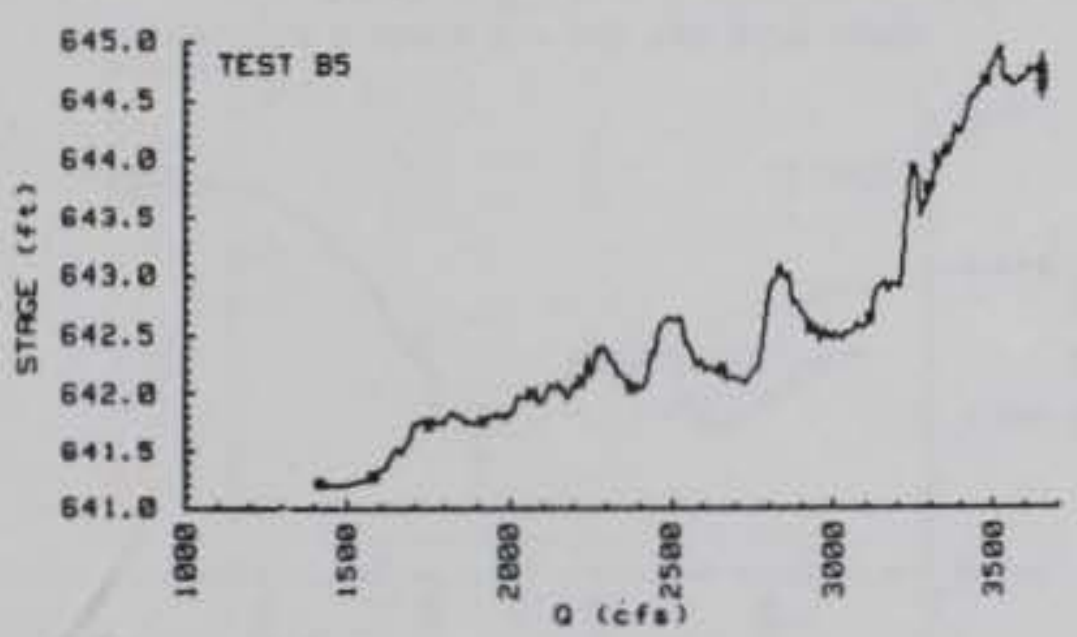

TEST SERIES WITH G-FT ICS - 9 PIERS

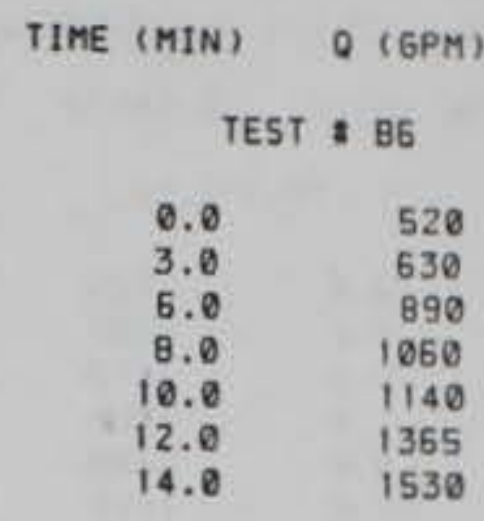

TEST WITH $6-\mathrm{ft}$ ICS - 9 PIERS

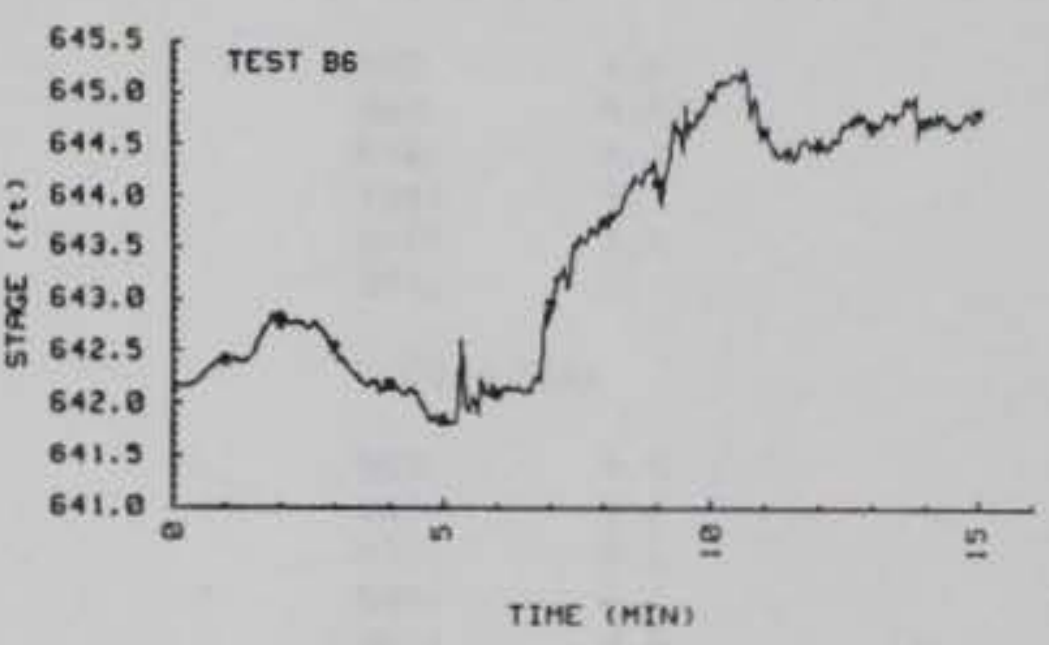

TEST HITH 6 - IT ICS - 9 PIERS

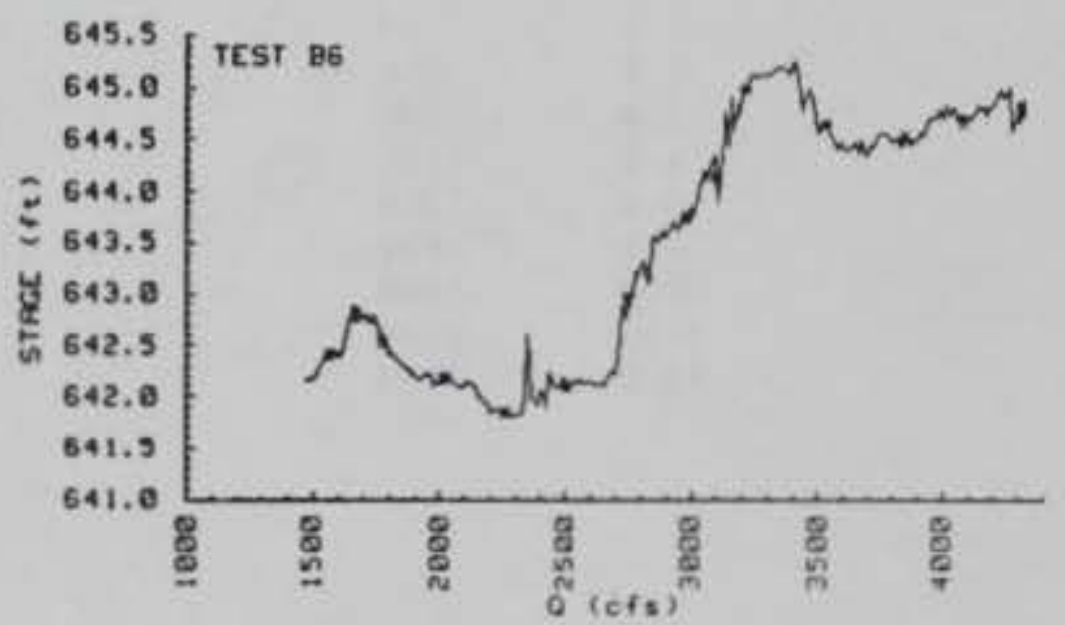


TEST SERIES WITH 6-FT ICS - 9 PIERS WIth FLOOOWAY

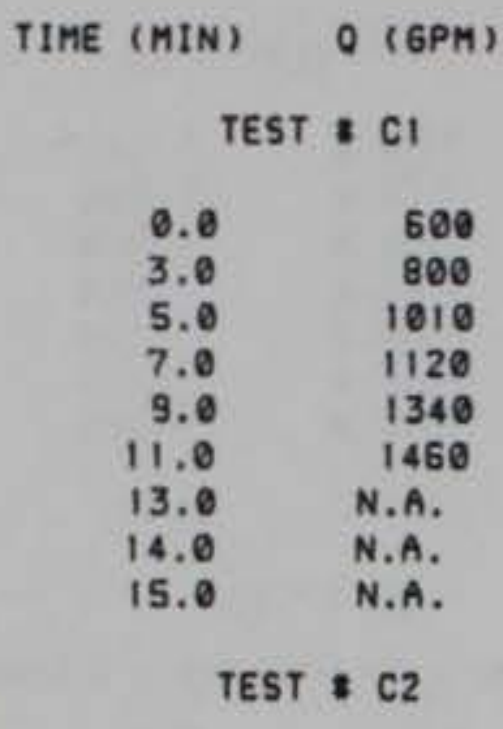

$\begin{array}{rr}0.0 & 600 \\ 3.0 & 800 \\ 5.0 & 1010 \\ 7.0 & 1120 \\ 9.0 & 1340 \\ 11.0 & 1460\end{array}$

TEST $: \mathrm{C3}$

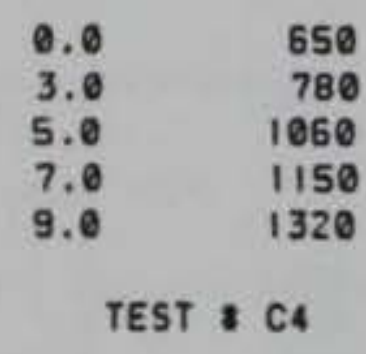

$\begin{array}{rr}0.0 & 650 \\ 3.0 & 800 \\ 4.5 & 1100 \\ 6.5 & 1240 \\ 8.5 & 1400 \\ 10.0 & 1500 \\ 11.5 & 1700 \\ 13.0 & 2000\end{array}$
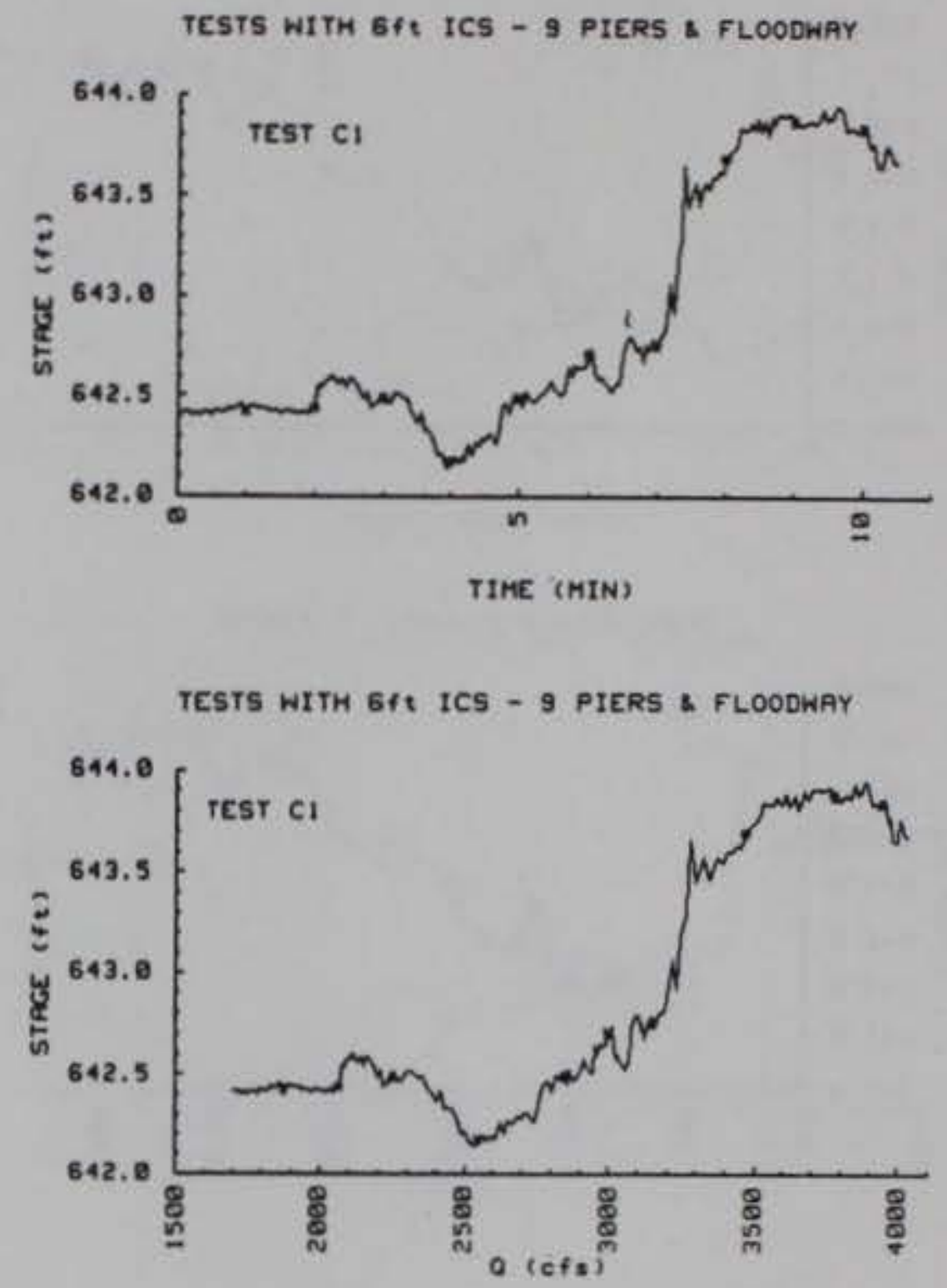

TESTS WITH $6 \mathrm{Ft}$ ICS - 9 PIERS \& FLOODWAY
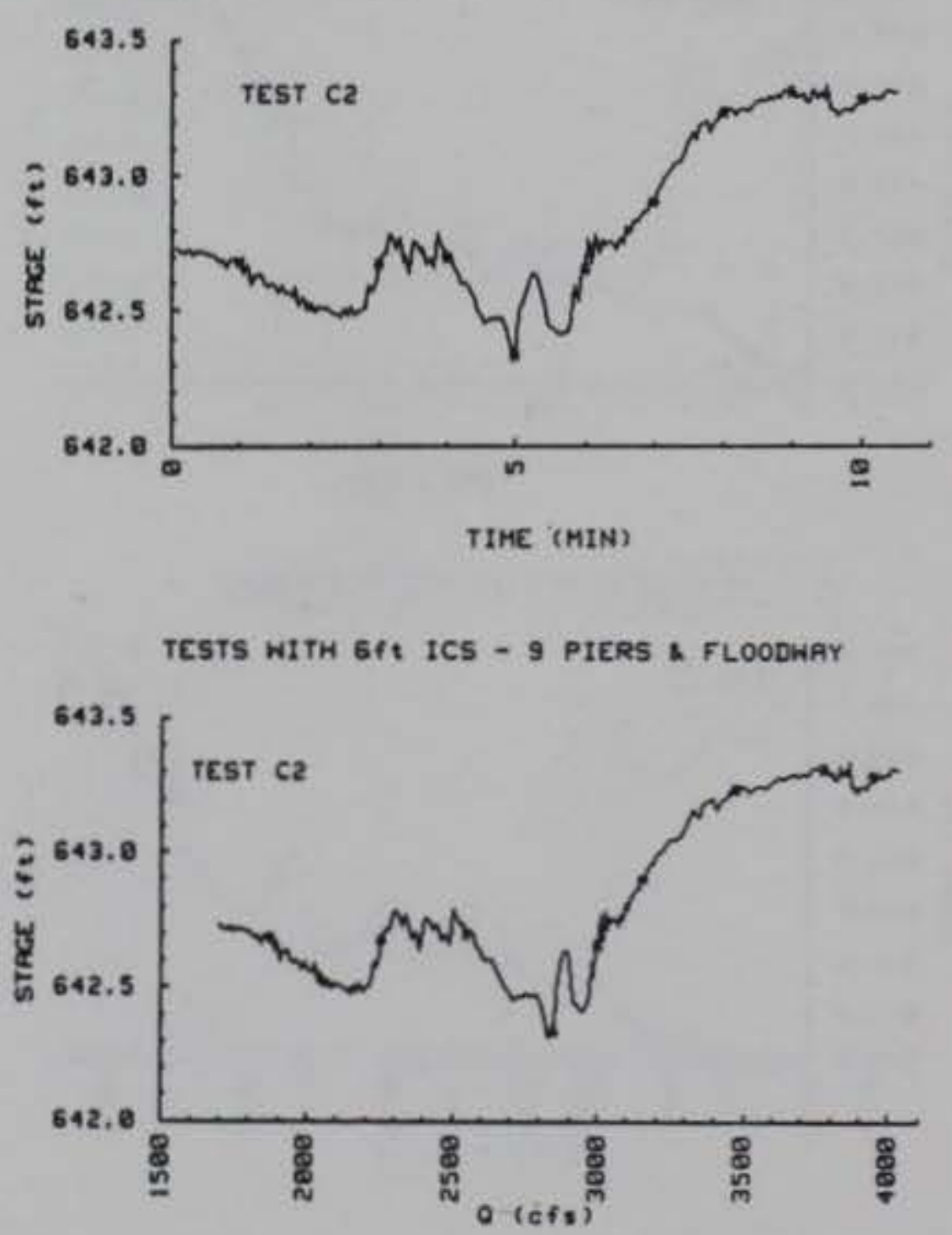
TESTS WITH $6 F \mathrm{t}$ ICS - 9 PIERS \& FLOODWRY

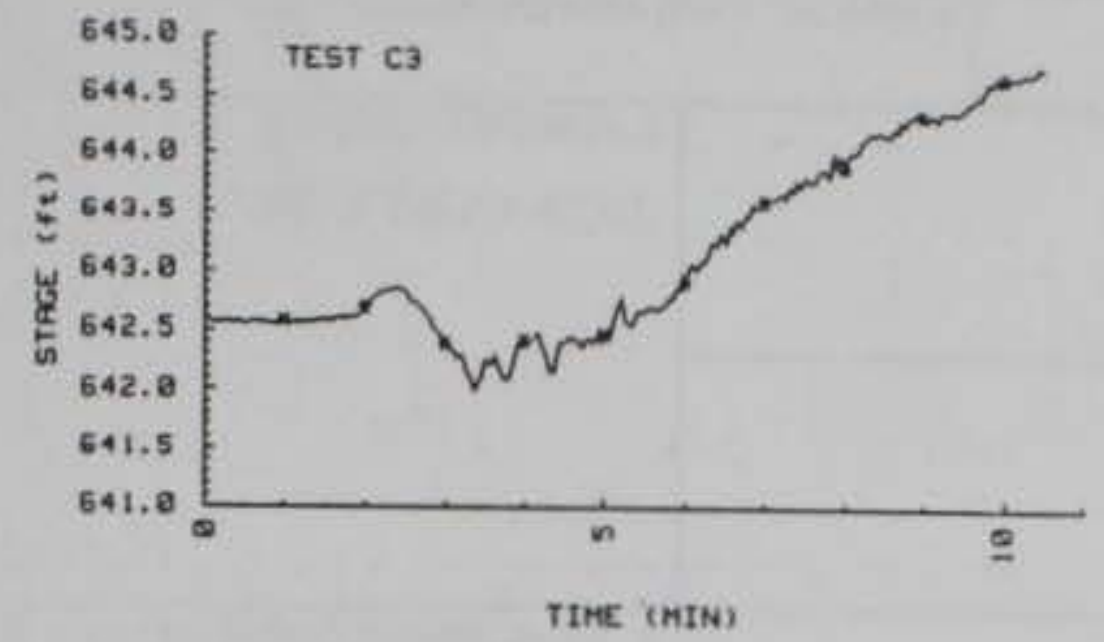

TESTS WITH 6 Ft ICS - 9 PIERS \& FLOODWAY

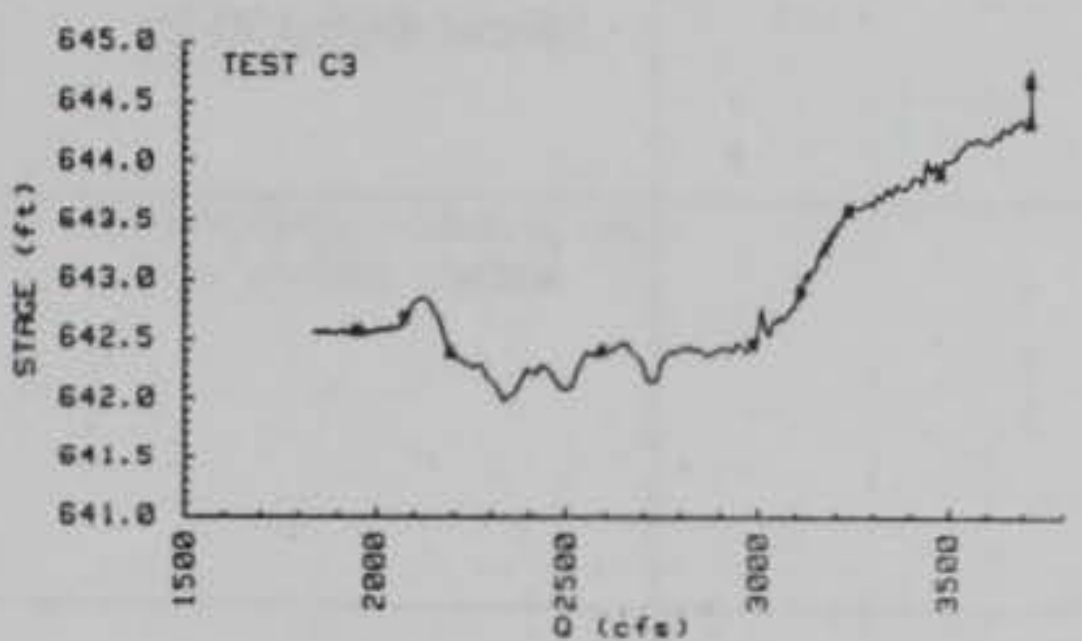

TESTS WITH $6 \mathrm{ft}$ ICS - 9 PIERS \& FLOODWAY

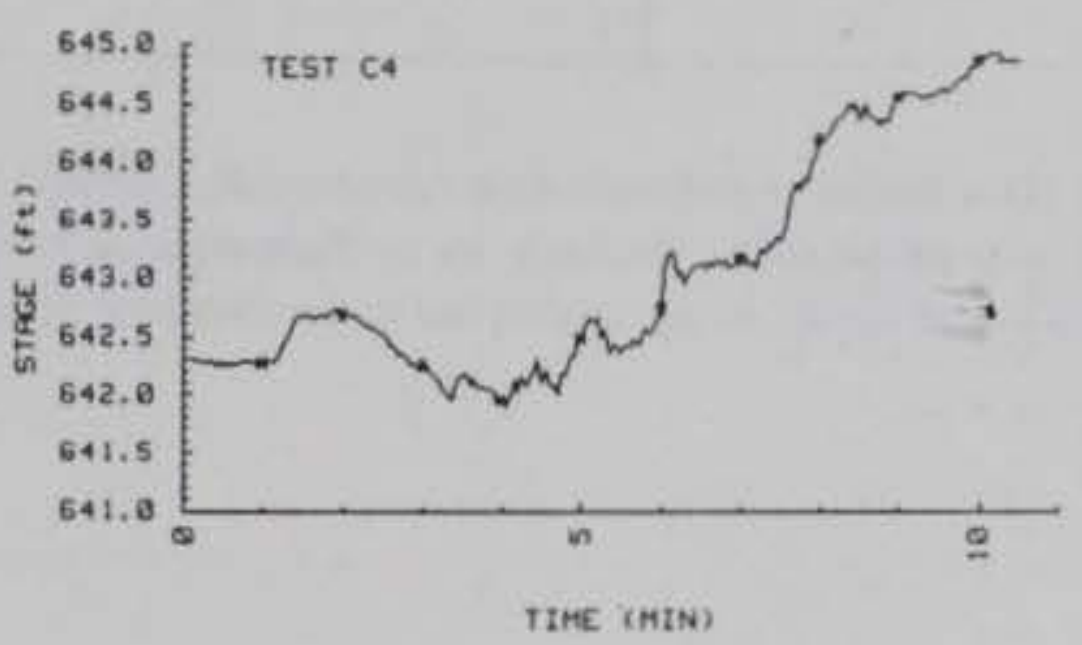

TESTS WITH $6 \mathrm{ft}$ ICS - 9 PIERS \& FLOODWAY

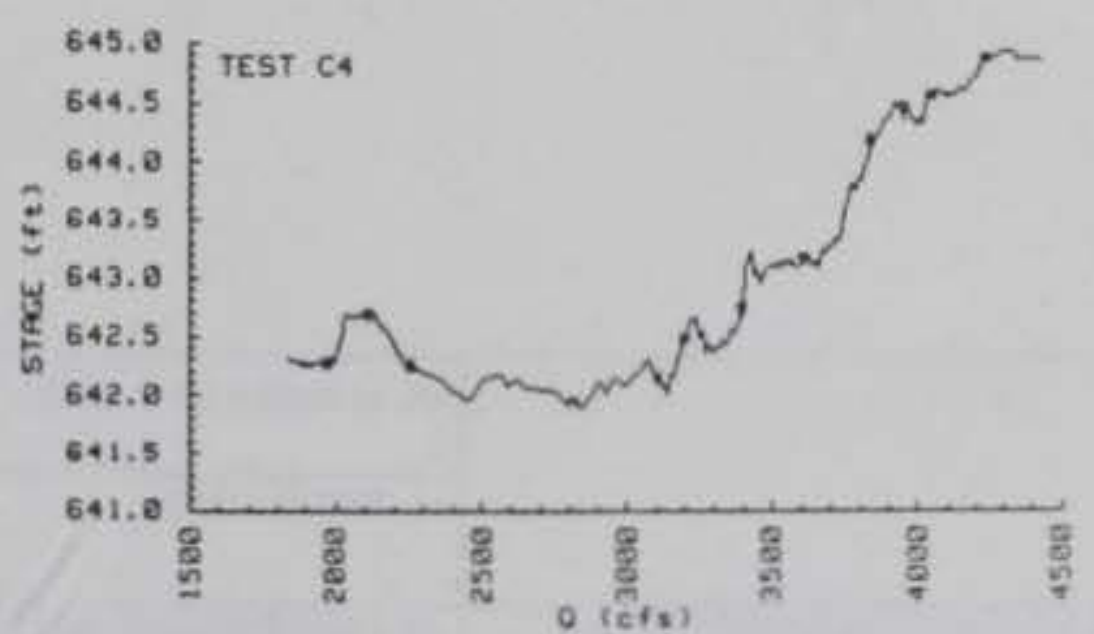




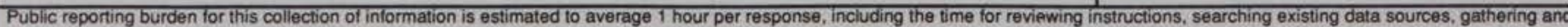

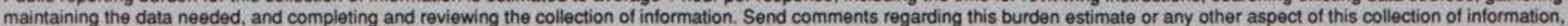

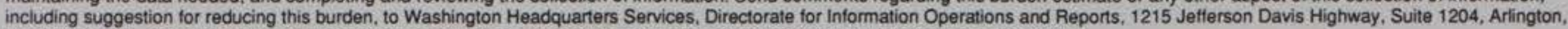
VA 22202-4302, and to the Office of Management and Budget, Paperwork Reduction Project (0704-0188), Washington, DC 20503.

\begin{tabular}{|l|l|l}
\hline 1. AGENCY USE ONLY (Leave blank) & $\begin{array}{c}\text { 2. REPORT DATE } \\
\text { August } 1990\end{array}$ & 3. REPORT TYPE AND DATES COVERED
\end{tabular}

\section{TITLE AND SUBTITLE}

Model Study of the Cazenovia Creek Ice Control Structure

\section{NCB-1A-83-87RC}

\section{AUTHORS}

Gordon E. Gooch and David S. Deck

7. PERFORMING ORGANIZATION NAME(S) AND ADDRESS(ES)

U.S. Army Cold Regions Research and Engineering Laboratory

72 Lyme Road

Hanover, New Hampshire 03755-1290

8. PERFORMING ORGANIZATION

REPORT NUMBER

Special Report 90-29

9. SPONSORING/MONITORING AGENCY NAME(S) AND ADDRESS(ES)

U.S. Army Engineer District

Buffalo, NY

11. SUPPLEMENTARY NOTES

12a. DISTRIBUTION/AVAILABILITY STATEMENT

12b. DISTRIBUTION CODE

Approved for public release; distribution is unlimited.

\section{ABSTRACT (Maximum 200 words)}

An ice control structure was chosen as a solution to ice-jam flooding of the business and residental communities of West Seneca and Buffalo, New York, along Cazenovia Creek. A model study was proposed to evaluate its performance before actual construction. This report describes the design, execution, and results of the model study, which led to the eventual acceptance of the proposed ICS by the U.S. Army Engineer District, Buffalo.

0. SPONSORING/MONITORING AGENCY REPORT NUMBER

14. SUBJECT TERMS
Ice jams

Flood control

Ice control
Ice prevention
17. SECURITY CLASSIFICATION OF REPORT

UNCLASSIFIED
18. SECURITY CLASSIFICATION OF THIS PAGE

UNCLASSIFIED
19. SECURITY CLASSIFICATION OF ABSTRACT

UNCLASSIFIED
15. NUMBER OF PAGES

16. PRICE CODE

20. LIMITATION OF ABSTRACT

UL 